THIS DOCUMENT CONFIRMED AS UNCLASSIFIED DIVISION OF CLASSIFICATION

BY

DATE

\title{
FOURTH PROGRESS REPORT OF LIGHT ARMOR PROGRAM
}

\author{
M. L. Wilkins \\ C. F. Cline
}

C. A. Honodel

June 4, 1969

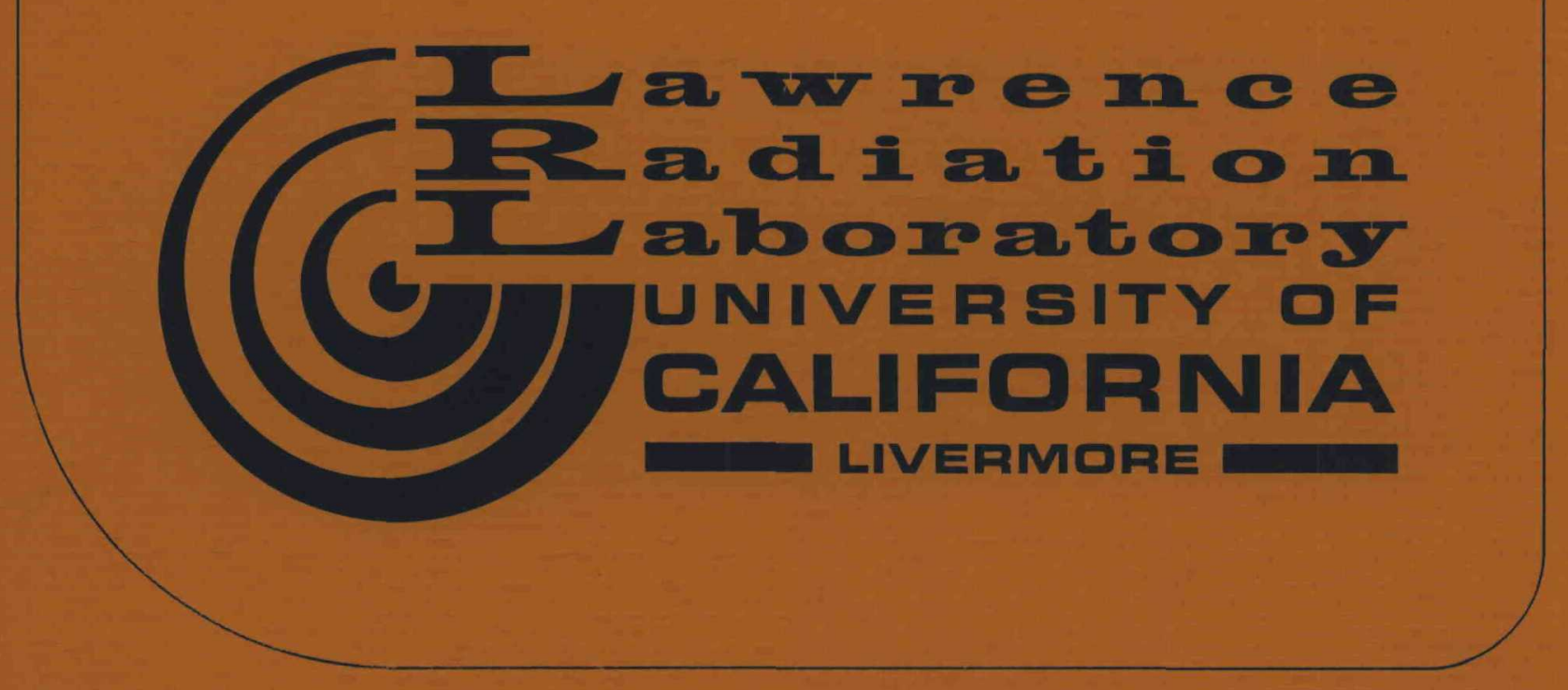




\section{DISCLAIMER}

This report was prepared as an account of work sponsored by an agency of the United States Government. Neither the United States Government nor any agency Thereof, nor any of their employees, makes any warranty, express or implied, or assumes any legal liability or responsibility for the accuracy, completeness, or usefulness of any information, apparatus, product, or process disclosed, or represents that its use would not infringe privately owned rights. Reference herein to any specific commercial product, process, or service by trade name, trademark, manufacturer, or otherwise does not necessarily constitute or imply its endorsement, recommendation, or favoring by the United States Government or any agency thereof. The views and opinions of authors expressed herein do not necessarily state or reflect those of the United States Government or any agency thereof. 


\section{DISCLAIMER}

Portions of this document may be illegible in electronic image products. Images are produced from the best available original document. 


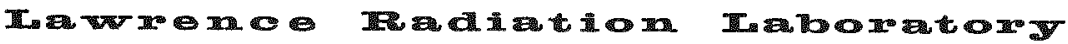 UNIVERSITY OF CALIFORMIA \\ LIVERMORE
}

\section{MASTER}

UCRL-50694

\section{FOURTH PROGRESS REPORT OF LIGHT ARMOR PROGRAM}

\author{
M. L. Wilkins \\ C. F. Cline \\ C. A. Honodel
}

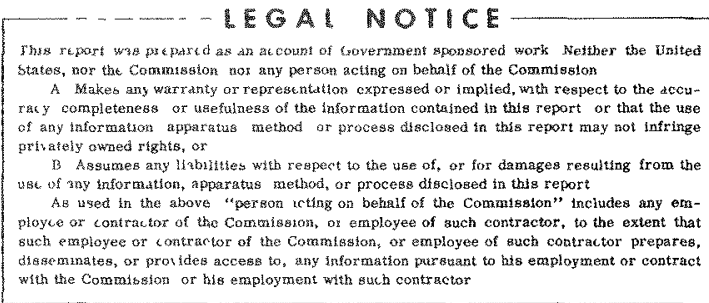




\section{Foreword}

The work reported here is a continuation of the program initiated by the Advanced Research Projects Agency (ARPA) and is described in the first, second, and third progress reports. ${ }^{1-3}$

The work of the following personnel of the Lawrence Radiation Laboratory is acknowledged. Hugh Heard performed the tri-axial compression tests. Richard Landingham made the cermet studies. William Gust did the equation-of-state measurements. Albert Holt did the work on graded armor. Charles Honodel, John OiConnor, and Nate Rawls performed the ballistic experiments. Dick Giroux was the programmer on the HEMP code, and T. Suyehiro worked on the special computer plot routines. Beb Luicanan and Katherine Spence were the computer assistants. Frank Wittmayer and Sam Digiallonardo did the microscopy studies. 


\section{Contents}

Forward

Abstract

Introduction

Physical Process in Penetration of Ceramic Armor $\quad . \quad$. $\quad$. . . . . $\quad$. 2

Important Parameters in Penetration Process . . . . . . . . . 7

Ductility in a Ceramic . . . . . . . . . . . . . . . . . . 11

Introducing Ductility into a Ceramic . . . . . . . . . . . . 15

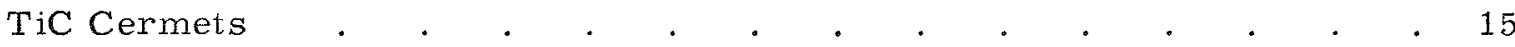

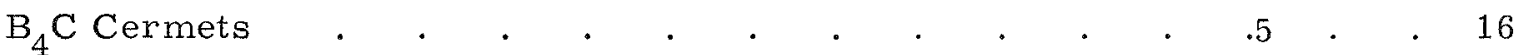

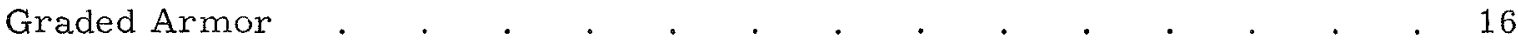

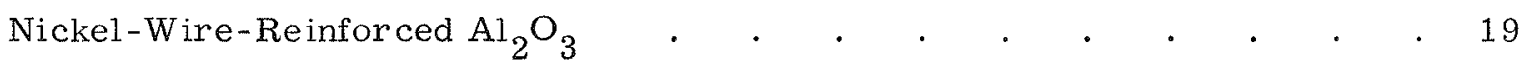

Experimental Ballistic Limits for Ceramics with an Aluminum Backup Plate $\quad 20$

Backup Plates . . . . . . . . . . . . . . . 25

Material Physical Parameters . . . . . . . . . . . . . 25

Conclusions . . . . . . . . . . . . . . . . . . . . 25

Recommendations . . . . . . . . . . . . . . . . . . 26

Appendix A. Mechanical Properties of Armor Materials at High Pressure $\quad$. 27

Appendix B. BeO Studies . . . . . . . . . . . . . . . 32

Appendix C. $\mathrm{B}_{4} \mathrm{C}$ Cermets . . . . . . . . . . . . . . 36

Appendix D. Beryllium Compounds . . . . . . . . . . . 44

Appendix E. Strength of Materials Measurements . . . . . . . 48

References . . . . . . . . . . . . . . . . . 56 


\title{
FOURTH PROGRESS REPORT OF LIGHT ARMOR PROGRAM
}

\begin{abstract}
The sequence of events that occurs when a sharp steel projectile strikes ceramic armor is examined using computer calculations in conjunction with experiments. Important physical properties of target materials that defeat penetration are identified. Experiments and calculations verify that the ballistic limit is very sensitive to the ceramic's tensile properties. The high stress load transmitted

through the ceramic to a backup plate results in the backup plate yielding directly under impact. Introduction of ductility into a ceramic promises to improve armor facing material. Fabrication of ceramics with ductility is discussed. Experimental equation-of-state data have been obtained for many current armor materials as well as for new armor material candidates.
\end{abstract}

\section{Introduction}

The light armor program has been aimed at understanding penetration mechanics in order to indicate the direction the material scientists should take to develop new materials. From the experiments and calculations that have been done previously, ${ }^{1-3}$ the current positions are these:

(1) The physical processes that occur during the penetration process are fairly well understood for impacts on hard and soft targets by blunt and sharp projectiles.

(2) The important material parameters that operate during the penetration process have been identified.

The problem that remains now is to incorporate this information into a material development program. There are two general directions that can be taken with the knowledge obtained in (1) and (2). One is to modify existing armor materials so as to have a better balance of physical properties needed to defeat penetration. The other is to fabricate new materials that may have intrinsically the desired properties. Both of these approaches are currently being undertaken at LRL.

A clearer picture of the motivation of the material development program can be given by summarizing some of the work that supports the two positions stated above for impacts of sharp projectiles on ceramic armor. (The projectiles are made from Allegheny steel 609, cylinder length 0.9 in, diameter 0.3 in. See Fig. 1 of Ref. 1.) 


\section{Physical Process in Penetration of Ceramic Armor}

Figure 1 gives the energy-vs-time history obtained from a calculation of a sharp steel projectile that strikes an $\mathrm{Al}_{2} \mathrm{O}_{3}$ ceramic target supported by an aluminum backup plate. The impact velocity is $2800 \mathrm{ft} / \mathrm{sec}$ which is just below the ballistic limit for this target; other details are given in Ref. 3. The following sequence of events correspond to Fig. 1:

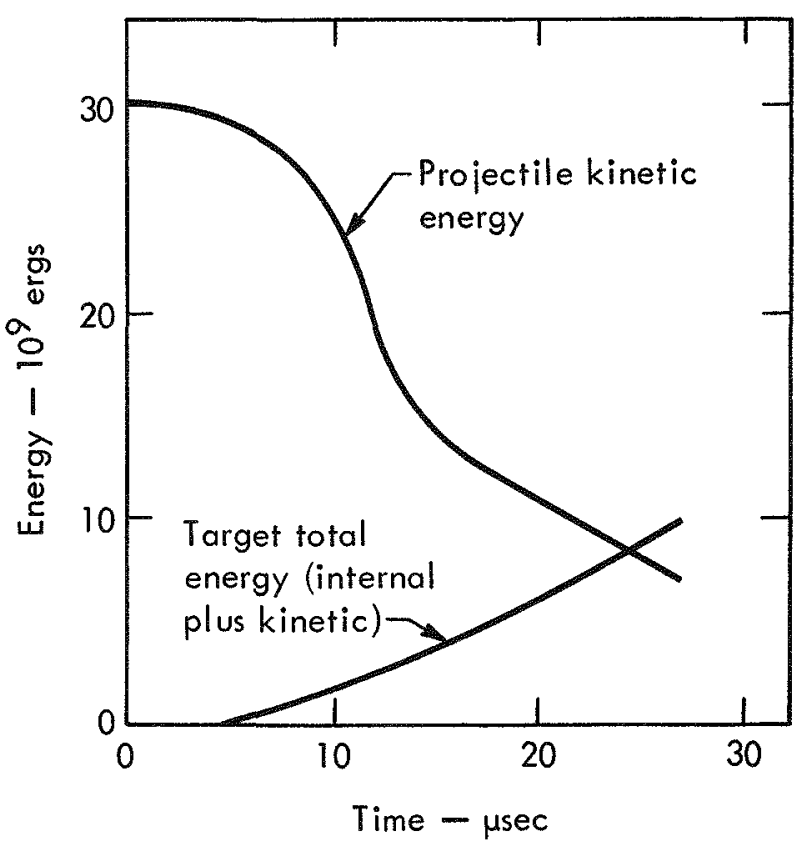

Fig. 1. Energy vs time for an impact at $2800 \mathrm{ft} / \mathrm{sec}$ of a sharp steel projectile with a target of $0.34-$ in. AD85 alumina backed by 0.25 -in. aluminum.

(1) From 0 to $9 \mu \mathrm{sec}$, the projectile tip is being destroyed. During this period, the backup plate yields at the ceramic interface. Resulting tension in the ceramic as it follows the motion of the backup plate initiates an axial crack.

Figure 2 shows a calculation of the initation of the axial crack at the ceramic backup-plate interface as well as the fracture conoid which starts at the impact surface. The axial crack moves back toward the impact surface. The fracture conoid proceeds toward the backup plate and effectively limits the amount of ceramic that participates in the impact process.

Figure 3 shows framing camera views of the tip of a projectile being destroyed by an impact on $\mathrm{Al}_{2} \mathrm{O}_{3}$. Figure 4 shows views of the interface of an $\mathrm{Al}_{2} \mathrm{O}_{3}$ target as seen through a glass backup plate during the impact of a sharp steel projectile. The breakout of the fracture conoid is seen. The last frame shows evidence of the axial crack which has been obscured by the grid lines. 4

(2) From 9 to $15 \mu \mathrm{sec}$, the projectile is eroded by the ceramic which has become a rubble from coalescing cracks within the fracture conoid. Approximately 40 percent of the projectile mass and 40 percent of the initial projectile energy is carried off by eroded projectile material. Erosion takes place because the stress level on the projectile is greater than the material strength of the projectile. Projectile material yields and flows perpendicular to the impact and is then swept back as the projectile moves into the ceramic. The maximum decelerating force on the projectile is thus related to projectile yield strength. The erosion process continues until the prevailing stress level falls below the projectile's yield strength.

Figure 5 shows a calculation and a flash radiograph immediately after an initially sharp projectile has completed the erosion process. Both the calculation and the radiograph show that projectile material has flowed out in the radial 


$$
\text { Cycle }=+167 \text { Time }=+2.652847
$$

$$
\text { Cycle }=+440 \quad \text { Time }=+3.238295
$$

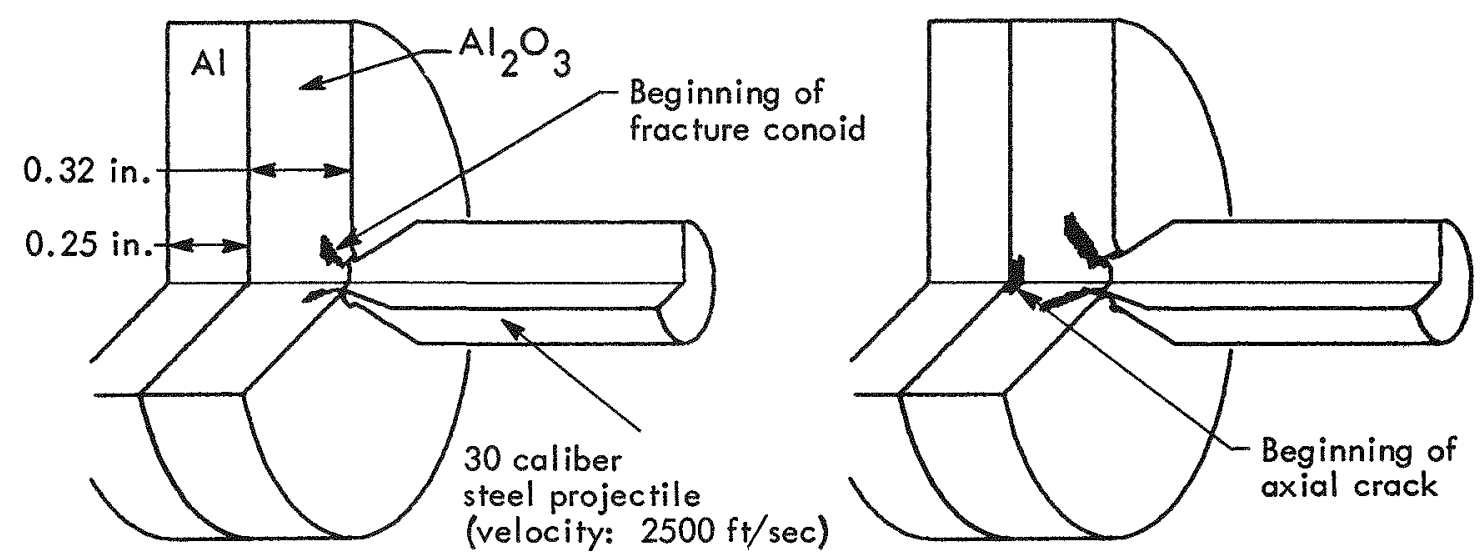

Cycle $=+693 \quad$ Time $=+4.151106$

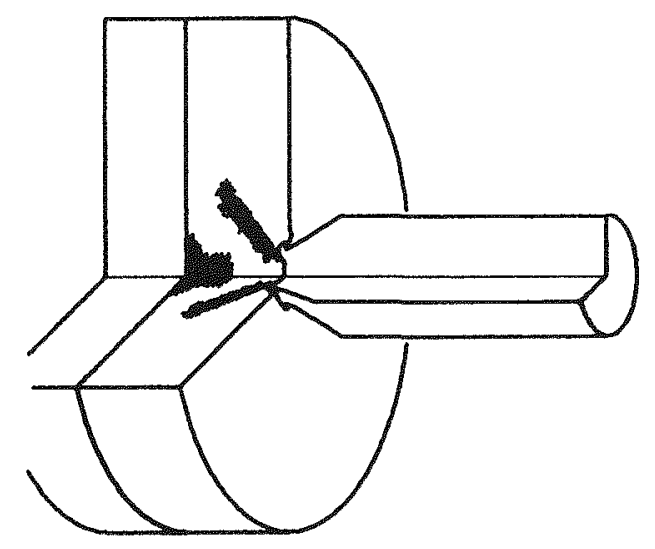

Cycle $=+986 \quad$ Time $=+4.901122$

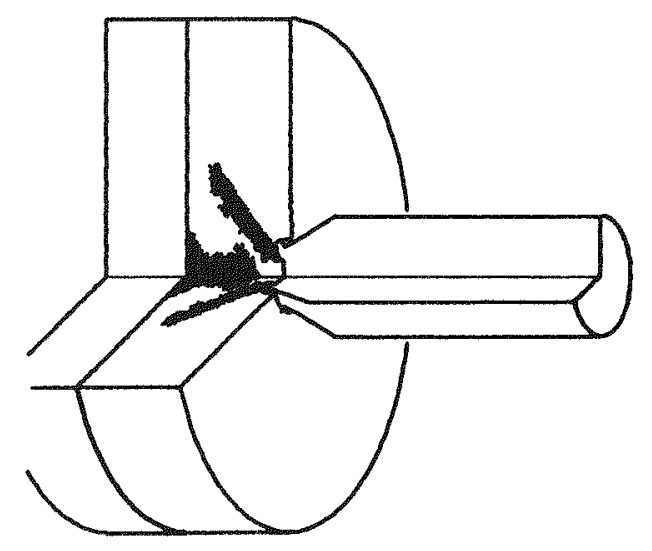

Cycle $=+1381 \quad$ Time $=+6.088165$

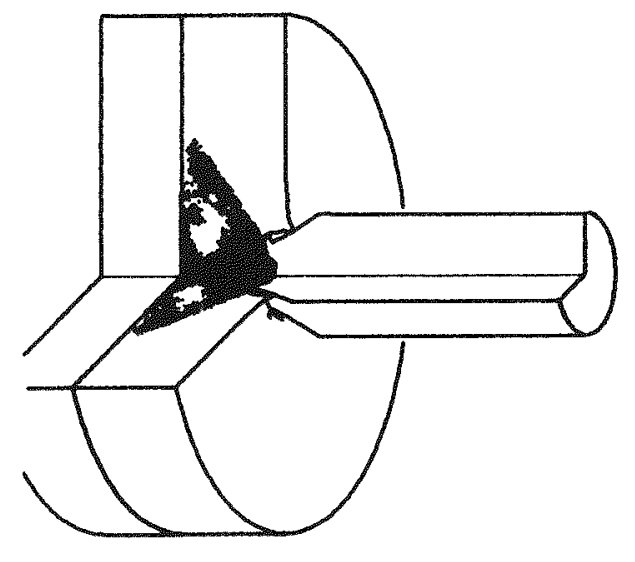

Fig. 2. Calculation of development of fracture and axial crack in alumina. 


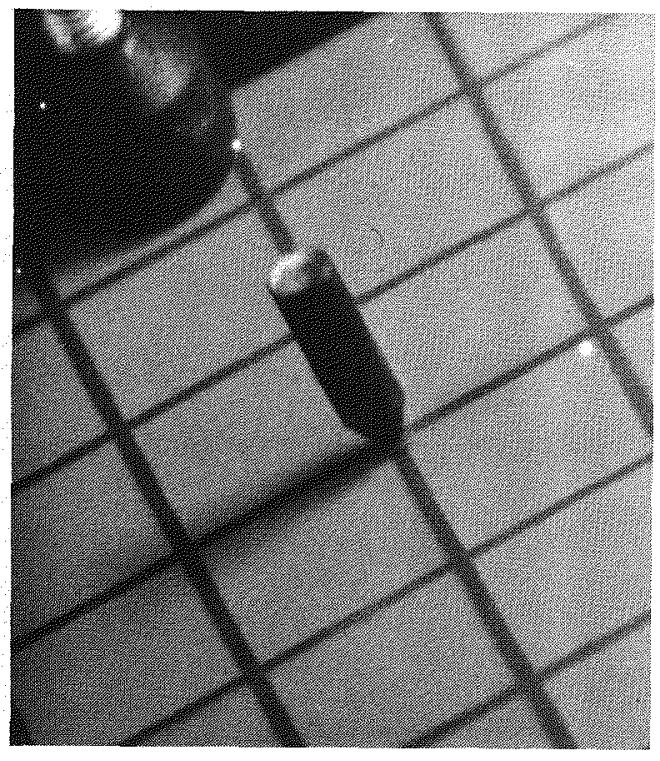

$t=1 \mu \mathrm{sec}$

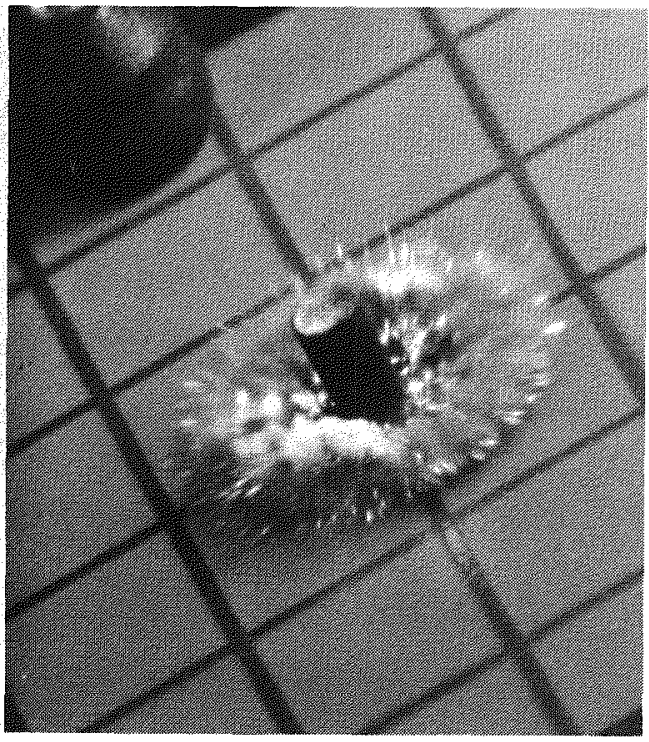

$t=17 \mu \mathrm{sec}$

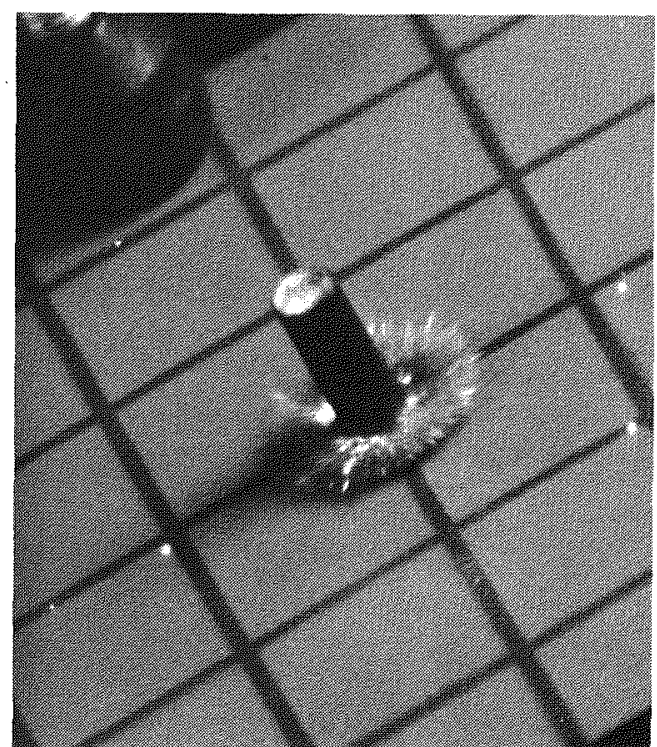

$t=9 \mu \mathrm{sec}$

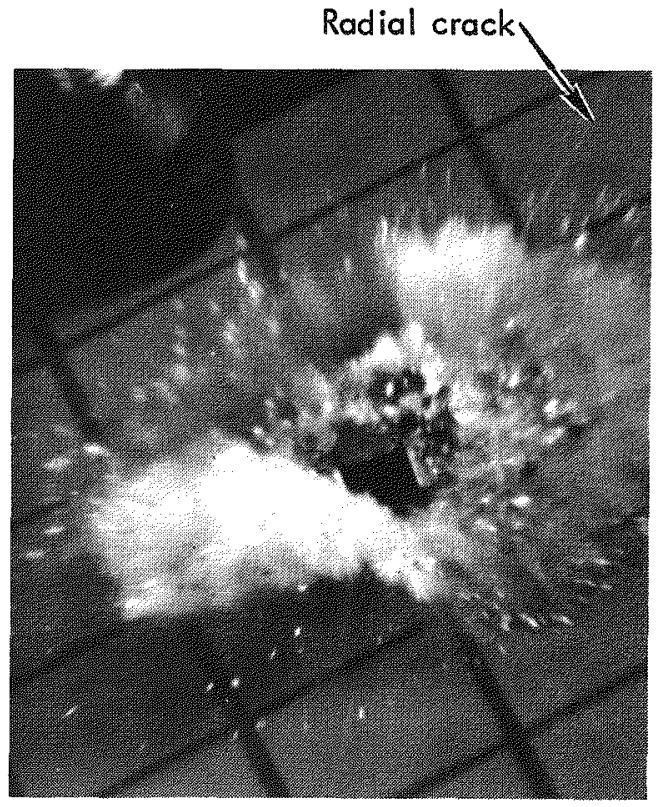

$\uparrow=33 \mu \mathrm{sec}$

Fig. 3. Impact of a 30 -caliber sharp projectile on $\mathrm{Al}_{2} \mathrm{O}_{3}$ ceramic. Impact velocity $=$ $2800 \mathrm{ft} / \mathrm{sec}$.

direction of the projectile and is being swept back by the ceramic. This material will eventually be stripped off the projectile.

(3) After $15 \mu \mathrm{sec}$, the erosion of the projectile stops and additional projectile energy loss equals the target energy gained. Total energy in the target-projectile system is 60 percent of the original energy and is absorbed by the backup plate.

The important energy loss mechanism for a projectile that strikes a ceramic 

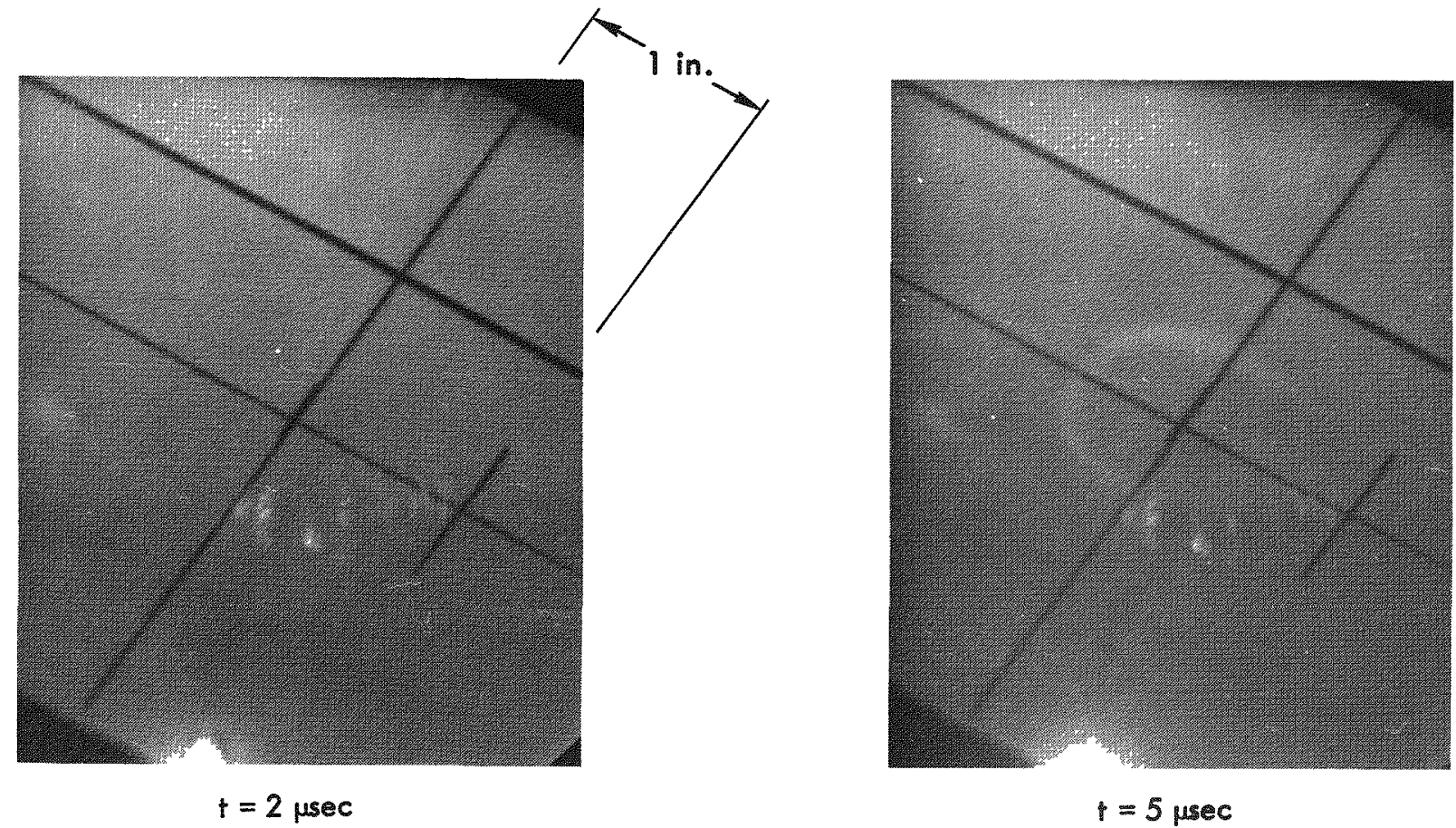

$t=5 \mu \mathrm{sec}$

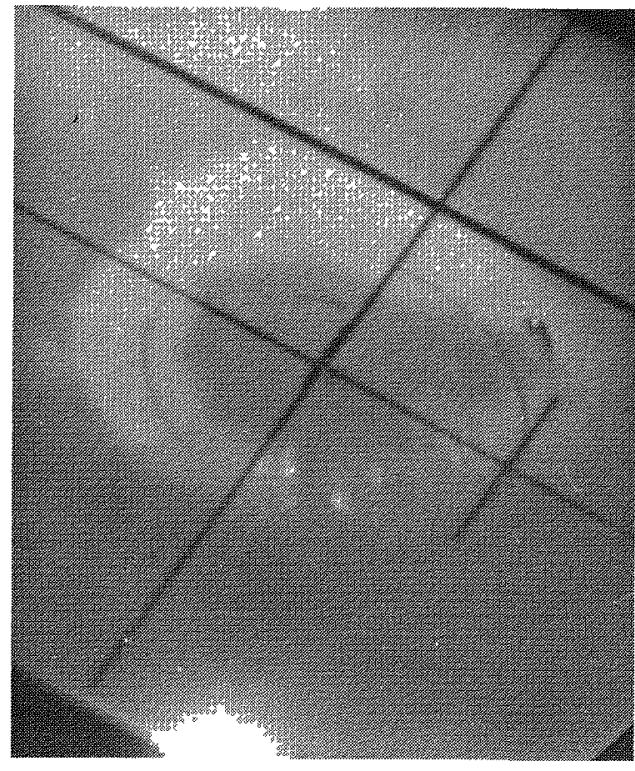

$t=9 \mu \mathrm{sec}$

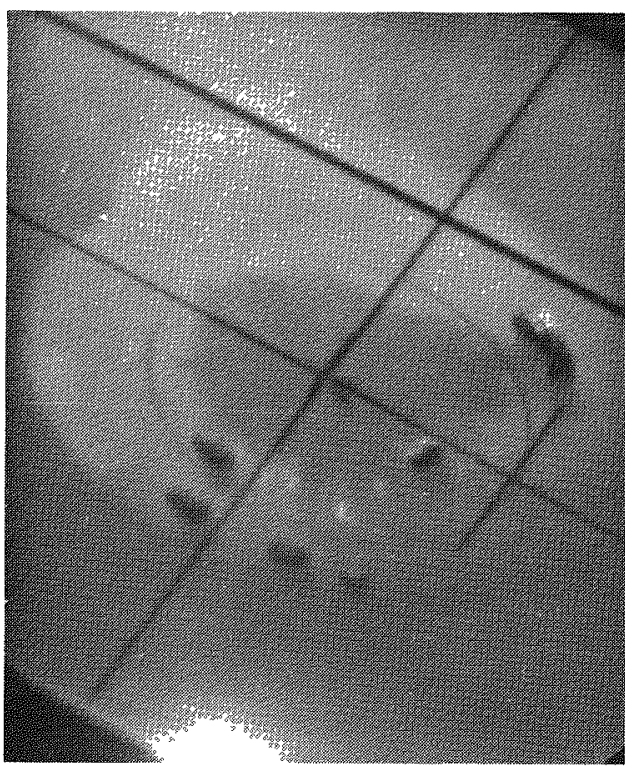

$t=11 \mu \mathrm{sec}$

Fig. 4. Experimental breakout of the fracture conoid in $\mathrm{Al}_{2} \mathrm{O}_{3}$ ceramic with a glass backup plate.

target is due to the loss of projectile mass during step (2) above. The rate of projectile energy loss shown in Fig. 1 is such that an increase of $250 \mathrm{ft} / \mathrm{sec}$ in the ballistic limit would occur if the time duration of step (2) could be extended by $2 \mu \mathrm{sec}$.
Because the duration of the projectile erosion phase is related to the time of breakup of the ceramic, it is important to maintain ceramic integrity for as long as possible. This can be done in two ways: 


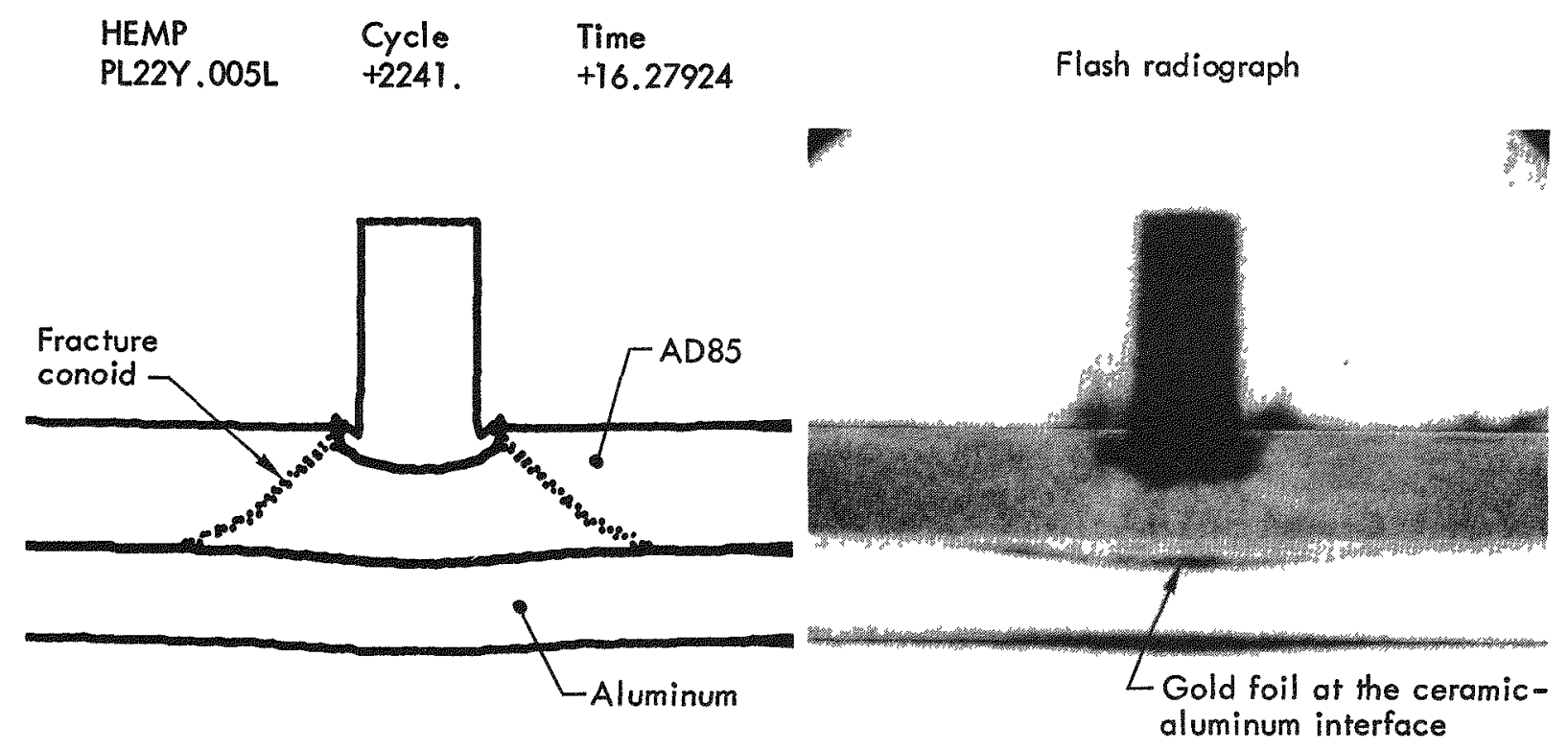

Fig. 5. Comparison of a calculation and an experiment at $16 \mu$ sec after impact of a sharp steel projectile with 0.34 -in. AD85 alumina bonded to 0.25 - in. aluminum. Impact velocity $=2800 \mathrm{ft} / \mathrm{sec}$. (The flash radiograph of the cylinder appears to have a smaller diameter than the actual diameter because of $x$-ray penetration of the edges.)

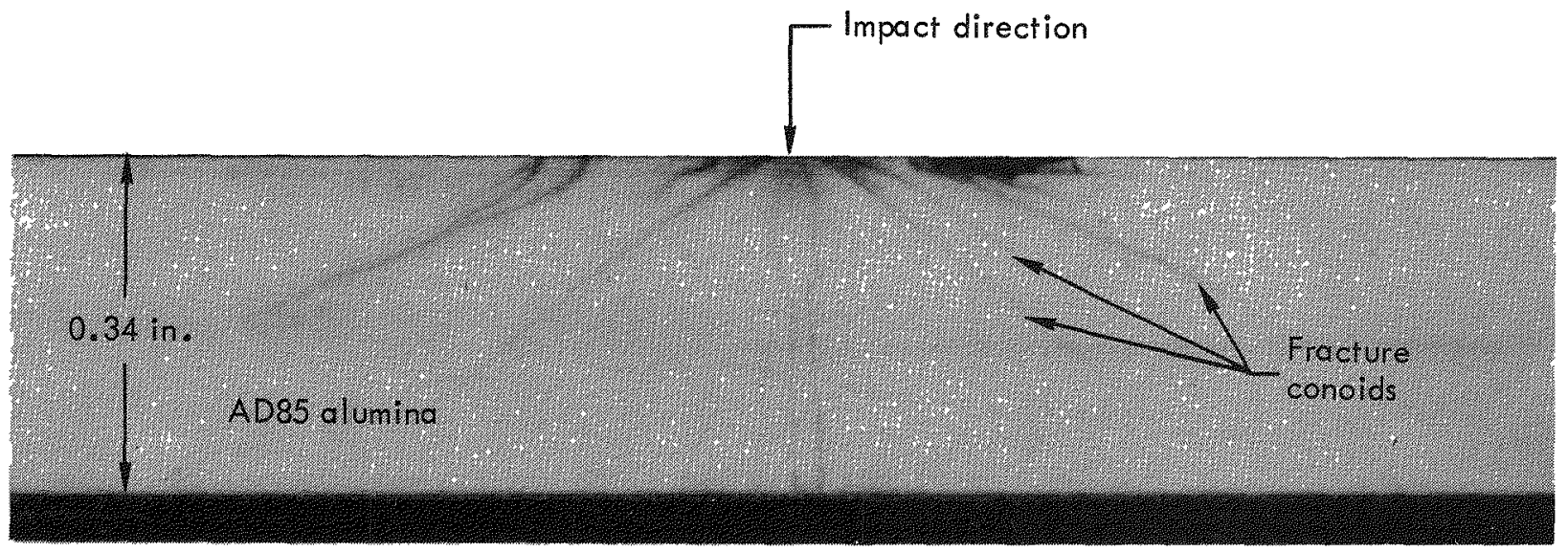

Fig. 6. Section view of rigid ceramic struck by a sharp steel projectile at $2300 \mathrm{ft} / \mathrm{sec}$.

(1) Synthesize a new backing material that will better support the ceramic in order to delay the onset of the ceramic tensile failure. The importance of this approach was investigated experimentally with a target of $0.34-$ in. thick AD-85 alumina supported by 1 in. of Starrett stock steel, which provided a nearly unyielding backup plate. There was no penetration of the ceramic when struck by the sharp steel projectile at a velocity of $2300 \mathrm{ft} / \mathrm{sec}$. The projectile was completely destroyed, but the ceramic still maintained its integrity (Fig. 6). This experiment suggests that ceramic armor would be even more effective if the backup plate could sustain higher loads.

(2) Synthesize a new ceramic which has improved tensile properties so as to delay the onset of the axial crack. 


\section{Important Parameters in Penetration Process}

Experiments and calculations verify that the ballistic limit is very sensitive to the ceramic's tensile properties. The high stress load transmitted through the ceramic to the backup plate results in the backup plate yielding directly under the impact. The attendant motion of the ceramic as it follows the backup plate is slight, but due to the high elastic modulus of the ceramic, a large tensile stress is set up in the ceramic. The axial crack that results is the beginning of the ceramic breakup under the projectile. A ceramic material property that would allow the ceramic to follow the motion of the backup plate further before failure is ductility. Two computer calculations were made (Fig. 7) to translate an improvement in ceramic tensile properties into a time delay before fracture. These calculations show fracture patterns for different times when the ceramic is considered to fracture when the tension reaches $3 \mathrm{kbar}$ and $8 \mathrm{kbar}$. The 3-kbar tension corresponds to about 0.1 percent strain, and the 8 -kbar tension corresponds to about 0.3 percent strain. Therefore the calculations compare the fracture pattern as a function of time when one ceramic is capable of a greater elongation before fracture. It should be emphasized that it does not matter if the material properties are such that a high tensile stress can be reached before fracture occurs, or if the material deforms plastically at a lower stress magnitude but fractures at the same value of strain. The results will be the same because the important parameter is the magnitude of the strain when fracture occurs. Thus, the expression "improved tensile properties" is used in the sense of an increase in strain before fracture from a tensile load.

Figure 7 shows that the accumulated damage to the ceramic is about the same at times $\mathrm{t}=4.15 \mu \mathrm{sec}$ and $\mathrm{t}=5.87 \mu \mathrm{sec}$ for the calculations with fracture at $3-\mathrm{kbar}$ tension and fracture at 8-kbar tension, respectively. Thus, for these calculations, a 0.2 percent increase in strain before fracture results in a $1.7 \mu \mathrm{sec}$ increase in the breakup time of the ceramics. When the ductile property of the ceramic is increased so that the time of breakup has been increased by $2 \mu \mathrm{sec}$, the calculated increase in the ballistic limit is $250 \mathrm{ft} / \mathrm{sec}$.

Note that there is not just one, but several important characteristics a target needs to defeat penetration. A ballistic impact on a ceramic creates large compressive stresses and subsequent tensile stresses. We have already discussed the importance of ductility or resistance to tensile failure. Adding ductility in a ceramic obviously would bring about an improvement if other parameters remained. unchanged. But most ceramics have essentially no ductility.' However, they are effective in armor because they present a high resistance to deformation from compressive loads.

We can identify several parameters associated with this characteristic with the aid of Fig. 8. Shown in this figure are Hugoniot curves for several ceramics and the reflected Hugoniot for steel. The intersection of the reflected Hugoniot curve for steel with a ceramic curve gives the stress state for a one-dimensional strain impact. The penetration process, of 

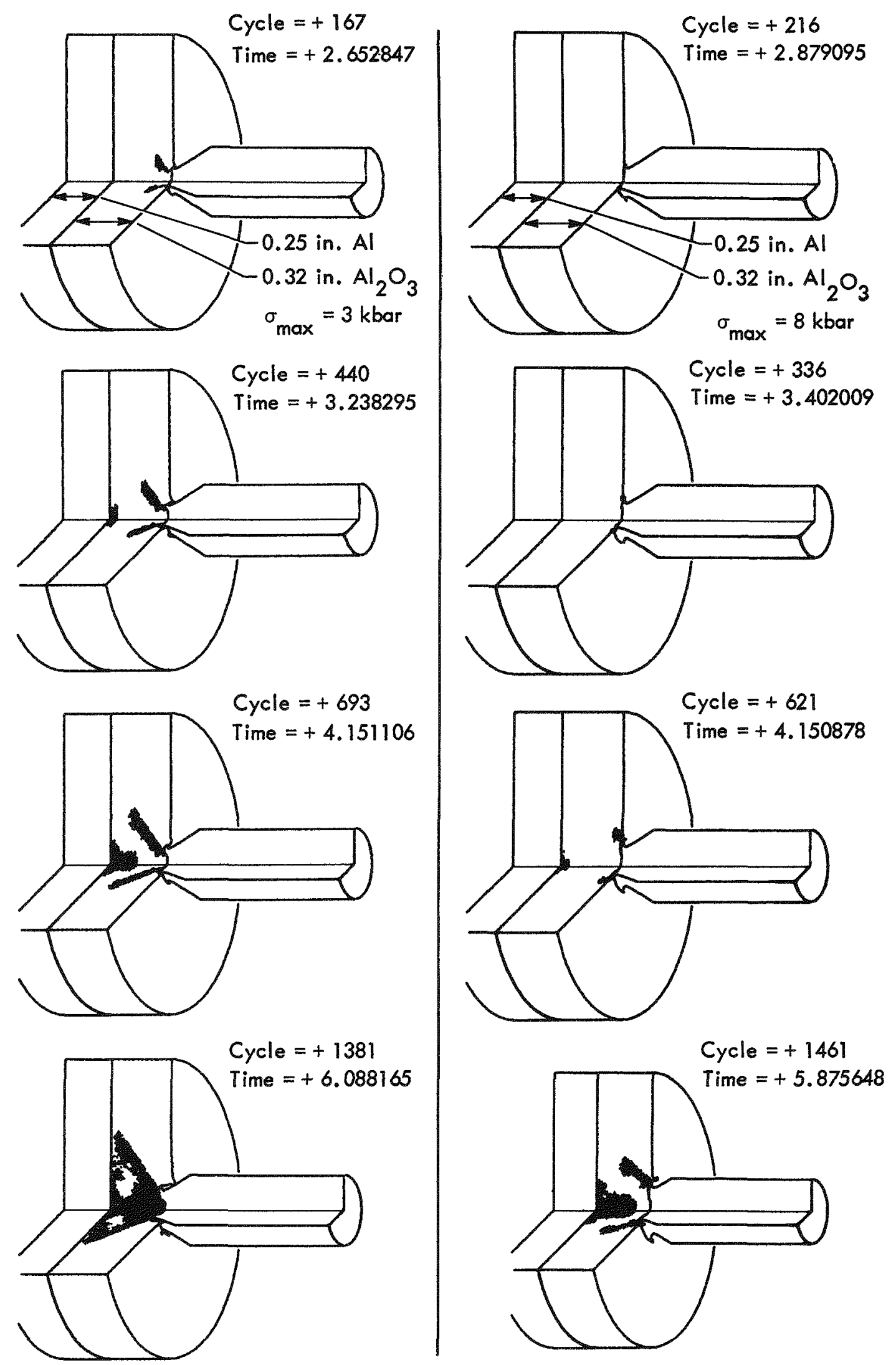

Fig. 7. Effect of fracture strength on time for fracture (left column: fracture strength = 3-kbar tension; right column: fracture strength $=8$-kbar tension) (time in $\mu$ sec). 


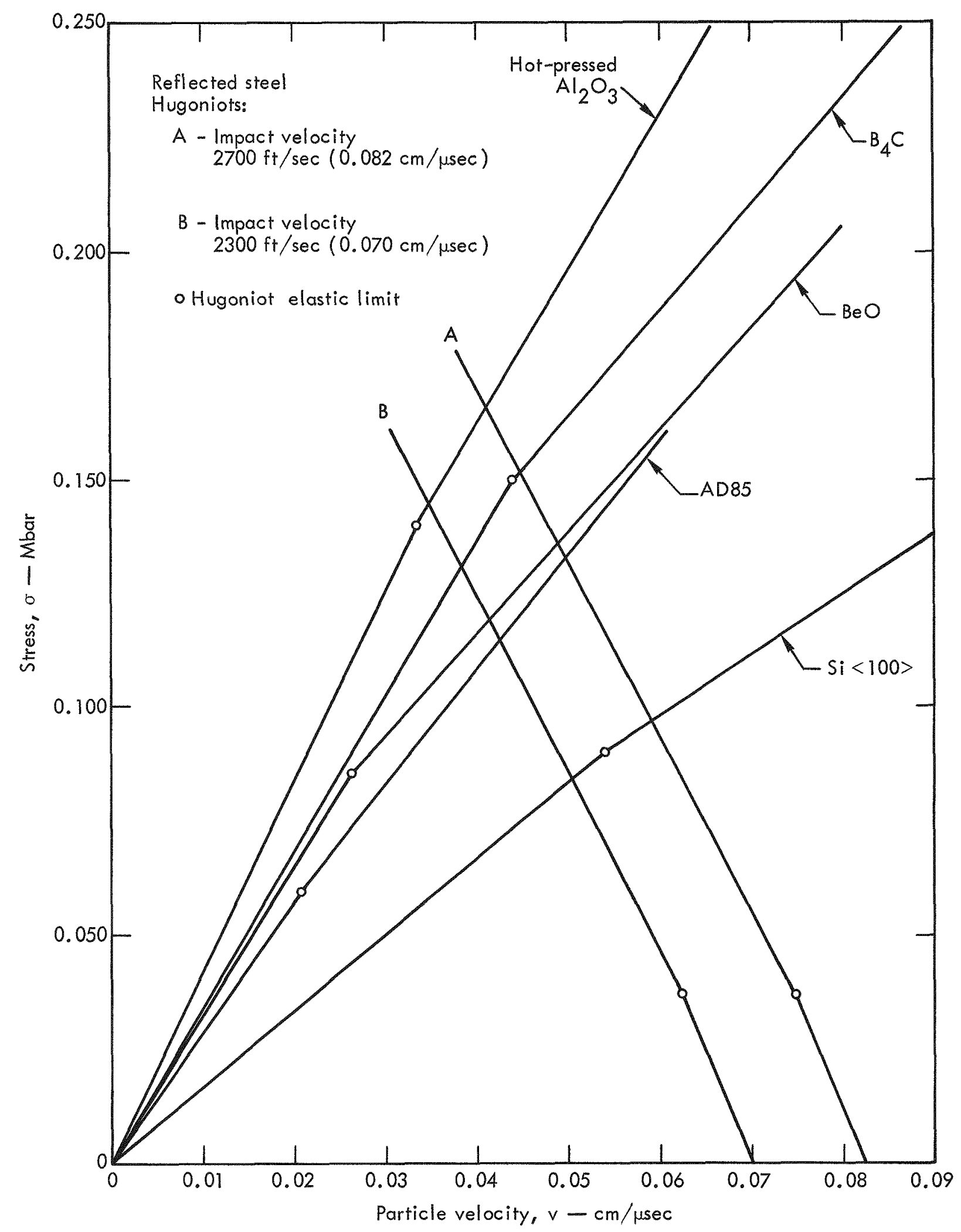

Fig. 8. One-dimensional strain impacts of steel on ceramics. 
course, involves more than one space dimension. However, some of the important aspects of material properties can be identified with reference to a onedimensional strain impact. The slope of the ceramic curves up to the Hugoniot elastic limit correspond to the elastic impedance, $\rho^{0} \mathrm{C}_{\ell}$. For a given projectile impact velocity, a higher elastic impedance implies a higher impact stress. The sharp point of a projectile is vulnerable to a high stress impact.

Another parameter implicit in these curves is the compressive yield strength $\mathrm{Y}^{0}$. The elastic impedance is a measure of the resistance to distortion of the material, while the yield strength is a measure of the amount of distortion that may occur before an elastic failure. It is not the elastic impedance at zero stress level that is important, but the impedance or resistance to distortion at the impact stress level. The compressive yield strength, $Y^{0}$, is the material parameter that determines the stress level where the impedance of the material changes value,
A high compressive strength $\mathrm{Y}^{0}$ when taken alone does not necessarily imply a good candidate for armor material. This point can be appreciated by referring to the curve for Si in Fig. 8. The yield strength for $\mathrm{Si}$ is $\mathrm{Y}^{0}=0.09$ Mbar. This is higher than the yield strength for AD85, which is $Y^{0}=0.038$ Mbar. However, the ballistic limit for a target with $\mathrm{Si}$ is much lower than a target with AD85 (Table 1). The low ballistic limit for Si can be understood by noting that the impact stress level is much lower for $\mathrm{Si}$ than it is for AD85 (Fig. 8). Actually, high impedance and high yield strength are components of a lumped parameter which is incompressibility at the impact stress.

From this discussion, it is obvious that a high elastic impedance and a high yield strength are important parameters when they exist together in the material. For these characteristics to be maintained as long as possible during the impact process, the tensile properties of the ceramic become important, i.e., ultimately a tensile load is placed on the material and a tensile failure becomes the weakest link.

Table 1. Elastic properties of TiC cermets.

\begin{tabular}{|c|c|c|c|c|c|c|}
\hline $\begin{array}{l}\text { vol } \% \\
(\mathrm{Ni}, \mathrm{Mo})\end{array}$ & $\begin{array}{c}\text { Density } \\
\rho^{0} \\
(\mathrm{~g} / \mathrm{cc})\end{array}$ & $\begin{array}{l}\text { Longitudinal } \\
\text { sound velocity } \\
\mathrm{C}_{\mathscr{\ell}} \\
(\mathrm{cm} / \mu \mathrm{sec})\end{array}$ & $\begin{array}{c}\text { Shear velocity } \\
\mathrm{C}_{\mathrm{s}} \\
(\mathrm{cm} / \mu \mathrm{sec})\end{array}$ & $\begin{array}{l}\text { Bulk } \\
\text { modulus } \\
\text { K } \\
\text { (Mbar) }\end{array}$ & $\begin{array}{l}\text { Shear } \\
\text { modulus } \\
\mu \\
\text { (Mbar) }\end{array}$ & $\begin{array}{c}\text { Elastic } \\
\text { impedance } \\
\rho^{0} \mathrm{C}_{\ell}\end{array}$ \\
\hline $0^{\mathrm{a}}$ & 4.88 & 0.95 & 0.58 & 2.61 & 1.32 & 4.63 \\
\hline $8^{b}$ & 5.56 & 0.93 & 0.57 & 2.41 & 1.81 & 5.17 \\
\hline $10^{\mathrm{b}}$ & 5.63 & 0.91 & 0.56 & 2.39 & 1.77 & 5.12 \\
\hline $14^{\mathrm{b}}$ & 5.81 & 0.89 & 0.54 & 2.39 & 1.69 & 5.17 \\
\hline $30^{\mathrm{b}}$ & 6.25 & 0.86 & 0.50 & 2.56 & 1.54 & 5.38 \\
\hline
\end{tabular}

\footnotetext{
$a_{\text {Kennametal. }}$

$\mathrm{b}_{\text {Ford Motor Company product. }}$
} 
Thus, the optimum ceramic should have a balance between elastic impedance, compressive yield strength, and the ability to withstand tensile stresses before fracture. These parameters are important in addition to low density. For a given target density, a low ceramic density permits a thicker ceramic facing, which in turn reduces the stress level on the backup plate, other parameters being equal. It has already been described how the stress level on the backup plate sets the stage for subsequent events. Studies have indicated that microhardness correlates fairly well with the Hugoniot elastic limit. Hardness measurements are easy tests that can be useful in evaluating ceramic materials for application to armor.

\section{Ductility in a Ceramic}

Information obtained from the calculations described indicates that the ballistic limit should improve if a ceramic were able to sustain tensile stresses longer before an ultimate failure by fracture. It is natural to examine ballistic limit experiments with various ceramics with the idea that perhaps ductility had contributed to the ballistic limit. Of the experiments available, all the ballistic 1 imits except BeO correlated with the material properties of incompressibility at the impact stress and low density. When tested at equal ceramic thickness, the ballistic limit for $\mathrm{BeO}$ is greater than the value for $\mathrm{B}_{4} \mathrm{C}$ and is almost equal to the value for hot pressed $\mathrm{Al}_{2} \mathrm{O}_{3}$.

Figure 8 shows that the Hugoniot curve for BeO lies below the curves for $\mathrm{B}_{4} \mathrm{C}$ and hot pressed $\mathrm{Al}_{2} \mathrm{O}_{3}$. It was suspected that $\mathrm{BeO}$ might possess better tensile properties than the other materials; this would compensate for the lower elastic impedance and compressive strength of BeO. Experiments that measure the shear strength of materials as a function of confining pressures showed that $\mathrm{B}_{4} \mathrm{C}$ and hot pressed $\mathrm{Al}_{2} \mathrm{O}_{3}$ failed in a brittle manner at confining pressures up to $7.5 \mathrm{kbar}$ (see
Appendix A). However, BeO yielded plastically and reached strains as high as 5 percent when the confining pressure was about 3 kbar and greater. The conclusion is that BeO has the desirable physical property of elongation before fracture as long as a confining pressure greater than $3 \mathrm{kbar}$ is present. This is just the calculated stress range that is operating at the ceramic backup-plate interface during the first $20 \mu \mathrm{sec}$ after the impact. (See Fig. 5 of Ref. 3.)

Optical examinations of the $\mathrm{BeO}$ taken from high-pressure shear tests indicated that the material had indeed deformed in a plastic manner. Additional evidence of plastic flow was obtained from $\mathrm{BeO}$ specimens subjected to ballistic tests and examined by microscopy.

Flash $\mathrm{x}$-ray experiments were done to compare the sequence of events for impacts of sharp steel projectiles on targets of equal thickness of $\mathrm{AD} 85, \mathrm{~B}_{4} \mathrm{C}$ and, $\mathrm{BeO}$, all backed by aluminum. Figures 9 and 10 show results for impacts on AD85- and BeO-faced aluminum targets.

The interface between the ceramics and the aluminum is seen by the $x$-rays because a 5 -mil-thick gold foil, 1/16 in. wide 


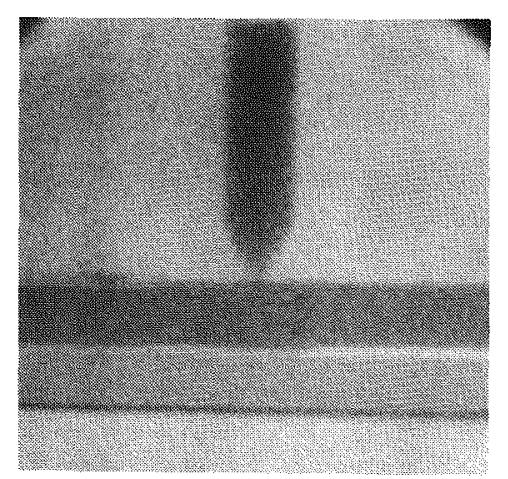

$t=2.2 \mu \mathrm{sec}$

$\stackrel{1}{\frac{1}{N}}$

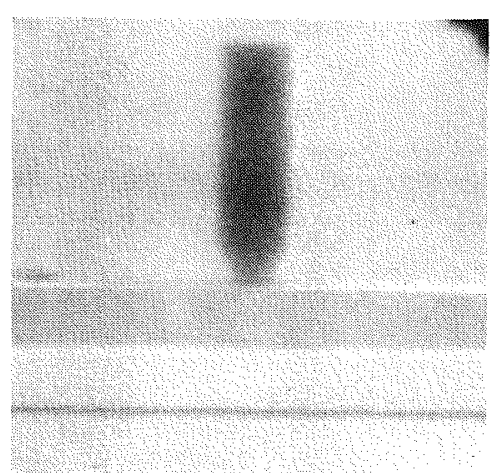

$t=5.1 \mu \mathrm{sec}$

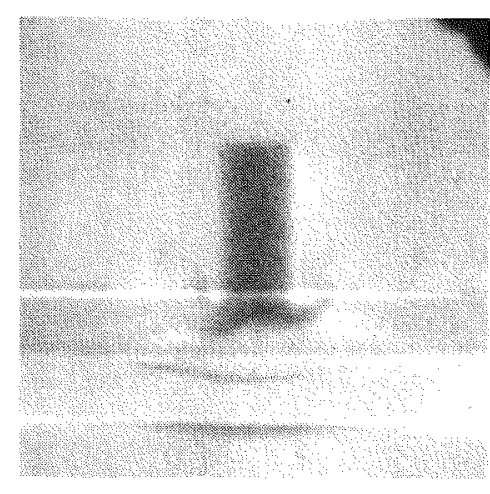

$t=20.0 \mu \mathrm{sec}$

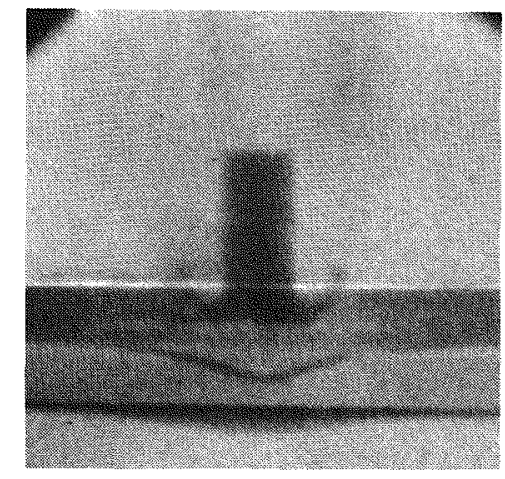

$t=25.1 \mu \mathrm{sec}$

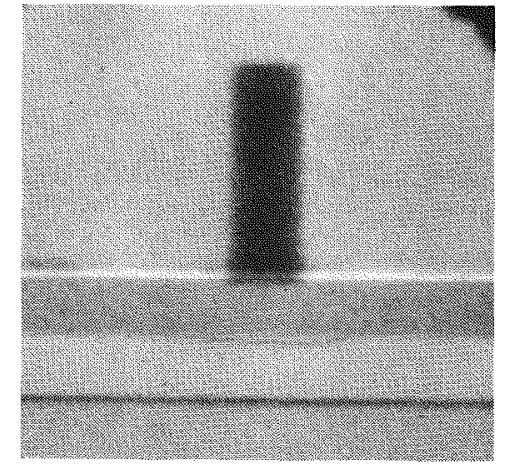

$t=10.1 \mu \mathrm{sec}$

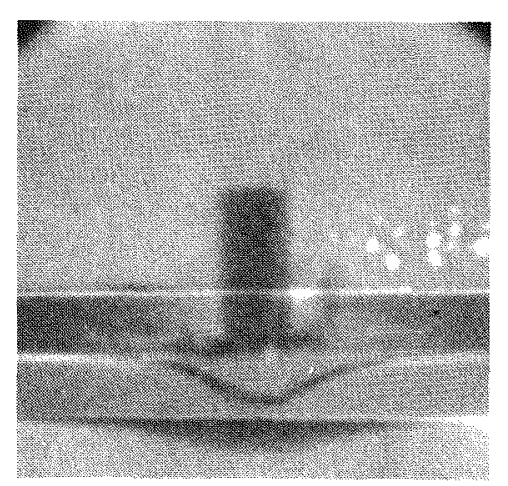

$t=30.1 \mu \mathrm{sec}$

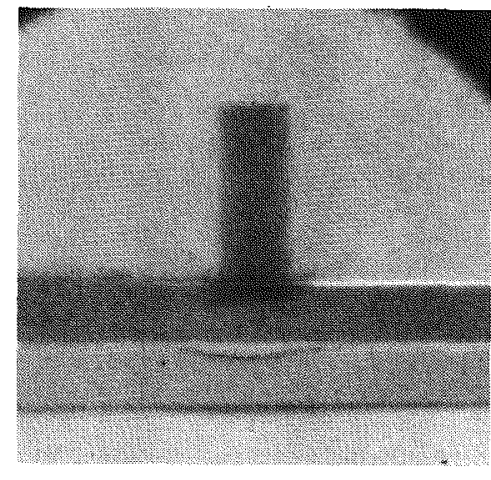

$t=15.1 \mu \mathrm{sec}$

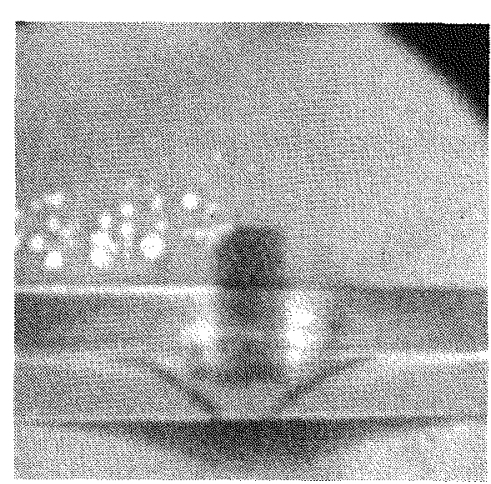

$t=40.1 \mu \mathrm{sec}$

Fig. 9. Flash radiographs of a sharp steel projectile striking 0.25-in. AD85 alumina bonded to 0.25-in. 6061-T6 aluminum. Projectile velocity $=2400 \mathrm{ft} / \mathrm{sec}$. 


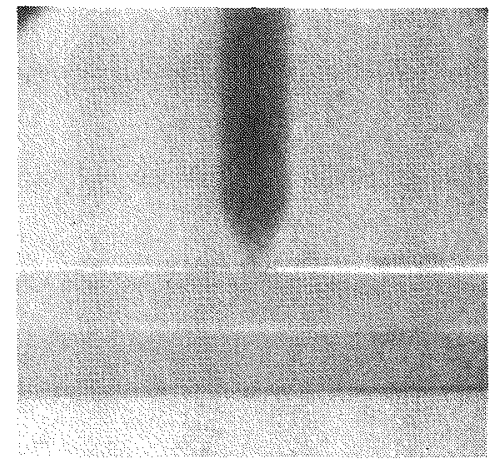

$t=2.0 \mu \mathrm{sec}$

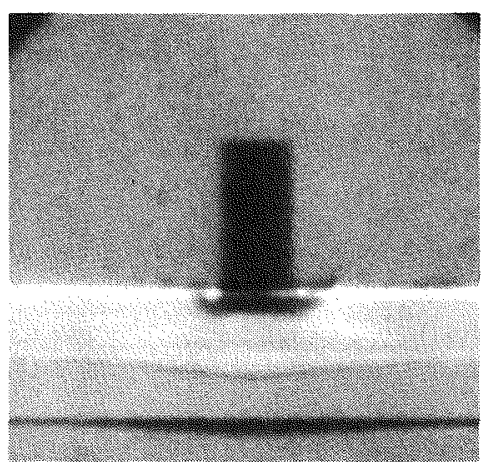

$t=20.0 \mu \mathrm{sec}$

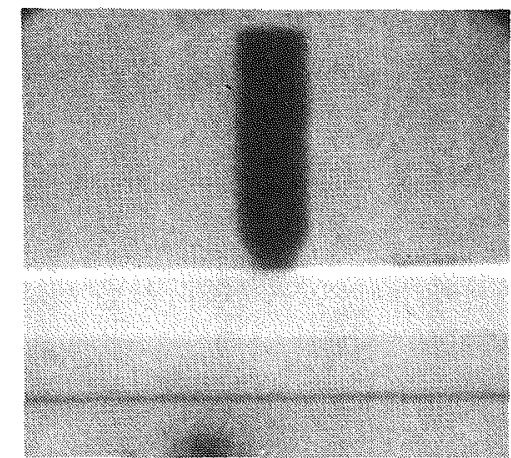

$t=5.0 \mu \mathrm{sec}$

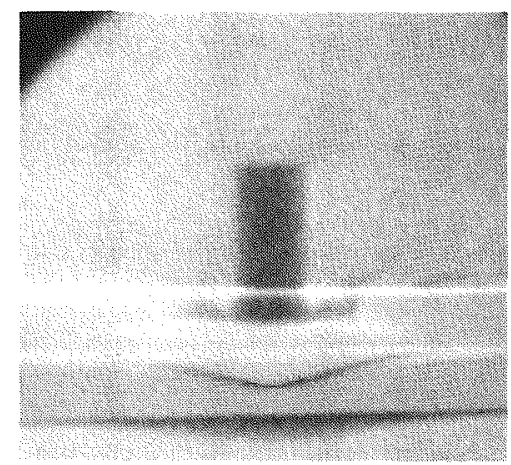

$t=25.1 \mu \mathrm{sec}$

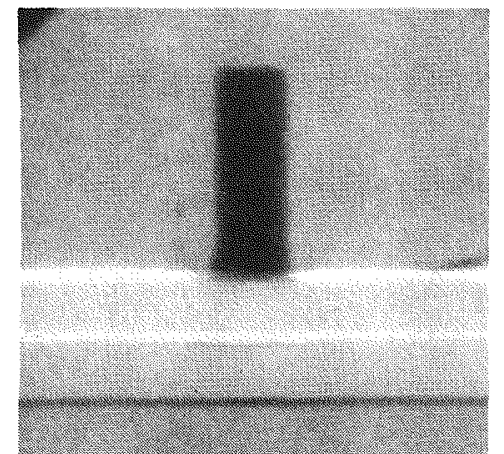

$t=10.0 \mu \mathrm{sec}$

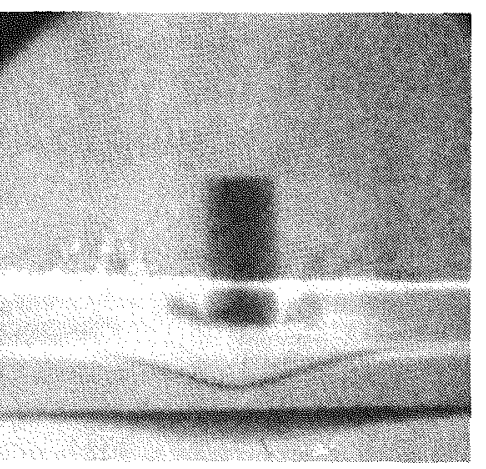

$t=30.0 \mu \mathrm{sec}$

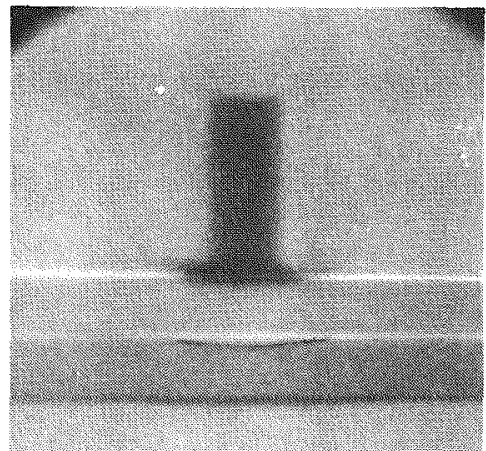

$t=15.1 \mu \mathrm{sec}$

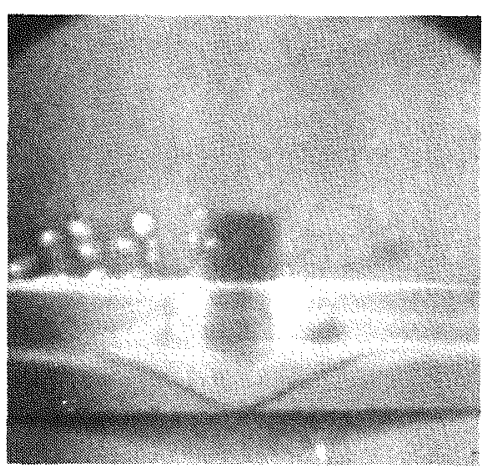

$t=40.0 \mu \mathrm{sec}$

Fig. 10. Flash radiographs of a sharp steel projectile striking $0.25-$ in. BeO bonded to $0.25-$ in. $6061-$ T6 aluminum. Projectile velocity $=2400 \mathrm{ft} / \mathrm{sec}$. 
Target: $\mathrm{B}_{4} \mathrm{C}+\mathrm{A} 1$
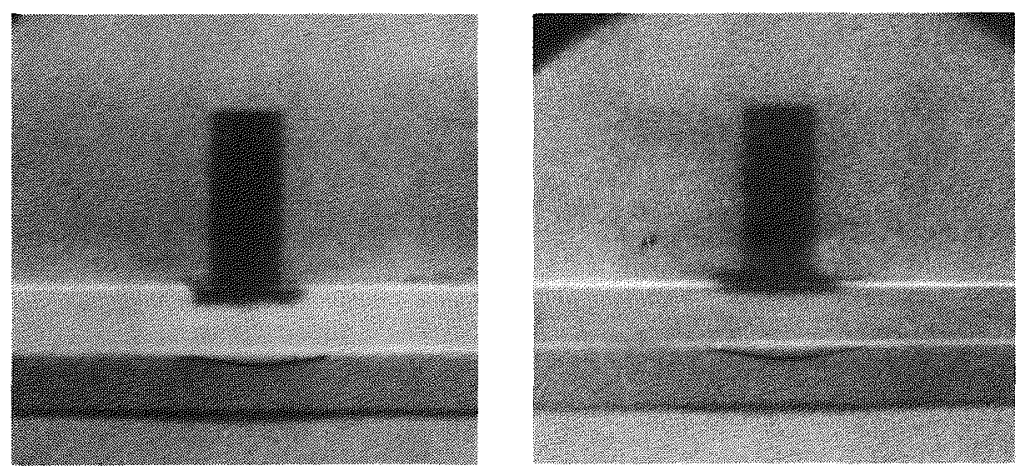

$t=15 \mu$ sec after impact
Target: $\mathrm{AD} 85+\mathrm{Al}$
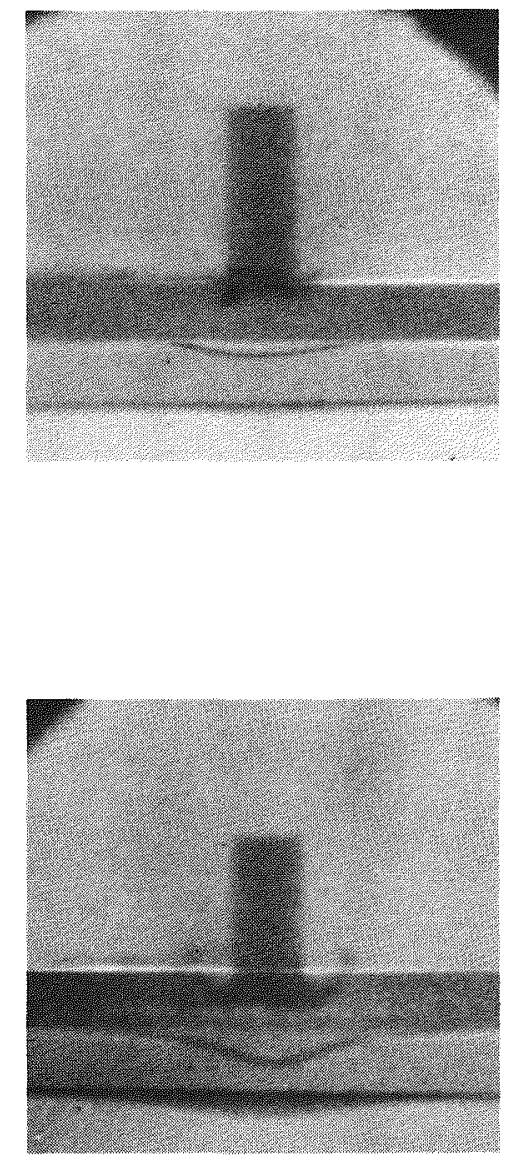
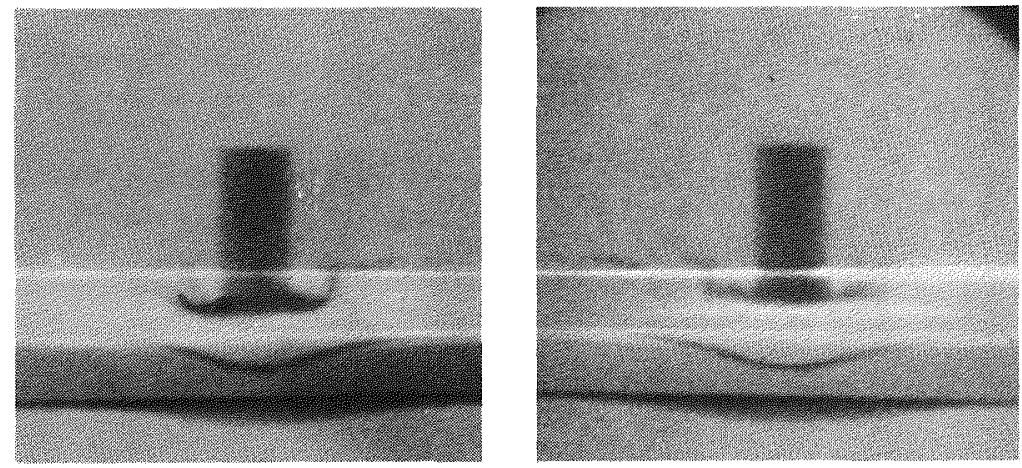

$f=25 \mu$ sec after impact

Fig. 11. Flash radiographs of a sharp steel projectile striking targets of 0.25 -in.

$\mathrm{B}_{4} \mathrm{C}, \mathrm{BeO}$, and $\mathrm{AD} 85$ each bonded to 0.25-in. 6061-T6 aluminum. Projectile impact velocity $=2400 \mathrm{ft} / \mathrm{sec}$.

was laid along the interface at the impact center perpendicular to the $x$ rays. ${ }^{3}$ Inspection of these figures at the same times shows that the projectile has not penetrated as far into the ceramic and is shorter (has undergone more erosion) for the impact on the $\mathrm{BeO}$ target compared to the AD85 target. At times $t=30 \mu \mathrm{sec}$ and $t=40 \mu \mathrm{sec}$ the gold foil reveals that the load on the aluminum backup plate is not as localized for the target with $\mathrm{BeO}$ as it is for the AD85 target.

Figure 11 compares $\mathrm{B}_{4} \mathrm{C}, \mathrm{BeO}$, and AD 85 targets struck by a sharp steel projectile. More projectile erosion has occurred with the $\mathrm{BeO}$ target compared to the other two.

A series of experiments was performed using shadowgraph $x$ rays to measure the residual mass and residual velocity for a sharp projectile penetrating AD85 and $\mathrm{BeO}$. Results showed the most projectile energy is lost for an impact on the $\mathrm{BeO}$.

These results mean that the capability for plastic flow, which delays the onset of tensile stresses, permits BeO to remain integral for a longer period of time. 
Thus, BeO is able to present an incompressible barrier to the projectile for a longer time than other ceramics that fail sooner when a tensile load occurs. For more data on the properties of $\mathrm{BeO}$ see Appendix B.

\section{Introducing Ductility into a Ceramic}

The impedance and yield strength of $\mathrm{B}_{4} \mathrm{C}$ appear to be more than adequate for the application of this material to ceramic armor. For example, these parameters are considerably smaller in magnitude for AD85 than they are for $B_{4} C$, yet AD85 is still a good armor material. The weakness in $\mathrm{B}_{4} \mathrm{C}$, as well as most other ceramics, is failure by brittle fracture from a tensile load.

It might be possible to degrade the impedance and yield strength of $\mathrm{B}_{4} \mathrm{C}$ in favor of improved ductility properties. Thus, a trade-off in impedance and strength for ductility is sought with an already low density ceramic. The values of elastic impedance and yield strength of AD85 provide a lower limit for the trade off of these parameters.

Preliminary work at LRL has considered the following systems:

\section{TiC CERMETS}

The indication that improved ductility might lead to a higher ballistic performance for ceramics has led us to the class of materials known as "cermets." The particular model system chosen for study was $\mathrm{TiC}-(\mathrm{Ni}, \mathrm{Mo})$. This particular system has been the subject of extensive study by Humenik and coworkers ${ }^{5-8}$ at Ford Motor Company. A cooperative effort was set up with Humenik, and samples were obtained with metal contents ranging from 8 to $30 \mathrm{vol} \%$. A control series of high density, hot pressed TiC was obtained from Kennametal, Inc. Elastic properties of the various materials are tabulated in Table 1. Note that longitudinal sound and shear wave velocities decrease linearly with increasing metal content.

The $\mathrm{TiC}-(\mathrm{Ni}, \mathrm{Mo})$ samples were in the form of 3 -in. diameter disks, $1 / 4 \mathrm{in}$. thick. For ballistic testing, the disks were bonded to 6 by 6 by $1 / 4$ in. 6061-T6 aluminum plates using a Scotchcast 221 adhesive.

Ballistic performances of the various samples are listed in Table 2. The LRL standard 30 caliber projectile was used in the tests. The $\mathrm{TiC}$ samples were examined by metallographic techniques to characterize the fracture behavior, and typical fracture features are shown in Figs. 12 and 13. We concluded that the fracture propagation is transgranular cleavage. It is not clear if the main fracture mode has changed due to metal additions, although the figures do show evidence of blunting of cracks at metal agglomerates. Figs. 12 and 13 show that in some cases, the crack front is stopped at the metal phase between $\mathrm{TiC}$ grains.

The metal phase of the TiC cermet has a density twice the value of the ceramic phase. Thus, the areal density of the tar get has been increased by the metal addition. However, the improved ballistic limit of the cermet (Table 2) is thought to be independent of the increased density due to the metal addition. In Table 2 a 
Table 2. Ballistic performance of $\mathrm{TiC}$ cermets with 0.25 in. 6061-T6 aluminum backup plate.

\begin{tabular}{cc}
\hline $\operatorname{vol} \%(\mathrm{Ni}, \mathrm{Mo})$ & $\mathrm{V}_{\mathrm{BL}}(1 / 4-\mathrm{in}, \mathrm{TiC})$ \\
\hline 0 & $2500 \pm 80$ \\
8 & $2960 \pm 50$ \\
10 & $3050 \pm 80$ \\
14 & $2970 \pm 50$ \\
30 & $2810 \pm 50$ \\
\hline
\end{tabular}

$500 \mathrm{ft} / \mathrm{sec}$ improvement in ballistic limit is seen for a 10 vol \% metal addition.

This result is viewed as an encouraging test of the concept. The problem now is to develop a cermet with a low density ceramic in a low density metal.

\section{$\mathrm{B}_{4} \mathrm{C}$ CERMETS}

The $\mathrm{B}_{4} \mathrm{C}$ ceramic was the first choice for a light weight cermet; however, the problem is to find a low density metal that has the needed wetting behavior, and forms strong bonds with the ceramic.

Aluminum was tried initially, but proper bonding could not be obtained (see Appendix C). Further emphasis on a lowdensity metal was then waived so that a better understanding of the effect of bonding could be obtained. The Russian literature ${ }^{9}$ states that iron and copper wet $\mathrm{B}_{4} \mathrm{C}$. We turned our efforts to fabricating $\mathrm{B}_{4} \mathrm{C}$ cermets with copper and iron. Samples were prepared by liquid-phase hot pressing (Appendix C).

We found that the wetting behavior of pure copper was not sufficient to permit the fabrication of structurally sound cermets, so this system was discarded. The addition of iron to $\mathrm{B}_{4} \mathrm{C}$ showed some promise. But the complexity of the reaction products and their interactions with the bonding process made $\mathrm{Fe}-\mathrm{B}_{4} \mathrm{C}$ a very poor system for studying the chemistry of bonding.

Recent bonding studies on systems of titanium with the compounds $\mathrm{TiBe}_{12}$ and $\mathrm{BeO}$ have been very encouraging. These systems are also very desirable for light armor materials because of low density. Therefore, further work on the understanding of bonding is planned for these systems.

\section{GRADED ARMOR}

Since the cracks which eventually compromise the ceramic armor facing originate from the interface between the ceramic and the armor backing, it is natural to ask if the armor can be improved by eliminating the interface and thereby inhibiting crack formation. At least in principle, the interface between the ceramic facing and the metal backing can be eliminated by means of a transition zone which is ceramic and metal combined in proportions which change smoothly from 100 percent ceramic at the ceramic side of the zone to 100 percent metal at the metal side of the zone. We call the material in the transition zone a "graded cermet," and 


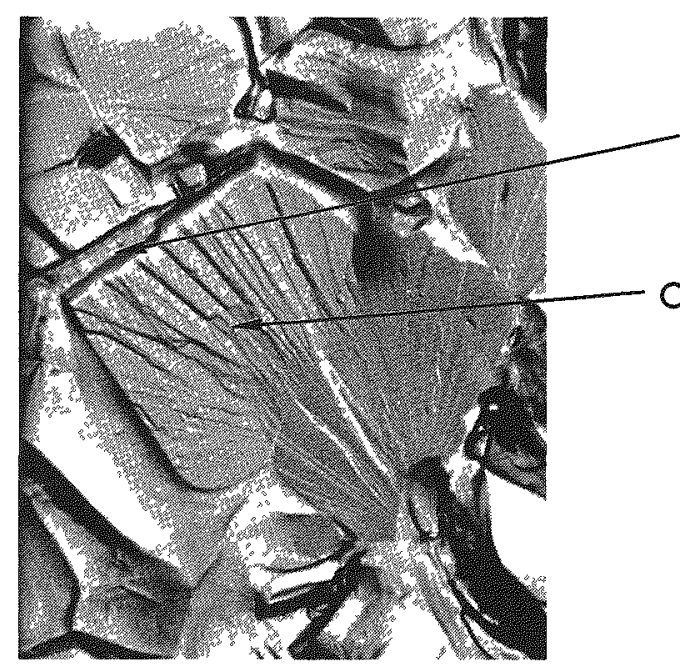

$20,000 \times$

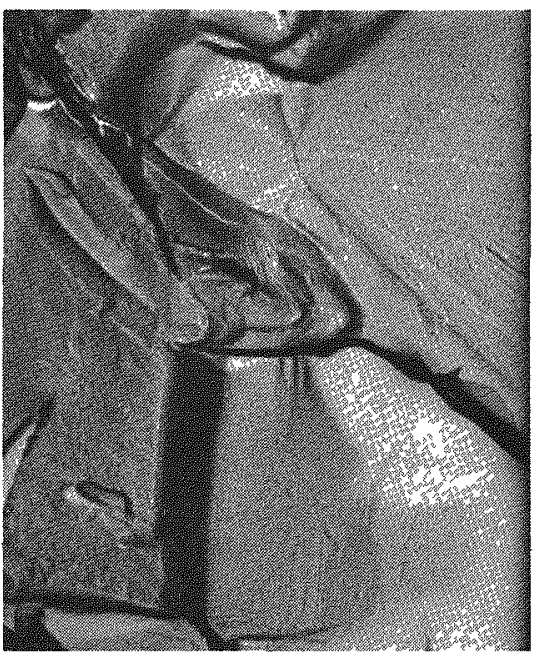

$25,000 \times$

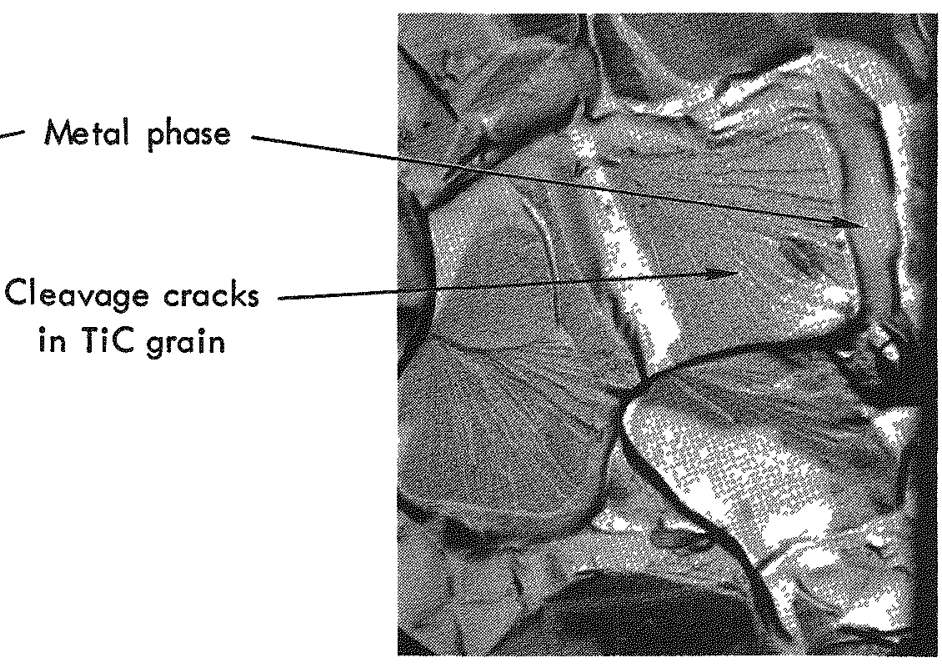

$21,000 \times$

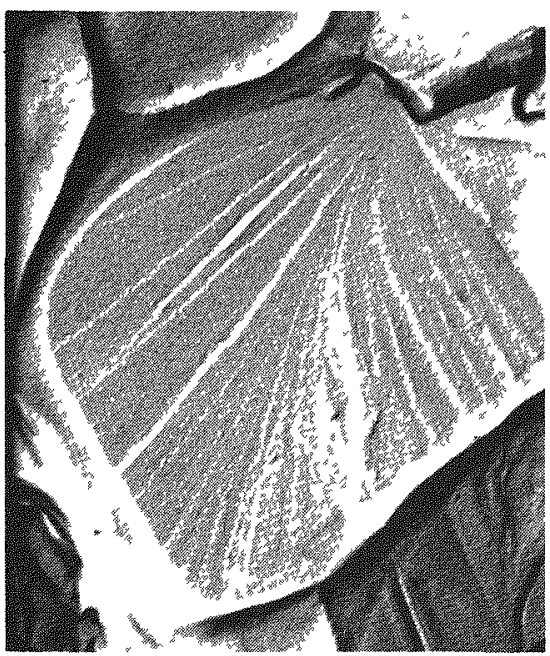

$35,000 \times$

Fig. 12. TiC $+30 \mathrm{vol} \%(\mathrm{Ni}, \mathrm{Mo})$ ballistically tested. Negative replica Pt-Pd shadow.

we call the armor built this way a "graded armor."

To test the graded armor idea, an outside manufacturer was asked to construct, for ballistic testing, sample plates of alumina and aluminum using the "plasma-spray" technique. The transition zone was plasma-sprayed onto a. layer of ceramic produced by conventional means, then the metal backing was sprayed onto the transition zone. A smooth transition from ceramic to metal was not 


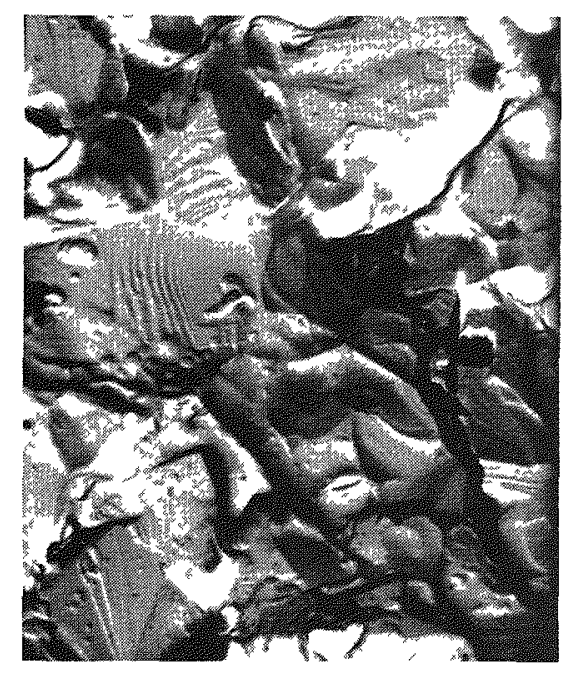

$9,500 \times$

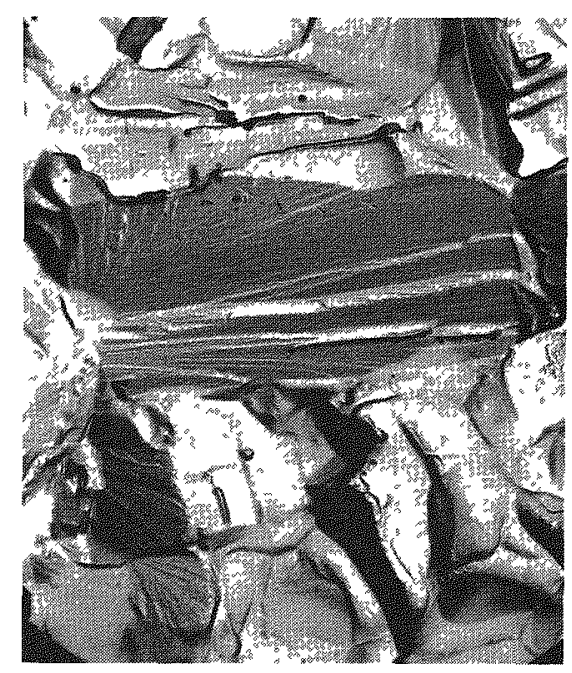

$16,000 \times$

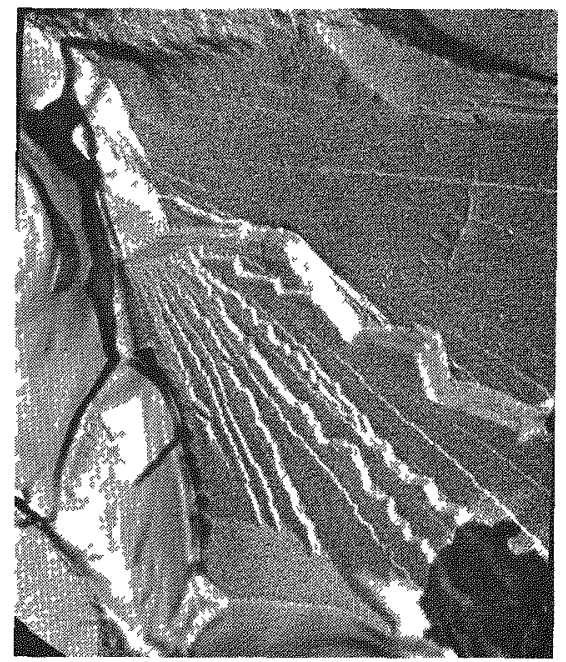

$29,000 \times$

Fig. 13. TiC +30 vol \% (Ni, Mo) ballistically tested. Negative replica Pt-Pd shadow.

attempted, instead a succession of small, but finite, composition changes were made.

The attempt to produce plates for ballistic testing was unsuccessful, probably because the original choice of materials turned out to be a bad one. The large difference in the coefficient of thermal expansion and melting temperatures of the aluminum and alumina made it very difficult to bond successive layers in the transition zone. This caused warping and 
cracking on the ceramic plate. The plasmasprayed cermet was less than 90 percent of theroretical density and was unsurtable for armor applications. Finally, under ballistıc loading, the plasma-sprayed aluminum behaved as a brittle, rather than ductile, material and it, too, had to be considered unsuitable for armor.

Fallure to produce an alumina-aluminum graded armor suggested certain stringent requirements for the components of a graded armor. We now feel that these requirements may be met by a graded mixture of titanium and titanium dodecaberyllide $\left(\mathrm{T}_{1} \mathrm{Be}_{12}\right)$. An encouraging feature of this system is that the two materials make an excellent metallurgical bond.

Another promising system that is currently being evaluated at LRL is beryllium oxide-titanium.

\section{NICKEL-WIRE-REINFOR CED $\mathrm{Al}_{2} \mathrm{O}_{3}$}

An attempt to gain macroscopic ductility in a ceramic was made by hot pressing a composite consisting of $20 \mathrm{vol} \%$ nicke1 wire (0.005-1n. diameter by $1 / 4$ in. long) in WESGO $300 \mathrm{Al}_{2} \mathrm{O}_{3}$ powder. It was necessary to slurry the mixture in isopropyl alcohol in order to get a good distribution. The mixture was then vacuum-dried and hot pressed in a graphite die to a temperature of $1365^{\circ} \mathrm{C}$ at a pressure of $5000 \mathrm{ps} 1$. The maximum temperature was maintained for $30 \mathrm{~min}$.

We knew the materials were dissimilar in thermal expansion properties, but felt that hot pressing might y1eld a dense structure. This optimism was not justified; final densities were about 85 percent of theoretical. This low density indicated that there was not a continuous ceramic phase in the material. This was borne

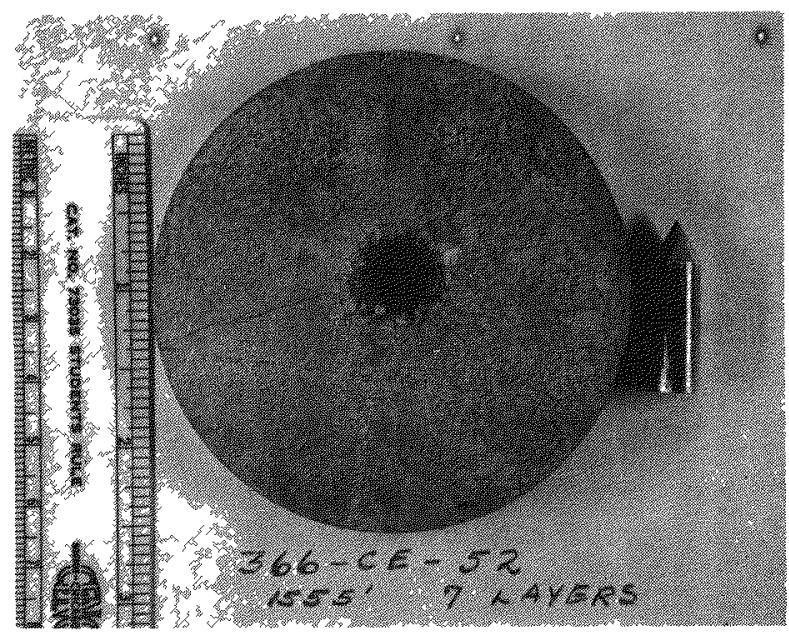

\section{A. Impact side}

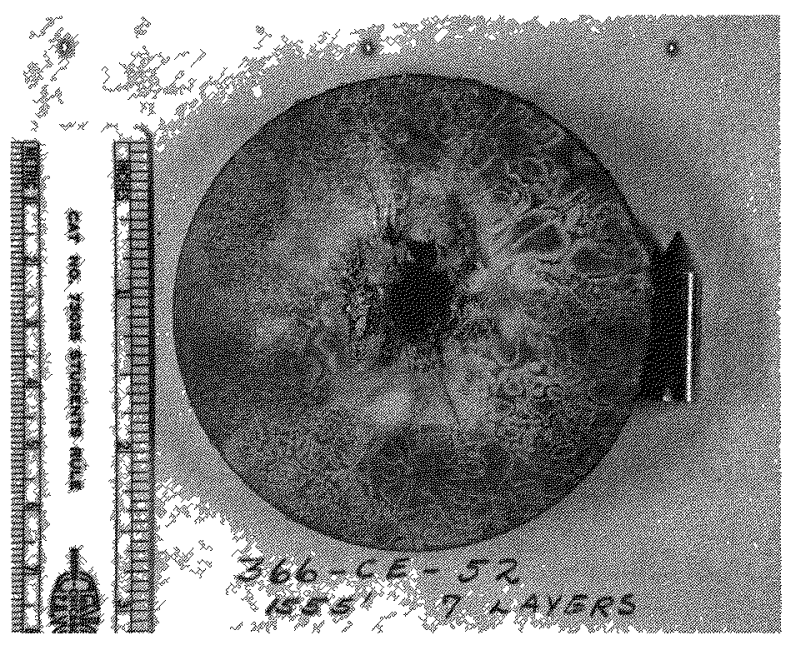

\section{B. Rear surface}

Fig. 14. Nickel-wire-reinfor ced $\mathrm{Al}_{2} \mathrm{O}_{3}$ (20 vol \% N1 in WESGO 300 $\mathrm{Al}_{2} \mathrm{O}_{3}$ )

out in ballistic tests (see Fig. 14). The structure was not strong enough to break off the projectile point, which is a minimum requirement. At this point, it was decided to drop this particular system, but the concept should be reexamined with a system involving more compatible materıls, ı.e., BeO-Tr. 


\section{Experimental Ballistic Limits for Ceramics with an Aluminum Backup Plate}

Experimental ballistic-limit studies with targets of AD85 alumina backed by aluminum ${ }^{3}$ showed that for a given backupplate thickness, the ratio of the ballistic limit to the ceramic thickness was constant. This relation is true for AD85 thicknesses between 0.2 and $0.4 \mathrm{in}$. and corresponds to a large range of ballisticlimit velocities. The physical reason for this result is that the behavior of ceramic targets is strongly dependent on the support provided by the backup plate. And the behavior of the backup plate, in turn, depends on the stress transmitted to it by the ceramic. Hence, the behavior of ceramic targets with backup plates is strongly dependent on the prevailing stress at the interface of the two materials. Now, the stress in the ceramic is directly proportional to the impact velocity since it is an elastic material. If it can be assumed that the stress in the ceramic falls off linearly with ceramic thickness, then the stress on the backup plate is proportional to the impact velocity and inversely proportional to the ceramic thickness.

We concluded from previous work that the ballistic limit is sensitive to the stress

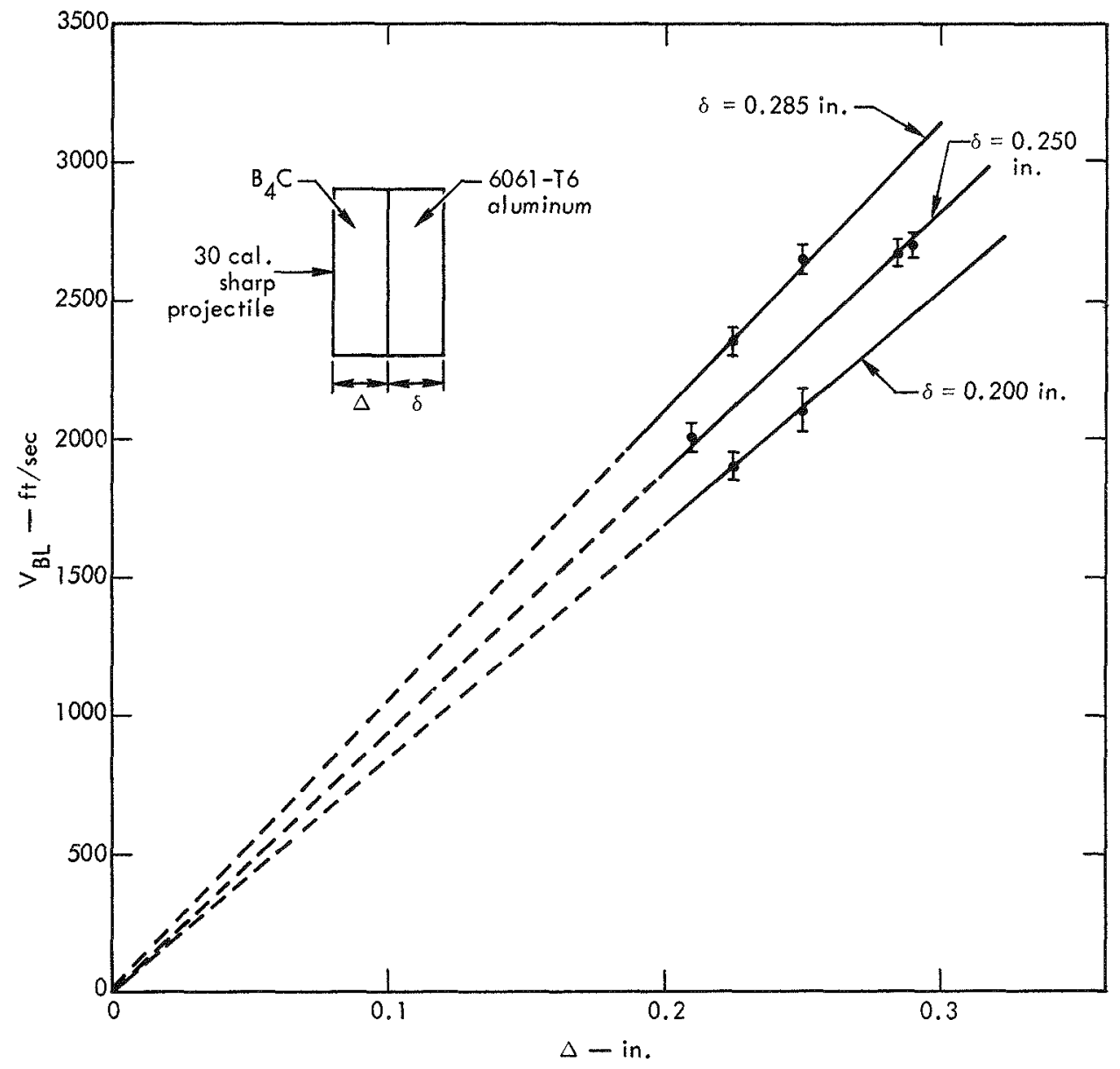

Fig. 15. Experimental ballistic limits for $\mathrm{B}_{4} \mathrm{C}$ bonded to aluminum. Straight-line fits of data pass through the origin. 


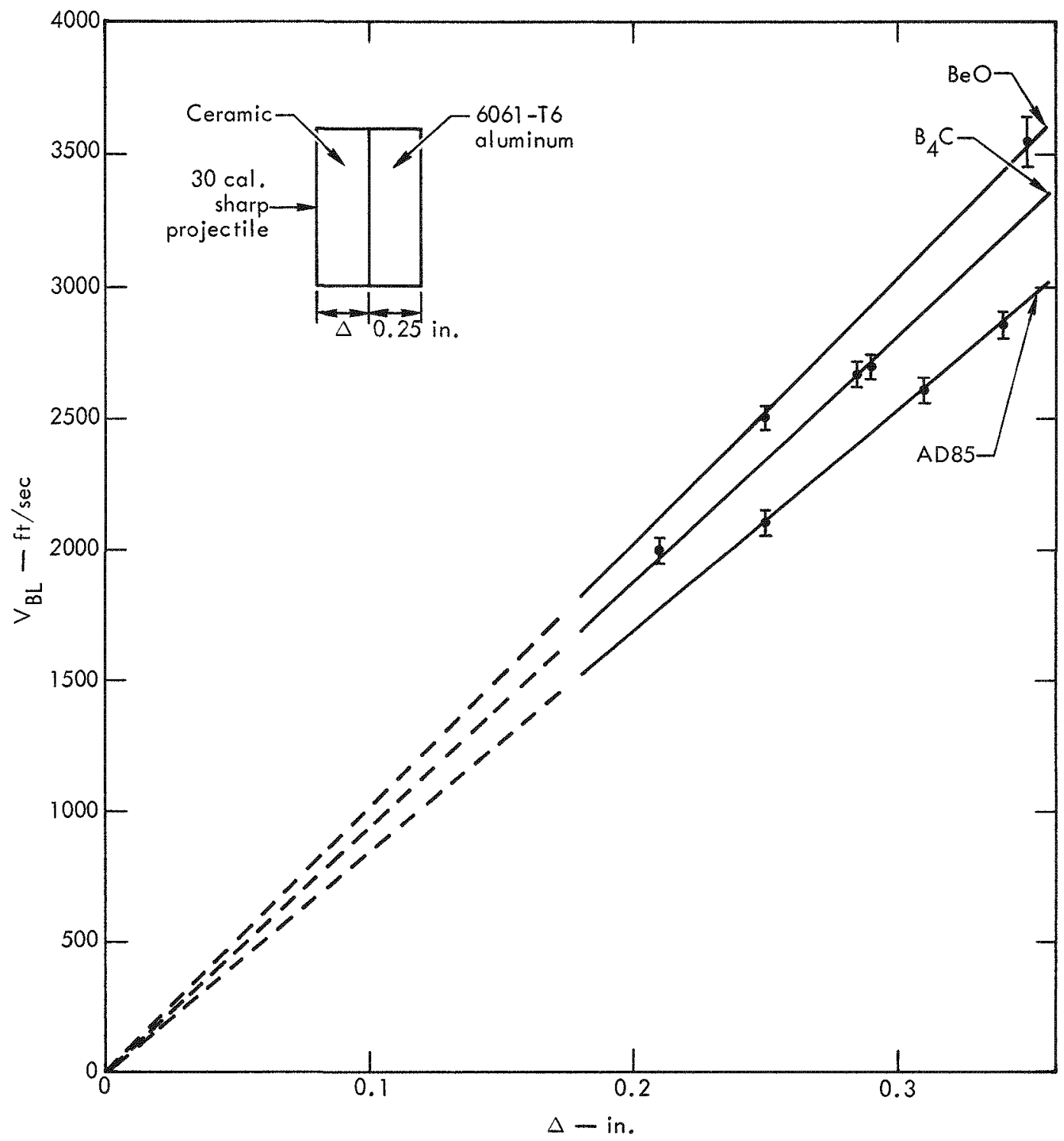

Fig. 16. Experimental ballistic limits of ceramics bonded to 0.25-in. aluminum. Straight-line fits of data pass through the origin.

on the backup plate. With the above assumptions, the stress on the backup plate is the same when the impact velocity divided by the ceramic thickness is the same. Thus, for a given backup-plate thickness the ballistic-limit velocity, $V_{B L}$, divided by the ceramic thickness, $\Delta$, should be a constant. The importance of this relation is that $V_{B L} / \Delta$ equals a constant is a line through the origin for plots of $V_{B L}$ vs $\Delta$. In the evaluation of new ceramics, it is desirable to make comparisons at the same ballistic limit velocity. With the as sumption that $V_{\mathrm{BL}} / \Delta$ equals a constant, the experimental ballistic limit for only one ceramic thickness is necessary in order to determine the ceramic thickness required to defeat a given impact velocity.

The assumption that $\mathrm{V}_{\mathrm{BL}} / \Delta$ is a constant was checked experimentally for $\mathrm{B}_{4} \mathrm{C}$ and $\mathrm{BeO}$. Figure 15 shows $\mathrm{V}_{\mathrm{BL}}$ vs $\Delta$ experimental data for $\mathrm{B}_{4} \mathrm{C}$ with three different aluminum backup plate thicknesses. The data lie on lines through the origin. Figure 16 shows a comparison of $V_{B L}$ vs $\Delta$ experimental data with a 
Table 3. Ballistic limits for various ceramics bonded to 0.25-in. 6061-T6 aluminum.

\begin{tabular}{|c|c|c|c|c|c|c|}
\hline Ceramic & $\begin{array}{l}\text { Density } \\
\rho^{0} \\
(\mathrm{~g} / \mathrm{cc})\end{array}$ & $\underset{(\mathrm{in} .)}{\Delta^{\mathrm{a}}}$ & $\begin{array}{c}\mathrm{V}_{\mathrm{BL}}^{\mathrm{b}} \\
(\mathrm{ft} / \mathrm{sec})\end{array}$ & $\begin{array}{l}\Delta 2700^{c} \\
(\text { in.) }\end{array}$ & $\begin{array}{l}\rho^{0} \Delta 2700^{\mathrm{d}} \\
\left(\mathrm{g} / \mathrm{cm}^{2}\right)\end{array}$ & $\phi^{\mathrm{e}}$ \\
\hline $\mathrm{B}_{4} \mathrm{C}$ & 2.50 & 0.290 & $2700 \pm 50$ & 0.29 & 1.84 & 1.00 \\
\hline $\mathrm{BeO}$ & 2.84 & 0.250 & $2500 \pm 50$ & 0.27 & 1.95 & 0.94 \\
\hline $\mathrm{BeO}+\mathrm{B}$ & 2.50 & 0.250 & $2320 \pm 80$ & 0.29 & 1.84 & 1.00 \\
\hline $\begin{array}{l}\text { Coors AD } 85 \\
\text { Alumina }\end{array}$ & 3.43 & 0.340 & $2850 \pm 50$ & 0.32 & 2.79 & 0.66 \\
\hline $\begin{array}{l}\text { Coors AD999 } \\
\text { alumina }\end{array}$ & 3.96 & 0.250 & $2660 \pm 80$ & 0.25 & 2.51 & 0.73 \\
\hline $\begin{array}{l}\text { WESGO } 995 \\
\text { alumina }\end{array}$ & 3.85 & 0.303 & $2870 \pm 50$ & 0.285 & 2.79 & 0.66 \\
\hline $\begin{array}{l}\text { Diamonite } \\
\text { alumina }\end{array}$ & 3.72 & 0.340 & $3170 \pm 50$ & 0.29 & 2.74 & 0.67 \\
\hline $\begin{array}{l}\text { Carborundum } \\
\text { hot-pressed } \\
\text { alumina }\end{array}$ & 3.92 & 0.250 & $2550 \pm 50$ & 0.26 & 2.59 & $0: 71$ \\
\hline Sapphire & 3.98 & 0.250 & $2470 \pm 80$ & 0.27 & 2.73 & 0.67 \\
\hline $\mathrm{Si}$ & 2.33 & 0.250 & $1200 \pm 50$ & 0.56 & 3.31 & 0.56 \\
\hline $\mathrm{SiC}$ & 3.09 & 0.250 & $2175 \pm 75$ & 0.31 & 2.43 & 0.76 \\
\hline $\mathrm{SiN}_{3}$ & 2.815 & 0.355 & $1450 \pm 50$ & 0.66 & 4.72 & 0.39 \\
\hline Quartzite & 2.58 & 0.250 & $1250 \pm 100$ & 0.54 & 3.54 & 0.52 \\
\hline B & 2.36 & 0.226 & $2100 \pm 80$ & 0.29 & 1.74 & 1.06 \\
\hline $\mathrm{AlB}_{12}$ & 2.53 & 0.250 & $2250 \pm 80$ & 0.30 & 1.93 & 0.95 \\
\hline $\mathrm{Be}_{2} \mathrm{~B}$ & 2.03 & 0.250 & $2150 \pm 50$ & 0.31 & 1.60 & 1.15 \\
\hline $\mathrm{TiB}_{2}$ & 4.46 & 0.236 & $2270 \pm 50$ & 0.28 & 3.17 & 0.56 \\
\hline $\mathrm{TiBe}_{12}$ & 2.25 & 0.250 & $2250 \pm 100$ & 0.30 & 1.74 & 1.06 \\
\hline $\begin{array}{l}\text { Pure } \\
\text { TiC }\end{array}$ & 4.88 & 0.25 & $2500 \pm 80$ & 0.27 & 3.25 & 0.55 \\
\hline $\begin{array}{l}\mathrm{TiC}+(\mathrm{Ni}, \mathrm{Mo}) \\
\text { cermet }\end{array}$ & 5.63 & 0.25 & $3050 \pm 80$ & 0.22 & 3.15 & 0.58 \\
\hline$W C-(k-a)$ & 15.24 & 0.25 & $3300 \pm 200$ & 0.20 & 7.7 & 0.24 \\
\hline
\end{tabular}

${ }^{a_{\Delta}}=$ ceramic thickness

$\mathrm{b}_{\mathrm{BL}}=$ experimental ballistic limit

${ }^{c_{22700}}=$ extrapolated ceramic thickness for $V_{B L}=2700 \mathrm{ft} / \mathrm{sec}$

${ }^{\mathrm{d}} \rho^{0} \Delta=$ ceramic areal density

$\mathrm{e}_{\phi}=\mathrm{B}_{4} \mathrm{C}$ areal density/ceramic areal density 
0.25-in. aluminum backup plate for AD 85 alumina, $\mathrm{B}_{4} \mathrm{C}$, and $\mathrm{BeO}$. The relation, $V_{B L} / \Delta$ equals a constant, holds for these three ceramics.

Table 3 gives the experimental $V_{B L}$ for several ceramics all backed by 0.25 -in. aluminum. The fifth column of the table gives the ceramic thickness required to defeat an impact of $2700 \mathrm{ft} / \mathrm{sec}$ obtained from the assumption that $V_{B L} / \Delta$ equals a constant. The seventh column gives a figure of merit, $\phi$, for the areal density of a given ceramic compared to the areal density of $\mathrm{B}_{4} \mathrm{C}$. The value of $\phi=1.15$ shown for $\mathrm{Be}_{2} \mathrm{~B}$ implies a 13 percent weight saving for this material compared to $\mathrm{B}_{4} \mathrm{C}$ to defeat the same ballistic threat. (See Appendix D for additional information on $\mathrm{Be}_{2} \mathrm{~B}$ and other beryllium compounds.)

Table 3 shows that low density ceramics are good light weight armor materials. Si appears to be an exception, but it is noted in Table 4 that the bulk modulus of this material is much less than the others; hence, it is much more compressible than the other materials, which is an undesirable characteristic.

Table 4. Elastic constants.

\begin{tabular}{|c|c|c|c|c|c|c|c|}
\hline Material & $\begin{array}{c}\text { Density } \\
\rho^{0} \\
\left(\mathrm{~g} / \mathrm{cm}^{3}\right)\end{array}$ & $\begin{array}{c}\text { Bulk } \\
\text { modulus } \\
\text { K } \\
\text { (Mbar) }\end{array}$ & $\begin{array}{c}\text { Shear } \\
\text { modulus } \\
\mu \\
\text { (Mbar) }\end{array}$ & $\begin{array}{c}\text { Sound } \\
\text { speed } \\
C_{\ell} \\
\text { (cm/ } / \mu \mathrm{sec})\end{array}$ & $\begin{array}{l}\text { Hugoniot } \\
\text { elastic } \\
\text { limit } \\
\text { (IMbar) }\end{array}$ & $\begin{array}{c}\text { Yield } \\
\text { strength } \\
\text { Y0 }^{-} \\
\text {(Mbar) }\end{array}$ & $\begin{array}{c}\text { Elastic } \\
\text { 1mpedance } \\
\rho{ }^{0} \mathrm{C}_{\ell}\end{array}$ \\
\hline $\begin{array}{l}\text { Coors AD } 85 \\
\text { alumina }\end{array}$ & 3.43 & 1.54 & 0.83 & 0.88 & 0.06 & 0.038 & 3.02 \\
\hline $\begin{array}{l}\text { Dramonife } \\
\text { alumina }\end{array}$ & 3.72 & 1.93 & 1.27 & 0.99 & 0.08 & 0.057 & 3.68 \\
\hline $\begin{array}{l}\text { WESGO } 995 \\
\text { alumina }\end{array}$ & 3.81 & 2.14 & 1.41 & 1.03 & 0.084 & 0.060 & 3.92 \\
\hline $\begin{array}{l}\text { Iot-pressed } \\
\text { alumina }\end{array}$ & 3.92 & 2.50 & 1.49 & 1.07 & 0.140 & 0.093 & 4.19 \\
\hline Boran carbide & 2.50 & 1.96 & 1.85 & 1.33 & 0.150 & 0.126 & 3.33 \\
\hline Beryllum oxıde & 2.84 & 1.85 & 1.43 & 1.15 & 0.085 & 0.064 & 3.27 \\
\hline $\mathrm{Be}_{2} \mathrm{~B}$ & 2.03 & 1.26 & 1.23 & 1.20 & 0.067 & 0.056 & 2.40 \\
\hline $\mathrm{A}_{1} \mathrm{~B}_{12}$ & 2.58 & 2.00 & 1.82 & 1.31 & $0.096^{\mathrm{a}}$ & $0.079^{\mathrm{a}}$ & 3.38 \\
\hline $\mathrm{B}$ & 2.36 & 2.09 & 2.01 & 1.42 & - & - & 3.35 \\
\hline $\mathrm{S}_{1} \mathrm{C}^{\mathrm{b}}$ (KT Carborundum) & 3.09 & 2.0 & 1.6 & 1.10 & 0.08 & 0.06 & 3.41 \\
\hline $\mathrm{T}_{2} \mathrm{Be}_{12}$ & 2.28 & 1.36 & 1.27 & 1.16 & 0.054 & 0.045 & 2.64 \\
\hline $\mathrm{T}_{1} \mathrm{C}^{\mathrm{C}}$ & 5.63 & 2.39 & 1.77 & 0.91 & - & - & 5.12 \\
\hline $\mathrm{T} 1 \mathrm{~B}_{2}$ & 4.52 & 2.60 & 2.41 & 1.13 & - & - & 5.11 \\
\hline $\mathrm{AD}-999 \mathrm{Al}_{2} \mathrm{O}_{3}$ & 3.95 & 2.56 & 1.58 & 1.09 & - & - & 4.30 \\
\hline $\mathrm{Zr} \mathrm{Be} e_{13}+2$ wt $\%$ & 2.69 & 1.32 & 1.19 & 1.04 & - & - & 2.8 \\
\hline $\mathrm{Zr}_{2} \mathrm{Be}_{17}$ & & & & & & & \\
\hline $\begin{array}{l}\text { Sapphire } \\
\left(\sim 58^{\circ} \text { to }{ }^{\prime \prime} C^{\prime \prime} \text { axis }\right)\end{array}$ & 3.98 & 2.36 & 1.79 & 1.09 & - & - & 4.35 \\
\hline $\mathrm{S}_{1}\langle 100\rangle$ & $\left\{\begin{array}{l}2.33 \\
2.33\end{array}\right.$ & $\begin{array}{l}0.60 \\
0.62\end{array}$ & $\begin{array}{l}0.80 \\
0.76\end{array}$ & $\begin{array}{l}0.84 \\
0.84\end{array}$ & $\begin{array}{l}0.090 \\
0.080^{\mathrm{a}}\end{array}$ & $\begin{array}{l}0.086 \\
0.074^{a}\end{array}$ & $\begin{array}{l}1.96 \\
1.96\end{array}$ \\
\hline
\end{tabular}

${ }^{\mathrm{a}}$ Ref. 2.

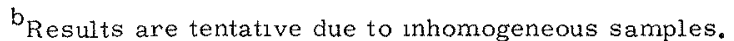

$\mathrm{c}_{\mathrm{N} 1 \text { bonded. }}$ 


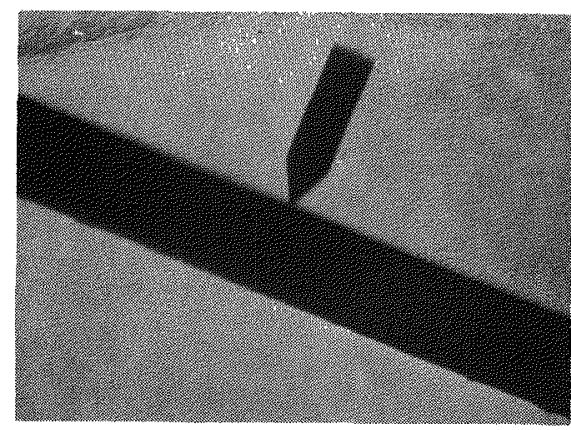

$\dagger=0 \mu \mathrm{sec}$

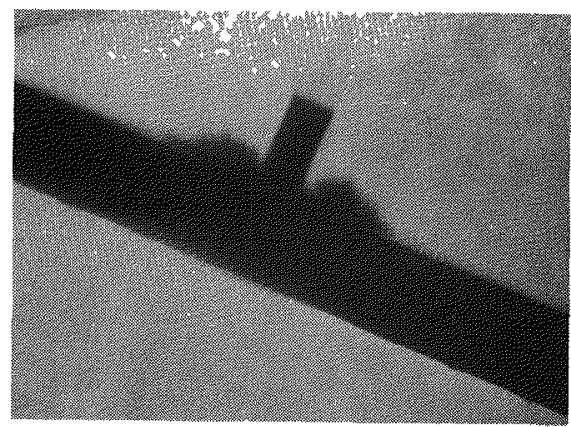

$t=16 \mu \mathrm{sec}$

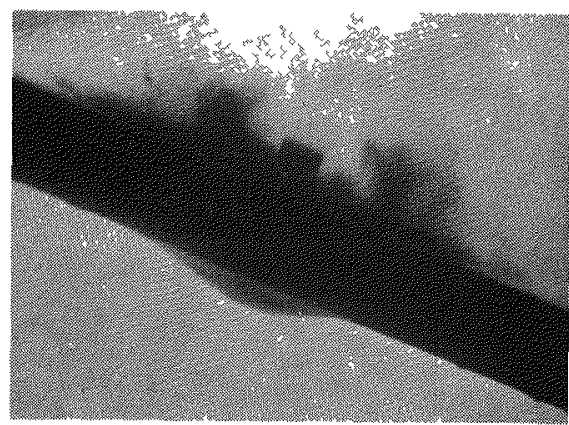

$t=32 \mu \mathrm{sec}$

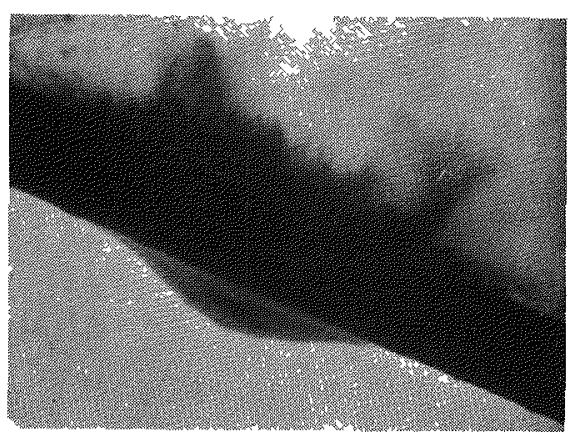

$t=48 \mu \mathrm{sec}$

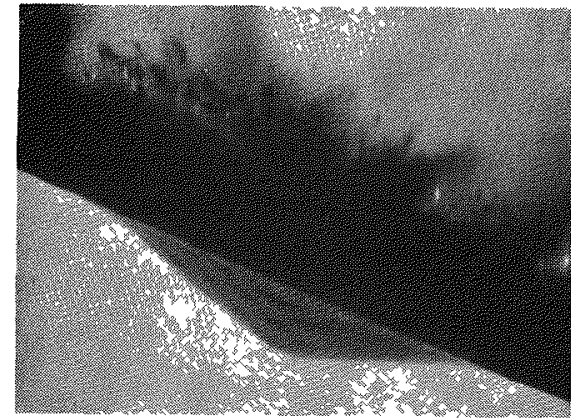

$t=72 \mu \mathrm{sec}$

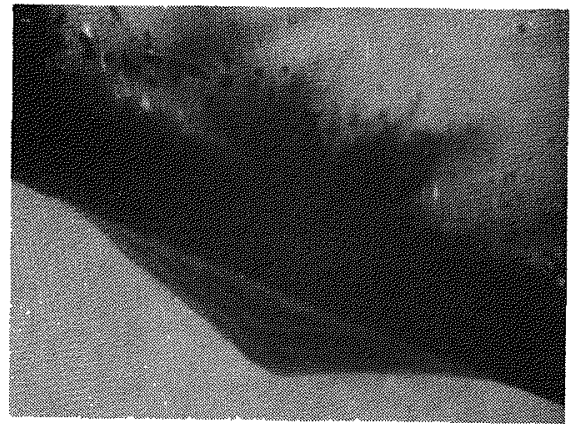

$t=96 \mu \mathrm{sec}$

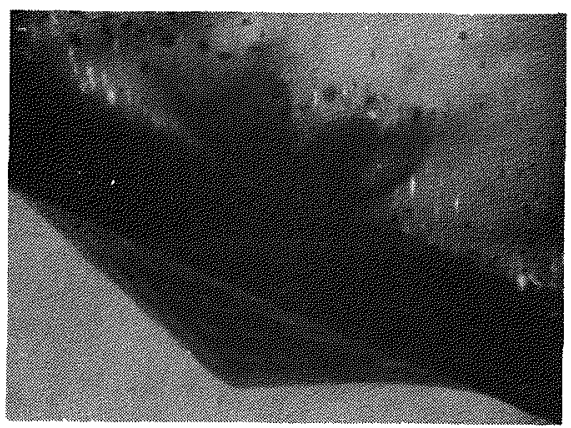

$t=120 \mu \mathrm{sec}$

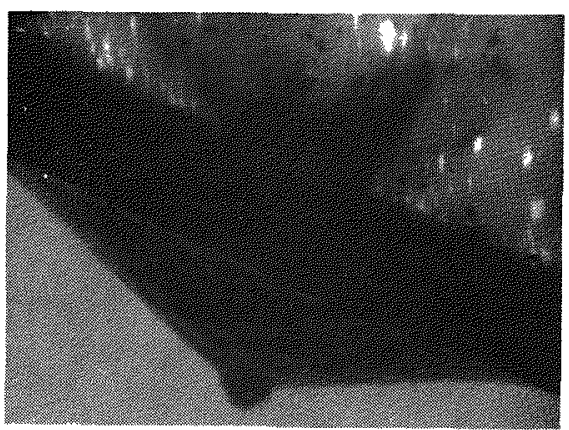

$t=180 \mu \mathrm{sec}$

Fig. 17. Framing camera views of the deflections of a 0.25 -1n. woven-roving backup plate. The 0.34-1n. AD85 ceramic armor was struck by a sharp steel projectile at an impact velocity slightly above the ballistic limit. 


\section{Backup Plates}

An optimum backup plate is made of a material that is stiff to a deflection, but not so stiff that a shear failure will occur at the periphery of the loading area. The plate must also be able to withstand a large deflection. Fiber glass backup plates are effective because they can undergo a large deflection, thus preventing high shear or punching stresses from occurring at the loading surface.

Figure 17 demonstrates the large excursion taken by a woven-roving fiber glass backup plate. In order to accomplish the large excursion the glass fibers must break away from the resin matrix. (See also Ref. 4.) It is thought that the finish on the glass fibers is the most important aspect of fiber glass composites used for armor because it is the finish that influences the bond between the fibers and the resin. A study has begun to vary the bond between the glass and the resin by varying the viscosity of the finish material. The object is to find the optimum bonding strength compatible with the resistance to shear or resistance to punching failure from the applied load. Evaluation must be made by dynamic tests since the performance of fiber glass backup plates is very sensitive to loading rates. The study is also planned for Be wire partially coupled to an aluminum matrix where the aluminum is an alloy chosen for a balance of good elongation and shear strength properties. The point here is to check the understanding of a fiber glass-resin system using a metal system.

\section{Material Physical Parameters}

The measured parameters for several ceramics are summarized in Table 4. A method for determining the strength of a material is given in Appendix E.

\section{Conclusions}

Computer calculations in conjunction with experiments have been used to gain understanding of ballistic penetration phenomena. The important target material parameters needed to defeat penetration by armor piercing projectiles have been identified. Ductility has been shown to be an important material parameter that is not present in most current ceramic armor materials. Weaknesses in the failure process of a target have been pointed out. Direction has been given for future material development where a tradeoff in material parameters is used to obtain a better balance of the necessary parameters to defeat penetration. Experimental equation-of-state data have been obtained for many current armor materials as well as for new armor material candidates. 


\section{Recommendations}

We recommend that emphasis be placed on material development for continued research in light armor. It is not necessary to do continued equation-of-state measurements and computer calculations for armor development. Nothing new is expected from continued work in this area. Cermets with not more than 10 vol \% metal show promise for an improved ceramic facing. Work is necessary to understand the wetting and bonding of the metal to the ceramic phase.

We also recommend that specific cermet systems, $\mathrm{Ti}-\mathrm{TiBe}_{12}$ and $\mathrm{Ti}-\mathrm{BeO}$ must be studied, and that the graded armor concept be pursued once a satisfactory armor cermet has been fabricated.

Boron and beryllium represent the ultimate light-weight materials for armor application. Compounds of these elements should be synthesized and evaluated.

In fiber glass composites, a systemmatic study is necessary where the bond strength of the fibers and resin matrix is changed in a controlled way. When the optimum dynamic decoupling has been found for a given glass-resin system, a similar study should be made with glass fibers with different elongation characteristics. 


\section{Appendix A \\ Mechanical Properties of Armor Materials at High Pressure}

The strength and ductility of most rockforming minerals (silicates, carbonates, and oxides) as well as the brittle metals and semi-metals may be enormously enhanced by mechanically testing the material while it is confined by a high hydrostatic pressure.

When a brittle material is deformed at atmospheric confining pressure, the axial differential stress increases linearly with axial strain up to the ultimate strength (rupture strength) and then immediately falls to zero. The test sample fragmentizes, and cohesion is lost across planes of both tensile and shear fracture. However, the shape of the stress-strain curve of the same brittle material, when tested under a confining pressure, is different. Here, due to the frictional sliding of broken fragments past one another with continued axial displacement, the differential stress does not fall to zero but decreases to a value near one-half to two-thirds of the rupture strength, and oscillates near that range until the test is terminated.

These fracture surfaces are observed to be uniquely oriented to the principal stress field, i.e., if we take $\sigma_{1}, \sigma_{2}$ and $\sigma_{3}$ to be the three principal stresses $\left(\sigma_{1} \geq \sigma_{2} \geq \sigma_{3}\right.$, tension $\left.=+\right)$, then the tensile fractures are always normal to $\sigma_{1}$, and the shear fractures are always 20 to 45 degrees to $\sigma_{3}$, containing $\sigma_{2}$ in their surfaces. Tensile fracture occurs at low mean pressures, shear at the intermediate ones, and complete ductility at high pressures. The tensile stress $\left(\sigma_{1}\right)$ for fracture is independent of mean pressure; the shear stress necessary to activate a shear fracture is strongly dependent on mean pressure, while true plastic flow is very nearly independent of pressure. Plastic flow at high pressures in the ordinarily brittle materials noted above involves crystallographic slip and/or twinning within individual grains of the minerals involved.

Limited test data available on ceramic materials, triaxially tested at high pressures, suggest that their behavior is similar to that of the brittle silicates and oxides noted above.

Triaxial compression tests have been performed on hot pressed $\mathrm{Al}_{2} \mathrm{O}_{3}, \mathrm{BeO}$, and $\mathrm{B}_{4} \mathrm{C}$ material at confining pressures $\left(-\sigma_{1}\right)$ ranging to $16 \mathrm{kbar}$ at a strain rate of $10^{-4} / \mathrm{sec}$ at $24^{\circ} \mathrm{C}$. Numerical data are presented in Table A-1 (also see Fig. A-1) in the form of maximum shear stress before and after fracture (brittle), or maximum shear stress at 5 percent strain

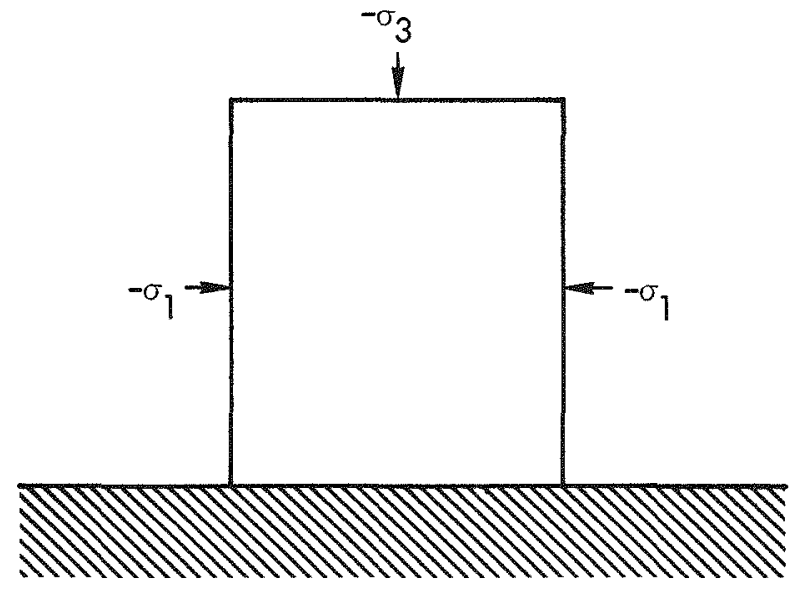

Fig. A-1. Schematic of experimental stress configuration (see Table A-1). 
Table A-1. Summary of triaxial compression tests.

\begin{tabular}{|c|c|c|c|c|c|c|c|c|}
\hline \multirow[b]{2}{*}{ Materials } & \multirow[b]{2}{*}{$-\sigma_{1}^{a}$} & \multirow[b]{2}{*}{ Behavior } & \multicolumn{3}{|c|}{ Virgin } & \multicolumn{3}{|c|}{ After Fracture } \\
\hline & & & $-\sigma_{3}^{b}$ & $\frac{\sigma_{1}-\sigma_{3}}{2}$ & $\mathrm{P}^{\mathrm{c}}$ & $-\sigma_{3}$ & $\frac{\sigma_{1}-\sigma_{3}}{2}$ & $\mathrm{P}$ \\
\hline & 0 & Brittle & 13.6 & 6.8 & 4.5 & 0 & 0 & 0 \\
\hline \multirow[t]{7}{*}{$\mathrm{BeO}$} & 1.0 & Brittle & 29.7 & 14.4 & 10.6 & 6.2 & 2.6 & 2.7 \\
\hline & 2.0 & Brittle & 31.6 & 14.8 & 11.9 & 13.8 & 5.9 & 5.9 \\
\hline & 2.0 & Brittle & 31.3 & 14.7 & 11.8 & 20.0 & 9.0 & 8.0 \\
\hline & 3.5 & Ductile ${ }^{\mathrm{d}}$ & 36.3 & 16.4 & 14.4 & - & - & - \\
\hline & 7.5 & Ductile $e^{d}$ & 40.4 & 16.5 & 18.5 & - & - & - \\
\hline & 10.0 & Ductile $^{d}$ & 44.2 & 17.1 & 21.4 & - & - & - \\
\hline & 0 & Brittle & 13.3 & 6.7 & 4.4 & 0 & 0 & 0 \\
\hline \multirow[t]{13}{*}{$\mathrm{Al}_{2} \mathrm{O}_{3}$} & 1.0 & Brittle & 53.3 & 26.2 & 18.4 & 14.2 & 6.6 & 5.4 \\
\hline & 1.0 & Brittle & 43.9 & 21.5 & 15.3 & 11.0 & 5.0 & 4.3 \\
\hline & 2.0 & Brittle & 52.7 & 25.4 & 18.9 & 19.4 & 8.7 & 7.8 \\
\hline & 2.0 & Brittle & 46.2 & 22.6 & 16.7 & 17.6 & 7.8 & 7.2 \\
\hline & 2.0 & Brittle & 60.8 & 29.4 & 21.6 & 13.4 & 5.7 & 5.8 \\
\hline & 3.5 & Brittle & 55.1 & 25.8 & 20.7 & 32.9 & 14.7 & 13.3 \\
\hline & 5.6 & Brittle & 58.3 & 26.4 & 23.1 & 36.0 & 15.2 & 15.7 \\
\hline & 8.3 & Brittle & 71.4 & 31.6 & 29.3 & 43.7 & 17.7 & 20.1 \\
\hline & 8.3 & Brittle & 69.7 & 30.7 & 28.7 & 49.5 & 20.6 & 22.0 \\
\hline & 9.2 & Brittle & 62.2 & 26.5 & 26.8 & 33.4 & 12.1 & 17.2 \\
\hline & 11.0 & Brittle & 72.6 & 30.8 & 31.5 & 49.8 & 19.4 & 23.9 \\
\hline & 12.5 & Brittle & 71.5 & 29.5 & 32.2 & 36.7 & 12.2 & 20.6 \\
\hline & 0 & Brittle & 13.0 & 6.5 & 4.3 & 0 & 0 & 0 \\
\hline \multirow[t]{6}{*}{$\mathrm{B}_{4} \mathrm{C}$} & 1.0 & Brittle & 54.2 & 26.6 & 18.7 & 7.3 & 3.1 & 3.1 \\
\hline & 2.0 & Brittle & 62.6 & 30.3 & 22.2 & 20.1 & 9.1 & 8.0 \\
\hline & 4.2 & Brittle & 67.3 & 31.6 & 25.2 & 27.4 & 11.6 & 11.9 \\
\hline & 7.2 & Brittle & 81.7 & 37.3 & 32.0 & 35.6 & 14.2 & 16.7 \\
\hline & 9.0 & Brittle & 70.2 & 30.6 & 29.3 & 39.0 & 15.0 & 19.0 \\
\hline & 15.8 & Brittle & 91.8 & 38.0 & 41.1 & 54.2 & 19.2 & 28.6 \\
\hline
\end{tabular}

Sign conventions: tensile stresses taken as positive

$\mathrm{a}_{\sigma_{1}}=\sigma_{2}=$ confining stress

$\mathrm{b}_{3}=$ load stress

$\mathrm{c}_{\mathrm{P}}=-\left(\frac{\sigma_{1}+\sigma_{2}+\sigma_{3}}{3}\right)$

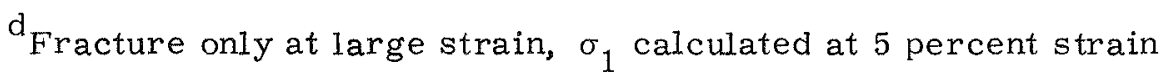


(ductile) vs both mean pressure and confining pressure. The $\mathrm{Al}_{2} \mathrm{O}_{3}$ and $\mathrm{B}_{4} \mathrm{C}$ behave quite similarly; both are brittle over the entire pressure range investigated and both exhibit a 5 to 6 fold increase in shear strength as the confining pressure ranges from zero to the maximum value.

BeO possesses a transition from brittle fracture to ductile (intragranular) flow near 3-kbar confining pressure. The strength of this material was enhanced by about 2.5 fold in the brittle region as confining pressure increased; only a slight strength increase was noted in the ductile flow region. It is expected that by increas ing the deformation rate by $10^{8}$, strengths of $\mathrm{Al}_{2} \mathrm{O}_{3}$ and $\mathrm{B}_{4} \mathrm{C}$ will increase less than 5 percent per decade in rate; in $\mathrm{BeO}$ this increase should be near 5 to 10 percent per decade in the ductile region. The brittle-ductile transition in $\mathrm{BeO}$ is to be expected at 5 to $7 \mathrm{kbar}$ at the higher rate $\left(10^{4} / \mathrm{sec}\right)$.

In Fig. A-2, envelopes of shear strength as a function of confining pressure for $\mathrm{Al}_{2} \mathrm{O}_{3}$ are shown connecting the values of

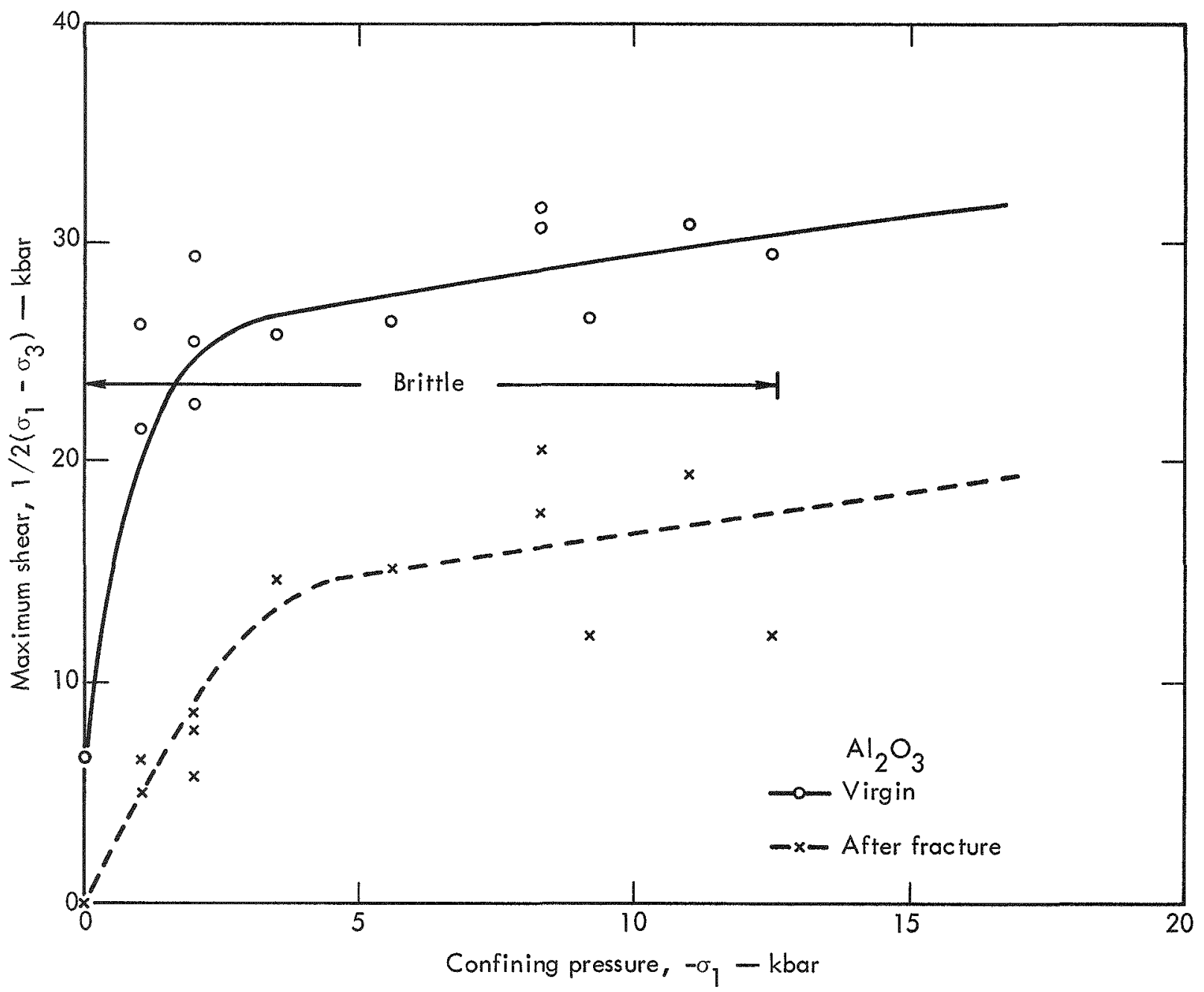

Fig. A-2. Maximum shear stress before and after fracture vs confining pressure for $\mathrm{Al}_{2} \mathrm{O}_{3}$ 
ultimate fracture strength (top) and shear strength after fracture (bottom) from many tests at different values of confining pressure. Although there appears to be a rather large scatter in the data, there is no doubt that the shear strength of the virgin $\mathrm{Al}_{2} \mathrm{O}_{3}$ as well as the shear strength after fracture is increasing with confining pressure. We believe that a large portion of this scatter may be due to local small scale inhomogeneities in the starting material.

In Fig. A-3, similar data are presented for $B_{4} C$. Results here seem more internally consistent. $\mathrm{B}_{4} \mathrm{C}$ possesses a slightly higher strength than the $\mathrm{Al}_{2} \mathrm{O}_{3}$ but the mechanical properties of the two materials are quite similar.

The third material, $\mathrm{BeO}$ behaves quite differently. At confining pressures of 2 kbar or less, its stress-strain curve is that of a brittle material. But at $3.5-\mathrm{kbar}$ confining pressure and higher, this material behaves like a ductile metal: it flows at nearly a constant stress difference until the load is removed. The strength does not, however, decrease during the change of mechanical behavior. The shear strength

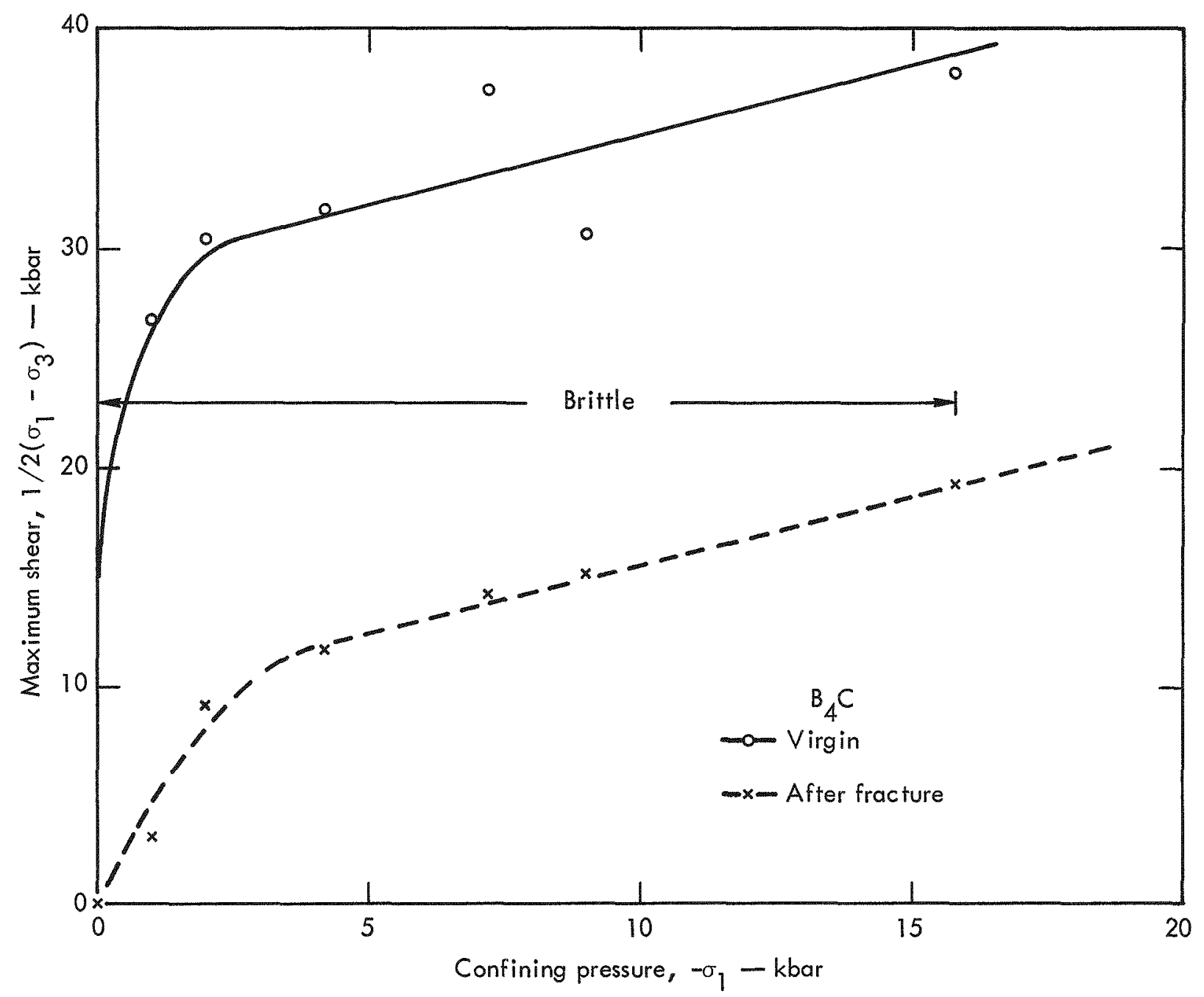

Fig. A-3. Maximum shear stress before and after fracture vs confining pressure for $\mathrm{B}_{4} \mathrm{C}$. 


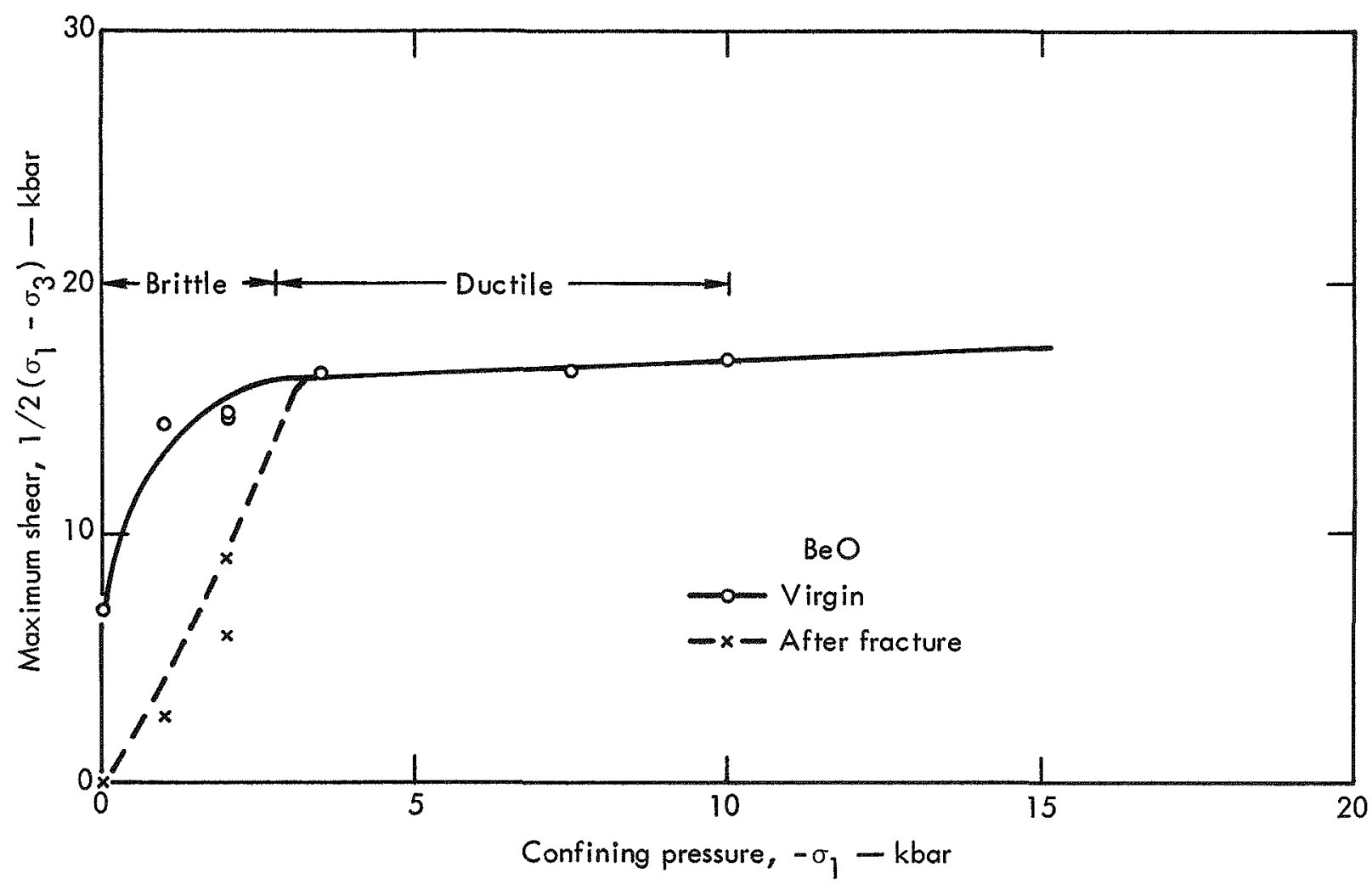

Fig. A-4. Maximum shear stress before and after fracture vs confining pressure for $\mathrm{BeO}$. (The stress shown in the ductile region is at 5 percent strain.)

of $\mathrm{BeO}$ is plotted in Fig. A-4 as a function of confining pressure. As both the virgin strength and strength after fracture are shown, direct comparisons may be made with $\mathrm{Al}_{2} \mathrm{O}_{3}$ and $\mathrm{B}_{4} \mathrm{C}$ in Figs. $\mathrm{A}-2$ and $\mathrm{A}-3$. $\mathrm{BeO}$ is noted to be appreciably weaker, especially at the higher confining pressures.

Clearly, to predict the mechanical response of one material to the impact of a projectile of another, the physical and especially the mechanical properties of both have to be delineated accurately. In extrapolating the mechanical response of brittle materials from tests at ordinary laboratory conditions to impact conditions, perhaps the most important parameter is the effect of a confining pressure (hydrostatic or isostatic). The effects of strainrate temperature and loading path are of lesser importance. 


\section{Appendix B}

BeO Studies

A research program on $\mathrm{BeO}$ was initiated with the premise that the material's ductility improved under high pressure. Triaxial compression tests on polycrystalline $\mathrm{B}_{4} \mathrm{C}, \mathrm{BeO}$, and $\mathrm{Al}_{2} \mathrm{O}_{3}$ as a function of pressure were conducted (Appendix A). $\mathrm{B}_{4} \mathrm{C}$ and $\mathrm{Al}_{2} \mathrm{O}_{3}$ behaved in a brittle fashion at all confining pressures, while $\mathrm{BeO}$ deformed in a ductile manner when the confining pressure exceeded 3.5 kbar. Metallographic examination of the samples after etching indicated that dislocation motion had indeed occurred. The etching behavior was not homogeneous, and indicated that only preferred orientations of grains might be involved, i.e., the deformation was not isotropic. See Figs. B-1 and B-2 for examples of the control and deformed sample.

The material used in initial investigations was obtained from Brush Beryllium Company and was their Thermalox grade. Samples had a density of $2.84 \mathrm{~g} / \mathrm{cc}$ and an average grain size of $30 \mu$.

Samples of Brush Beryllium Company "UOX" grade BeO powder were then fabricated at LRL by two different techniques.
One involved induction how pressing ( $F$ ig. $\mathrm{B}-3)$ at $1700^{\circ} \mathrm{C}$ and 5000 psi in graphite dies, the other involved isostatic pressing and sintering $\left(1850^{\circ} \mathrm{C}\right.$ in $\left.\mathrm{H}_{2}\right)$. The two techniques used powder from the same lot. Ballistic performance and elastic properties of the three sets of samples are given in Table B-1. It shows that the hot pressed material is inferior. This behavior is because of the orientation of the UOX powder induced by the hot-pressing operation. X-ray intensity measurement of the various samples indicated a strong $<10 \overline{1} 0>$ (prismatic) orientation for the hotpressed plates, and also that the " $c$ " axis is oriented parallel to the face and perpendicular to the impact. The consequence of this orientation is twofold in that: (1) the cleavage plane in $\mathrm{BeO}$ is the $\langle 10 \overline{1} 0\rangle$ which could lower the fracture strength for this loading geometry, and (2) basal slip can not occur. Dislocation motion occurs on the basal plane. This plane should be oriented at 45 degrees to the impact direction so that the dislocations can carry the plastic strain.

Table B-1. Ballistic and elastic properties of BeO.

\begin{tabular}{|c|c|c|c|c|c|}
\hline $\begin{array}{c}\text { Type } \\
\text { fabrication }\end{array}$ & $\begin{array}{c}\rho^{0} \\
(g / c c)\end{array}$ & $\begin{array}{c}\mathrm{C}_{\ell} \\
(\mathrm{cm} / \mu \mathrm{sec})\end{array}$ & $\stackrel{\mathrm{cm}_{\mathrm{s}}}{\left.\mathrm{S}_{\mathrm{sec}}\right)}$ & $\rho^{0} \mathrm{C}_{\ell}$ & $\begin{array}{c}V_{B L}{ }^{a} \\
(\mathrm{ft} / \mathrm{sec})\end{array}$ \\
\hline Brush Thermalox & 2.84 & 1.15 & 0.703 & 3.27 & $2500 \pm 50$ \\
\hline Hot-pressed UOX & 3.00 & 1.15 & 0.673 & 3.45 & $2140 \pm 50$ \\
\hline $\begin{array}{l}\text { Isostatic pressed } \\
\text { and sintered }\end{array}$ & 2.87 & 1.15 & 0.701 & 3.30 & $2460 \pm 75$ \\
\hline
\end{tabular}


Current experiments are using hotpressed plate samples which were cored out in three orientations: (1) perpendicular to the pressing direction, (2) parallel to the pressing direction, and (3) at 45 degrees to the pressing direction. These right circular cylinders will be characterized by pole figure measurements and then deformed in triaxial compression as a function of confining pressure to determine their strength properties. Furthermore, single crystals have been prepared in orientations suitable for the study of their mechanical properties under triaxial compression.

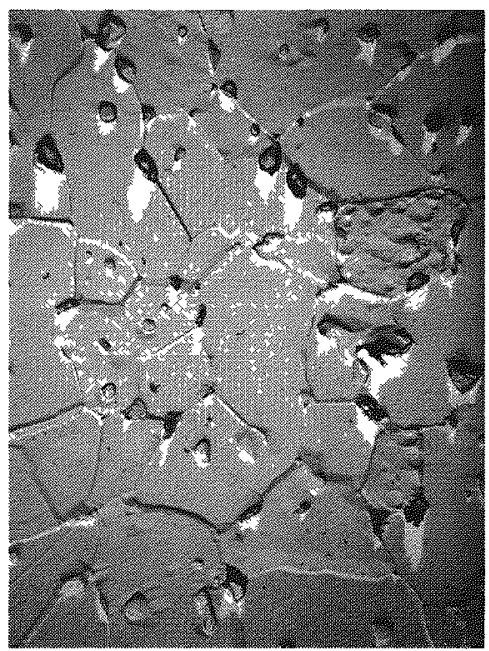

$1,000 \times$

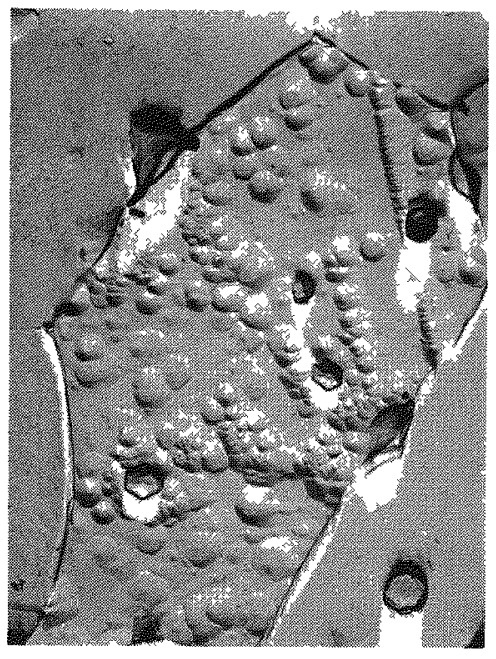

$3,000 \times$

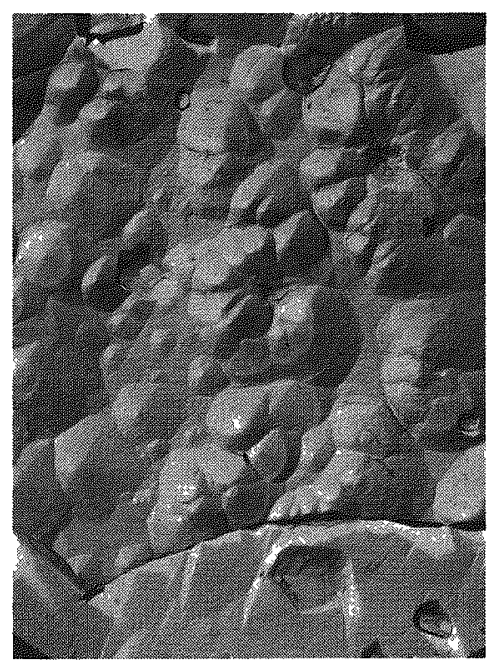

$4,000 \times$

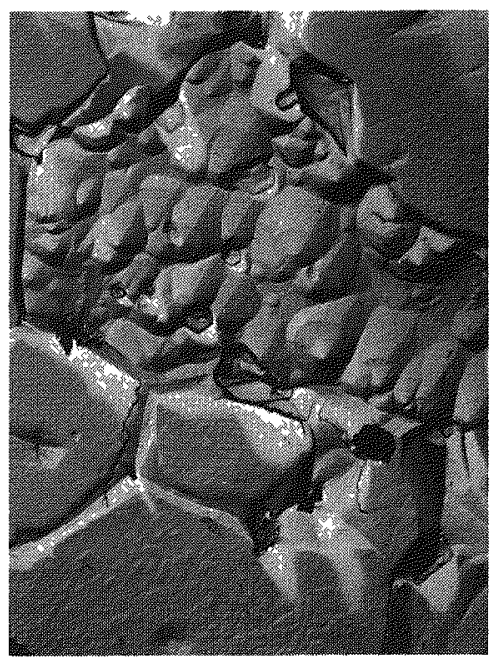

$5,200 \times$

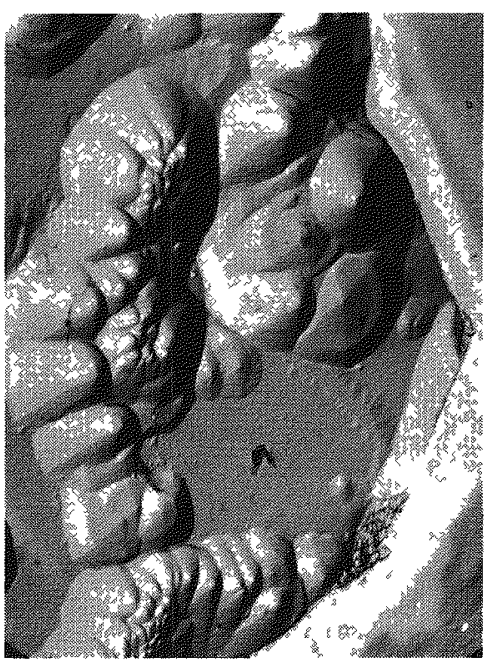

$8,000 \times$

Fig. B-1. BeO (Brush Thermalox) control. As-received material. Etched 45 min in a solution of one drop hydrofluosilic acid to $1 \mathrm{cc} \mathrm{H}_{2} \mathrm{O}$ at $\sim 90^{\circ} \mathrm{C}$. Note low etch pit density (dislocation density) even though etch time was $45 \mathrm{~min}$. Negative replica Pt-Pd shadow. 


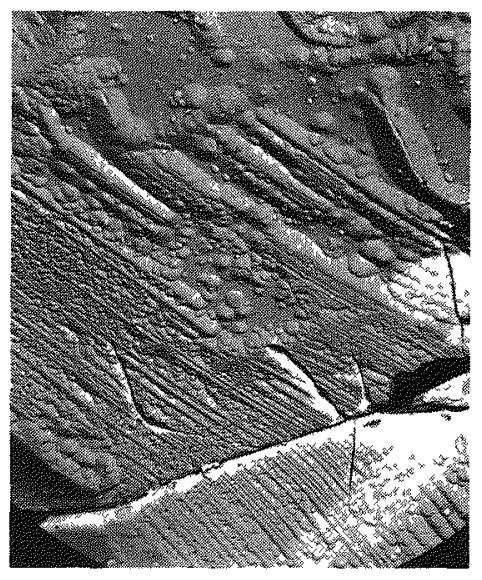

$5,000 \times$

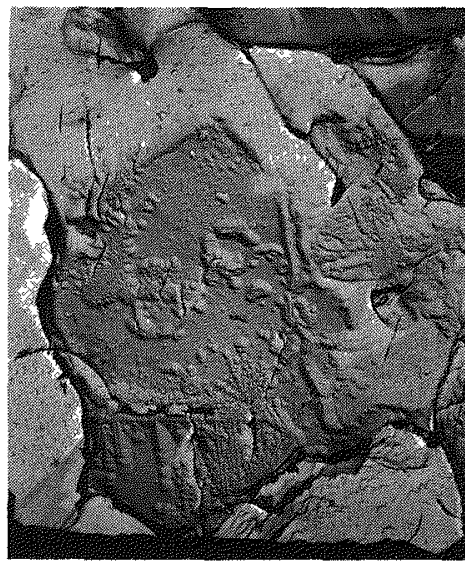

$5,200 \times$

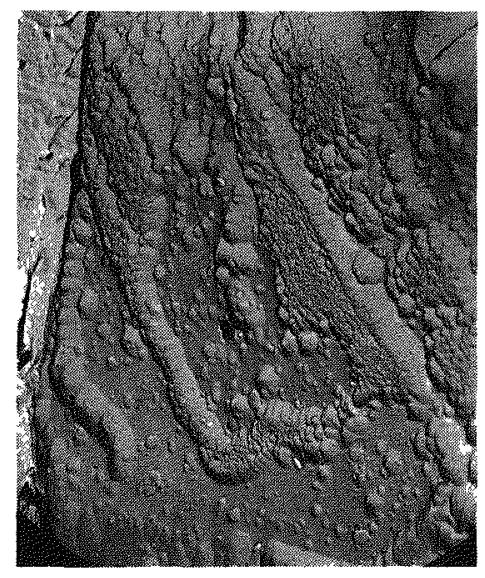

$5,000 \times$

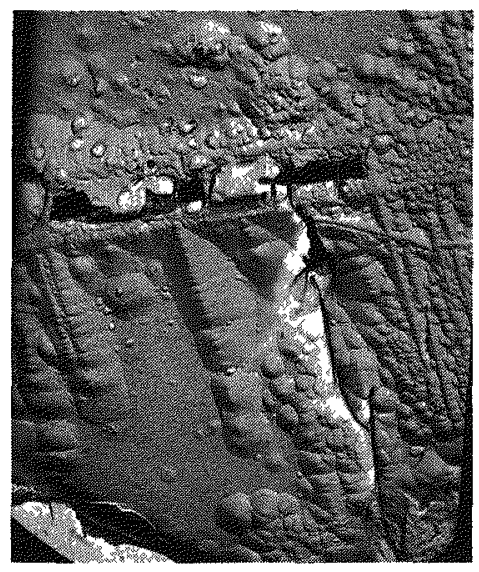

$6,000 \times$

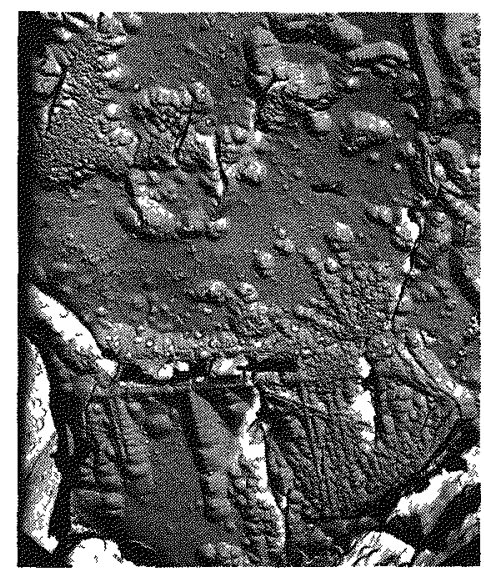

$5,000 \times$

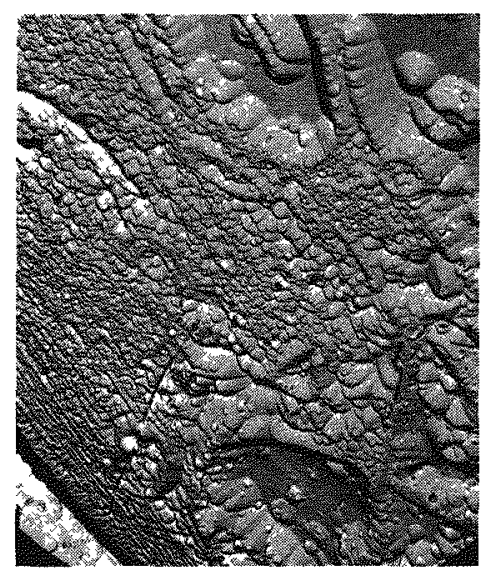

$10,000 \times$

Fig. B-2. BeO (Brush Thermalox) deformed at $25^{\circ} \mathrm{C}$ in tri-axial compression with a confining pressure of $10.0 \mathrm{kbar}=\sim 10^{-5} / \mathrm{sec}$. Etched $14 \mathrm{~min}$ in a solution of one drop hydrofluosilic acid to $1 \mathrm{cc} \mathrm{H}_{2} \mathrm{O}$ at $\sim 90^{\circ} \mathrm{C}$. Note high (greater than $10^{8} / \mathrm{cm}^{2}$ ) dislocation density. Negative replica Pt-Pd shadow. 


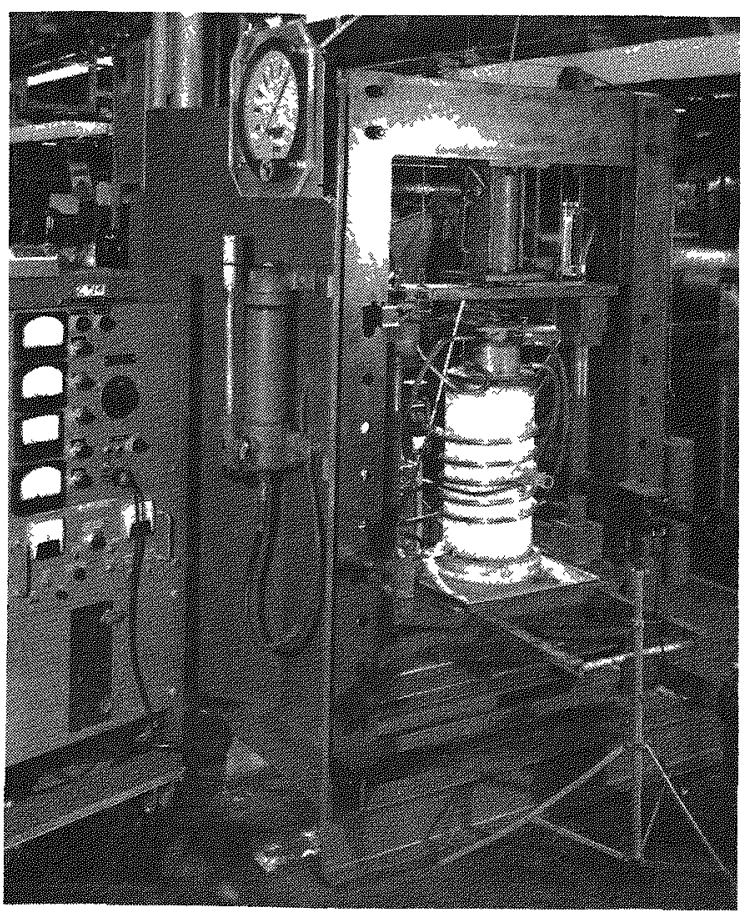

Fig. B-3. Induction hot press. 


\section{Appendix C \\ $\mathrm{B}_{4} \mathrm{C}$ Cermets}

\section{VACUUM INFILTRATION OF ALUMINUM}

Initial attempts to infiltrate isostaticpressed compacts of $\mathrm{B}_{4} \mathrm{C}$ powder with aluminum at $1000^{\circ} \mathrm{C}$ in $\mathrm{Al}_{2} \mathrm{O}_{3}$ crucibles were unsuccessful. To improve wetting channels throughout the $\mathrm{B}_{4} \mathrm{C}$ compact, the isostatic compacts were made of a mixture of $\mathrm{B}_{4} \mathrm{C}$ and aluminum powders. The $\mathrm{B}_{4} \mathrm{C}$ powder was a $7: 1$ blend of $20-$ to $30-\mu$ diameter and 1 - to $5-\mu$ diameter $\mathrm{B}_{4} \mathrm{C}$, respectively, and the aluminum powder was a reagent grade -325 mesh powder. Aluminum bar stock (99.99 percent purity) was used to provide an excess of molten aluminum to cover the compact in the crucible.

Complete wetting of the $\mathrm{B}_{4} \mathrm{C}$ powder was not observed until the oil diffusion pump on the infiltration chamber was replaced with a turbomolecular pump. The improved vacuum, from $10^{-4}$ to $10^{-5} \mathrm{~mm}$ $\mathrm{Hg}$, allowed molten aluminum to fill all pores greater than $0.35-\mu$ diameter.

Isostatic-pressed $\mathrm{Al}-\mathrm{B}_{4} \mathrm{C}$ compacts (3-in. diameter by 5 in. long) of 35,30 , and 20 vol \% aluminum have been infiltrated with aluminum by this technique. The aluminum content in the infiltrated bar does not continue to decrease with decreasing aluminum content in the isostatic compacts. The packing density of $\mathrm{B}_{4} \mathrm{C}$ particles ultimately determines the lower limit of aluminum content.

Subsequent heat treatments on 3-in. diameter by $1 / 4$-in. -thick disks cut from the infiltrated bars have reduced the aluminum content by forming $\mathrm{AlB}_{2}$. Additional heat treatments are in progress to reduce the aluminum content below 20 vol \%. Ballistic results on as-infiltrated and heattreated disks of $\mathrm{Al}-\mathrm{B}_{4} \mathrm{C}$ and $\mathrm{Al}-\mathrm{AlB}_{2}-\mathrm{B}_{4} \mathrm{C}$ indicate that these disks behave similar to pure aluminum. The $\mathrm{B}_{4} \mathrm{C}$ in the aluminum matrix must be bonded at the interfaces in order to provide the microstructure required for the erosion of the projectile.

\section{LIQUID-PHASE HOT PRESSING OF $\mathrm{B}_{4} \mathrm{C}$
WITH COPPER}

Commercial $\mathrm{B}_{4} \mathrm{C}$ powder was blended. in a $7: 1$ weight ratio, 20 - to $30-\mu$ diameter to 1 - to $5-\mu$ diameter $\mathrm{B}_{4} \mathrm{C}$ powder respectively, to improve the compaction density of the irregular shaped $\mathrm{B}_{4} \mathrm{C}$ powder. Copper powder of -200 mesh and iron powder of -200 mesh were $\mathrm{V}$-blended and ball milled with the blend of $\mathrm{B}_{4} \mathrm{C}$ powder to get 30 vol $\% \mathrm{Cu}-\mathrm{B}_{4} \mathrm{C}$ and 30 vol $\% \mathrm{Fe}-\mathrm{B}_{4} \mathrm{C}$ blends for hot pressing. Powder from the above blends was loaded into an 0.81 -in. diameter graphite die, resistance heated to the desired temperature and then pressed at 5000 psi. After $1 \mathrm{~min}$ at the desired temperature, the die was allowed to air cool, and the pellet was extracted for evaluation,

The density of the pellets listed in Tables $\mathrm{C}-1$ and $\mathrm{C}-2$ was determined from the measured dimensions of the pellet and its weight. The retained metal content in the pellet was determined by the difference of initial metal content and extruded metal.

The rapid decrease in copper retained in the hot-pressed pellet above $1450^{\circ} \mathrm{C}$ was attributed to the preferred extrusion of 
Table C-1. Summary of data on hot pressed 30 vol $\% \mathrm{Cu}-\mathrm{B}_{4} \mathrm{C}$ powder blend. Compacts $(0.81$-in. diam) were held at temperature for $1 \mathrm{~min}$ at 5000 psi in a graphite die.

\begin{tabular}{ccccc}
\hline $\begin{array}{c}\text { Pellet } \\
\text { number }\end{array}$ & $\begin{array}{c}\text { Hot press } \\
\text { temp. } \\
\left({ }^{\circ} \mathrm{C}\right)\end{array}$ & $\begin{array}{c}\text { Dimensional } \\
\text { density } \\
(\%)\end{array}$ & $\begin{array}{c}\text { Theoretical } \\
\text { density } \\
(\%)\end{array}$ & $\begin{array}{c}\text { Vol \% of } \\
\text { Cu retained }\end{array}$ \\
\hline 5 & 1700 & 2.43 & 95 & 1 \\
7 & 1400 & 3.30 & 83.0 & 22.4 \\
8 & 1300 & 3.26 & 83.4 & 21.6 \\
9 & 1200 & 3.23 & 80.4 & 22.5 \\
10 & 1525 & 2.37 & 82.0 & 5.8 \\
11 & 1450 & 3.39 & 90.6 & 18.9 \\
12 & 1475 & 2.92 & 87.3 & 12.8 \\
13 & 1425 & 3.27 & 87.3 & 19.2 \\
15 & 1500 & 3.39 & 90.0 & 18.5 \\
16 & 1450 & 2.9 & 79.3 & 17.7 \\
\hline
\end{tabular}

\footnotetext{
${ }^{a}$ Based on actual composition after hot pressing.
}

copper between die and punches rather than into the finer porosity in the $\mathrm{B}_{4} \mathrm{C}$ powder (see Fig. C-1). The density varies with the amount of retained copper and the tolerance of the die assembly. One pressfit die assembly did retain 18.5 vol \% copper, but the density of less than 95 percent was still too low. The only pellet that achieved sufficient density had extruded nearly all of the copper ( $<1 \%$ retained). This latter pellet indicates that relatively low-temperature consolidation of $\mathrm{B}_{4} \mathrm{C}$ is possible with liquid-phase hot pressing. Insufficient wetting of the $\mathrm{B}_{4} \mathrm{C}$ by copper was observed under these conditions to warrant further study of the $\mathrm{Cu}-\mathrm{B}_{4} \mathrm{C}$ system.

\section{LIQUID-PHASE HOT PRESSING OF $\mathrm{B}_{4} \mathrm{C}$
WITH IRON}

The initial experiments in the $\mathrm{Fe}-\mathrm{B}_{4} \mathrm{C}$ system used 30 vol \% iron. A rapid reaction rate of the metal phase with the $\mathrm{B}_{4} \mathrm{C}$ occurred at $1375^{\circ} \mathrm{C}$, thus forming $\mathrm{FeB}$ and $\mathrm{Fe}_{3} \mathrm{C}$. The result is a rapid decrease in the amount of free iron (see Fig. C-2). This is undesirable since the object of introducing the $\mathrm{Fe}$ was to provide a ductile metal phase around the ceramic. Table C-2 summarizes the initial hot pressing experiments.

Metallographic examinations of pellet No. 3 showed that two major phases were present (Fig. C-3). The grey phase was identified by its high microhardness as $\mathrm{B}_{4} \mathrm{C}$. The white phase was identified by 
Table C-2. Summary of data on hot-pressed 30 vol $\% \mathrm{Fe}-\mathrm{B}_{4} \mathrm{C}$ powder blends. Compacts $(0.81-i n$. diam) were held at temperature for $1 \mathrm{~min}$ at 5000 psi in a graphite die.

\begin{tabular}{ccccc}
\hline $\begin{array}{c}\text { Pellet } \\
\text { number }\end{array}$ & $\begin{array}{c}\text { Hot press } \\
\text { temp. } \\
\left({ }^{\circ} \mathrm{C}\right)\end{array}$ & $\begin{array}{c}\text { Dimensional } \\
\text { density } \\
(\mathrm{g} / \mathrm{cc})\end{array}$ & $\begin{array}{c}\text { Theoretical } \\
\text { density } \\
(\%)\end{array}$ & $\begin{array}{c}\text { Wt \% of } \\
\text { Fe retained }\end{array}$ \\
\hline 1 & 1450 & 2.46 & 97.8 & 0.6 \\
2 & 1350 & 3.69 & 91.8 & 54.7 \\
3 & 1375 & 3.18 & 93.1 & 38.6 \\
4 & 1300 & 3.40 & 84.2 & 55.0 \\
5 & 1200 & 3.33 & 81.1 & 57.1 \\
6 & 1450 & 2.53 & 92.4 & 11.6 \\
$7^{\mathrm{b}}$ & 1100 & 2.76 & 67.4 & 56.5 \\
8 & 1100 & 3.10 & 75.8 & 56.5 \\
9 & 1250 & 3.39 & 82.5 & 57.1 \\
10 & 1400 & 2.72 & 98.2 & 13.6 \\
$11^{\mathrm{c}}$ & 1350 & 1.77 & 65.5 & 0.8 \\
$12^{\mathrm{c}}$ & 1345 & 3.57 & 90.6 & 46.1 \\
\hline
\end{tabular}

${ }^{a_{B}}$ Based on actual composition after hot pressing.

$\mathrm{b}_{\text {Pressed at }} 2500$ psi instead of 5000 psi.

$\mathrm{c}_{\mathrm{Held}}$ at temperature for $3 \mathrm{~min}$ instead of $1 \mathrm{~min}$.

$x$-ray diffraction analysis as a mixture of $\mathrm{Fe}, \mathrm{FeB}$, and $\mathrm{Fe}_{3} \mathrm{C}$.

A 3 -in. diameter disk is required for ballistic evaluation of a ceramic face material. The existing resistance-heated hot press is limited to disk diameters less than 1-1/2 in.; therefore an inductionheated hot press was used to consolidate the 3 -in. diameter disks. The use of an induction-heated hot press resulted in a longer time to reach the consolidating temperature. The additional time allowed undesirable reactions to occur between the iron and $\mathrm{B}_{4} \mathrm{C}$. Table $\mathrm{C}-3$ summarizes the data.
No vaporization of iron was observed in any of the 3 -in. diameter hot pressing operations. This retention of iron was attributed to the press-fit dies and slow heating rate $\left(\sim 55^{\circ} \mathrm{C} / \mathrm{min}\right)$. The most significant feature observed was the difference between the disks from Mix D-4 and the other five mixes. Disks from Mix D-4 achieved higher densities than the other mixes because of compound formation. Further attempts to reach similar densities (greater than $4.00 \mathrm{~g} / \mathrm{cc}$ ) by going to higher hot-pressing temperatures $\left(1388^{\circ} \mathrm{C}\right.$ for $\mathrm{Mix} \mathrm{D-6-2)}$ were unsuccessful. 


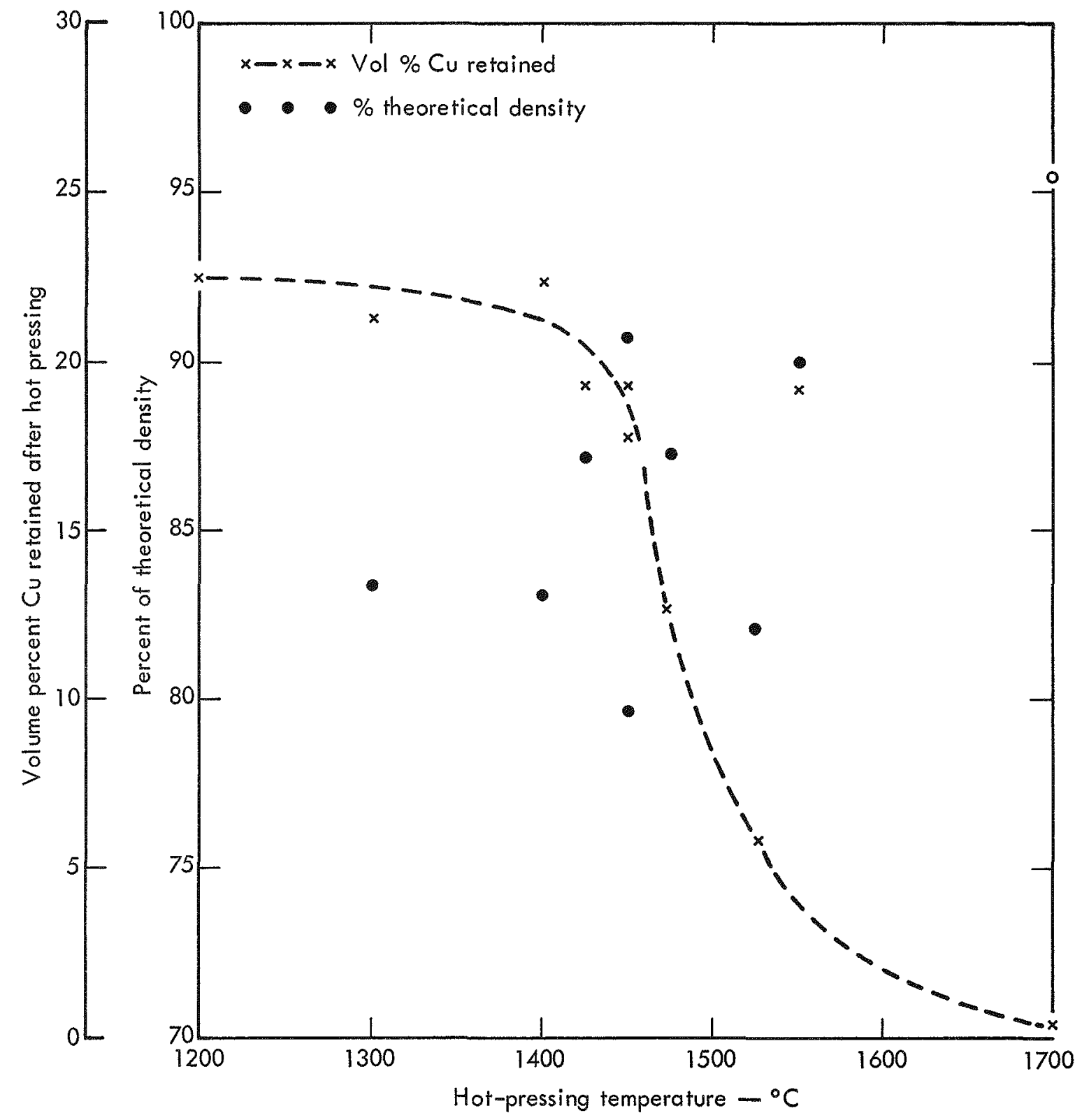

Fig. C-1. Hot pressed pellets (0.81-in. diam) from 30 vol $\% \mathrm{Cu}-\mathrm{B}_{4} \mathrm{C}$ powder blend. Resistance heated in graphite dies and held at temperature for $1 \mathrm{~min}$ at 5000 psi.

Evaluation of the fracture behavior on ballistically tested samples indicated a marked increase in transgranular fracture for the high-density disks as compared to the low-density disks, implying a stronger bond between the binder and ceramic phase. Metallographic examination of pieces of the high- and low-density disks after ballistic testing confirmed this mode of fracture. The microstructure of the low density induction-heated disks (A of Fig. C-4) was similar to that observed for the resistance hot-pressed samples (Fig. $\mathrm{C}-3$ ), while extensive reaction at the surfaces of the $\mathrm{B}_{4} \mathrm{C}$ particles has taken place in the high-density disks (B 
of Fig. C-4 and Fig. C-5). X-ray diffraction results revealed only the presence of $\mathrm{FeB}, \mathrm{B}_{4} \mathrm{C}$, and trace quantities of graphite in these disks.

Emission spectographic results on the original $\mathrm{B}_{4} \mathrm{C}$ powder used in the $\mathrm{D}-4$ mixes are listed in Table $\mathrm{C}-4$. The increased reaction at the surface of $\mathrm{B}_{4} \mathrm{C}$ particles in Mix D-4 is attributed to the excessively high impurity content in the $\mathrm{B}_{4} \mathrm{C}$ powder.

In summary, the unanticipated formation of the compound FeB resulted in a stronger bond between the particles. This increased the path length for fracture, which is a desirable effect, but there was no ductile metal phase present.

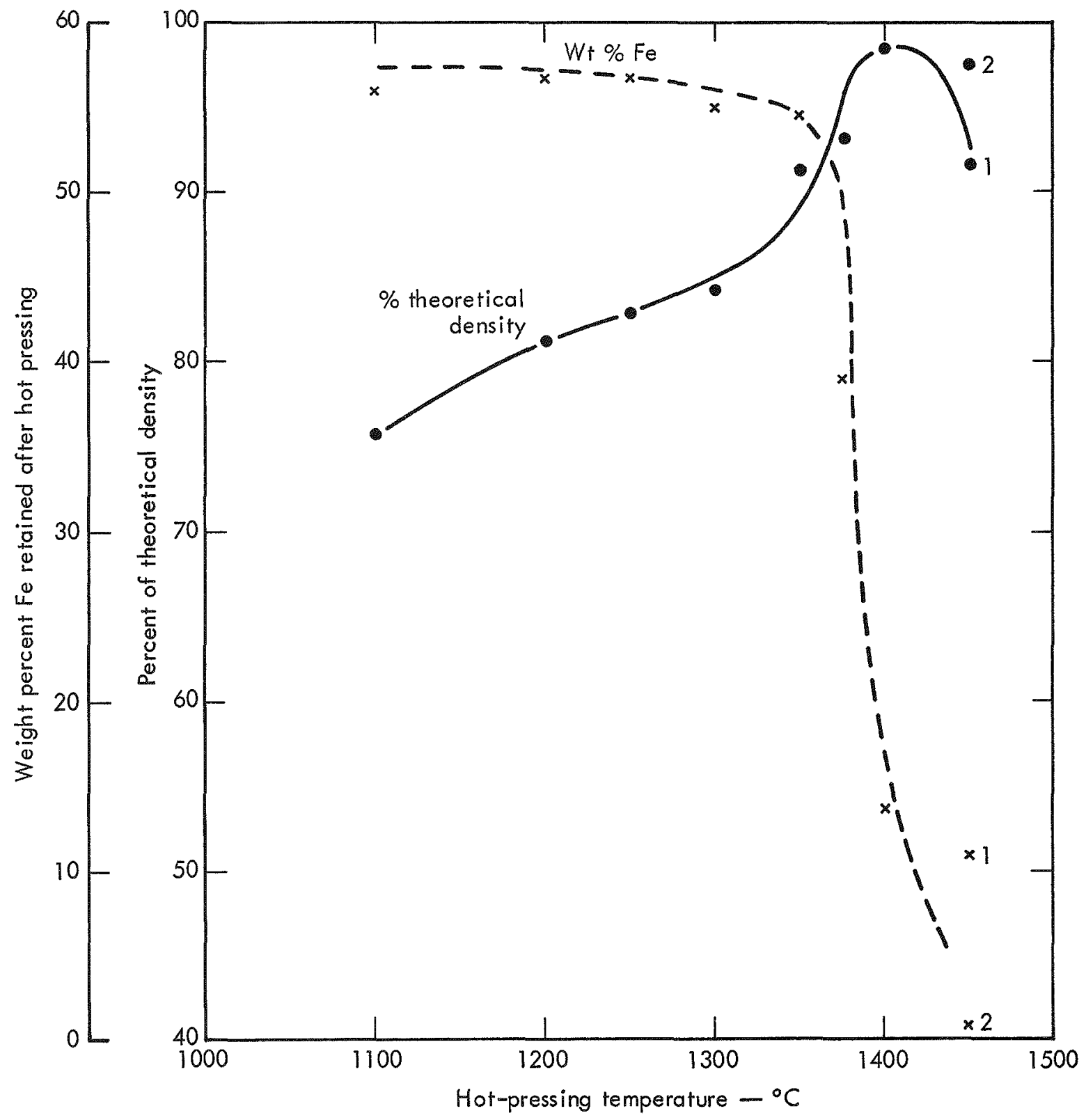

Fig. C-2. Hot pressed pellets (0.81-in. diam) from 30 vol $\%$ Fe-B 4 powder blend. Resistance heated in graphite dies and held at temperature for $1 \mathrm{~min}$ at 5000 psi. 
Table C-3. Summary of data on hot-pressed 30 vol $\% \mathrm{Fe}-\mathrm{B}_{4} \mathrm{C}$ powder blends. Compacts (3-in. diam) were pressed at 5000 psi.

\begin{tabular}{|c|c|c|c|c|c|}
\hline \multirow{2}{*}{\multicolumn{2}{|c|}{$\begin{array}{l}\text { Pellet } \\
\text { number }\end{array}$}} & \multirow{2}{*}{$\begin{array}{l}\text { Hot pressing } \\
\text { temp. } \\
\left({ }^{\circ} \mathrm{C}\right)\end{array}$} & \multirow{2}{*}{$\begin{array}{c}\text { Dimensional } \\
\text { density } \\
(\mathrm{g} / \mathrm{cc})\end{array}$} & \multicolumn{2}{|c|}{ Hg porosimeter } \\
\hline & & & & $\begin{array}{c}\text { density } \\
(g / c c)\end{array}$ & $\begin{array}{c}\text { Porosity } \\
(\%)\end{array}$ \\
\hline \multicolumn{6}{|c|}{ Mix D-4- } \\
\hline & 1 & 1325 & 3.56 & - & - \\
\hline & 2 & 1360 & 4.09 & 4.10 & 7.7 \\
\hline & 3 & 1365 & broke in die & 4.40 & 1.8 \\
\hline & 4 & 1350 & 4.13 & 4.20 & 4.8 \\
\hline
\end{tabular}

$\operatorname{Mix} \mathrm{D}-4 \mathrm{a}-$

$\begin{array}{lll}1 & 1350 & 3.74 \\ 2 & 1357 & 3.74 \\ 3 & 1359 & 3.80 \\ 4 & 1352 & 3.83\end{array}$

Mix D-4b-

$\begin{array}{lll}1 & 1360 & 3.68 \\ 2 & 1362 & 3.69 \\ 3 & 1362 & 3.72\end{array}$

$3.84 \quad 5.2$

\section{Mix $1-4$ b}

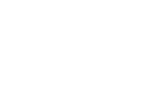

3
-1360

$\begin{array}{lll}\text { Mix D }-4 c-1 & 1360 & 3.69\end{array}$

Mix D-5-

$\begin{array}{lll}1 & 1352 & 3.65 \\ 2 & 1358 & 3.65\end{array}$

Mix D-6-

\begin{tabular}{llllll}
1 & 1362 & 3.70 & - & - \\
2 & 1388 & 3.72 & - & - \\
\hline
\end{tabular}


Table C-4. Emission spectrographic results of $\mathrm{B}_{4} \mathrm{C}$ powders used in the 30 vol $\% \mathrm{Fe}-\mathrm{B}_{4} \mathrm{C}$ mixes.

\begin{tabular}{|c|c|c|c|c|}
\hline \multirow{2}{*}{$\begin{array}{c}\text { Mix number } \\
\mathrm{B}_{4} \mathrm{C} \text { size }\end{array}$} & \multicolumn{2}{|c|}{$D-4$} & \multicolumn{2}{|c|}{$D-4 a, 4 b, 4 c$} \\
\hline & Fine & Coarse & Fine & Coarse \\
\hline $\mathrm{Fe}$ & $>5000$ & 4000 & 200 & 5000 \\
\hline $\mathrm{Al}$ & 800 & $>>1000$ & 1000 & $>1000$ \\
\hline $\mathrm{S}_{1}$ & 600 & $>1000$ & $>800$ & 400 \\
\hline $\mathrm{Ca}$ & 400 & 400 & 400 & 400 \\
\hline $\mathrm{Cr}$ & 300 & 400 & 400 & 200 \\
\hline $\mathrm{Zr}$ & 150 & 250 & 250 & 150 \\
\hline $\mathrm{Nl}_{1}$ & 300 & 300 & 250 & 250 \\
\hline $\mathrm{T}_{1}$ & 100 & 100 & 100 & 200 \\
\hline $\mathrm{Cu}$ & 60 & 60 & 125 & 18 \\
\hline $\mathrm{Pb}$ & 100 & 100 & 100 & $<20$ \\
\hline $\mathrm{Mn}$ & 70 & 45 & 4 & 500 \\
\hline
\end{tabular}

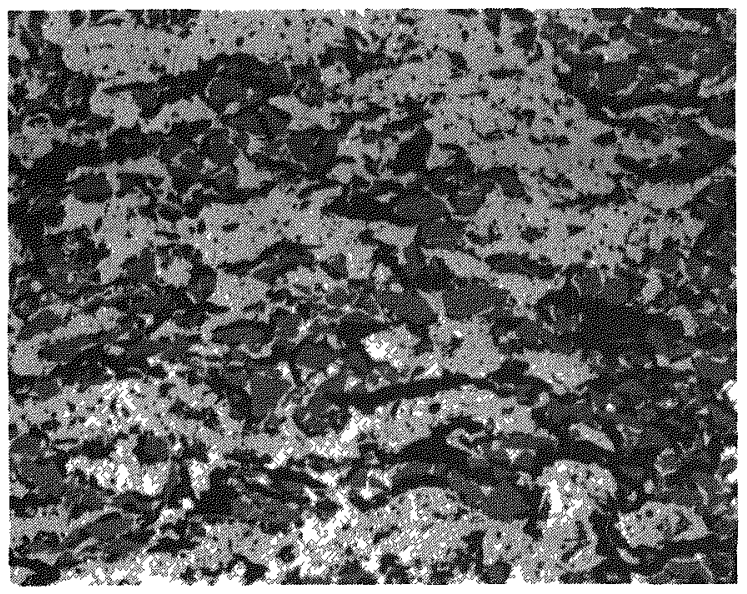

Fig. C-3. Microphotograph (500X) of 30 vol $\% \mathrm{Fe}-\mathrm{B}_{4} \mathrm{C}$ powder after hot pressing at $1375^{\circ} \mathrm{C}$ for 1 min in a graphite die. 


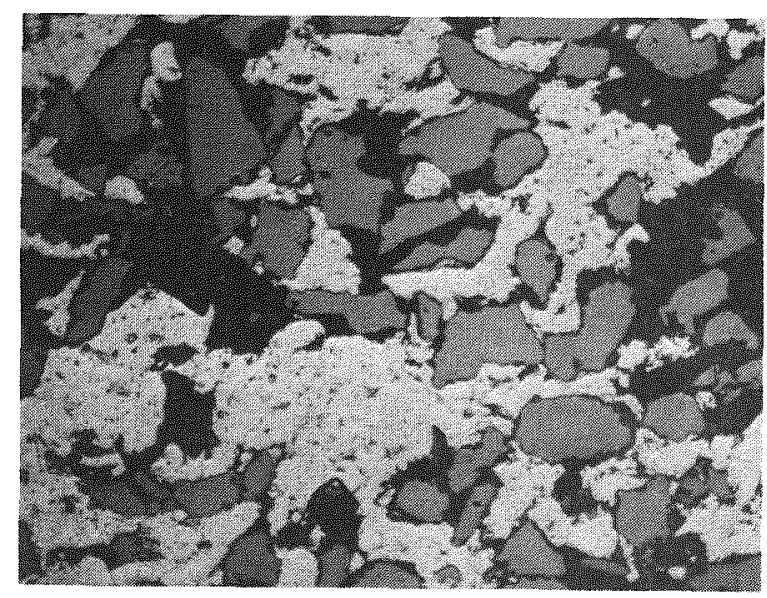

A. Typical of low density $(\sim 3.7 \mathrm{~g} / \mathrm{cc}) 3-\mathrm{in}$. diam pellets.

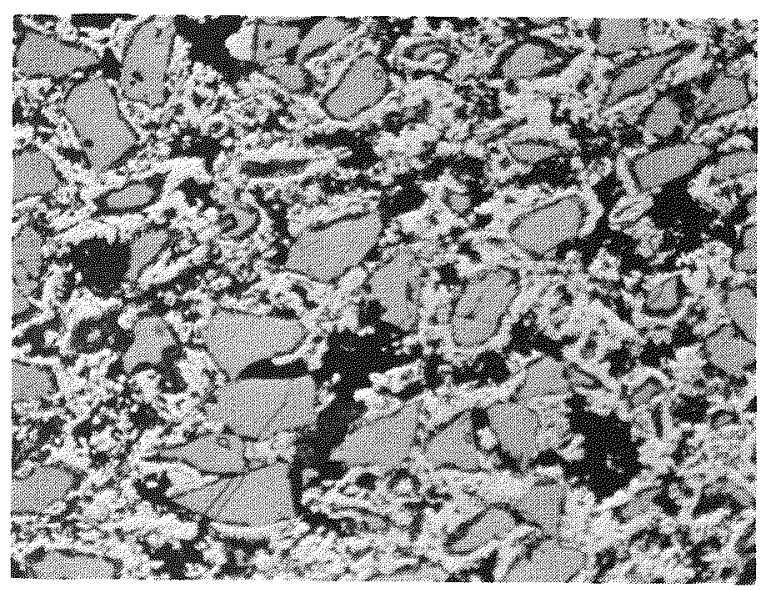

B. Typical of high density $(\sim 4.1 \mathrm{~g} / \mathrm{cc}) 3-\mathrm{in}$. diam pellets.

Fig. C-4. Photomicrographs $(200 \times)$ of 30 vol $\%$ Fe-B 4 C powder consolidated by induction heated hot pressing at 5000 psi in graphite dies.

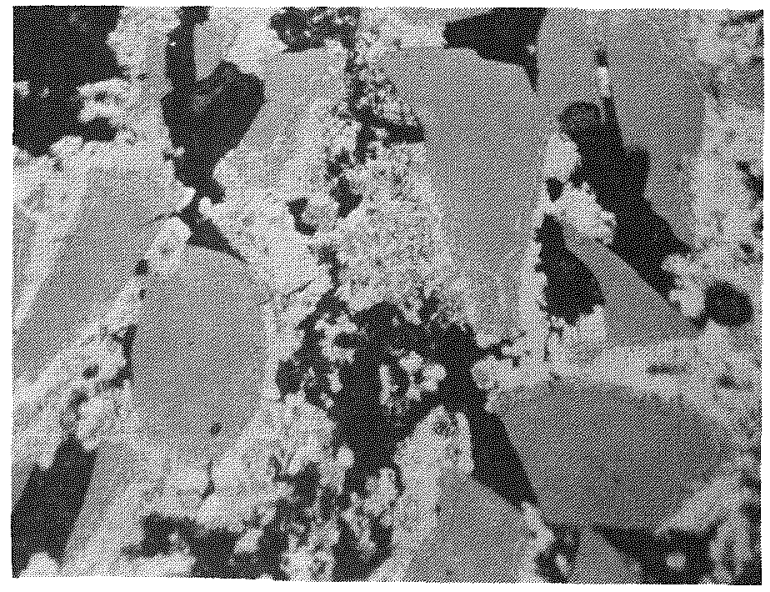

Fig. C-5. Photomicrograph (500X) of 30 vol $\% \mathrm{Fe}-\mathrm{B}_{4} \mathrm{C}$ powder consolidated by induction heated hot pressing at 5000 psi in a graphite die. 


\section{Appendix D \\ Beryllium Compounds}

\section{BERYLLIUTI BORIDES}

A class of materials that boasts the desirable properties of low density, high hardness, and high sound speeds appears to be optimized in the borides and beryllides. The beryllium-boron system is therefore promising for developing new armor materials. A summary of the main beryllium-boron compounds is given in Table D-1. Table D-2 gives the elastic properties of several beryllium compounds.
The LRL program centered about diberyllium boride $\left(\mathrm{Be}_{2} \mathrm{~B}\right)$, which has these properties:

(1) Low density

(2) An adequate hardness which implies an adequate Hugoniot elastic limit

(3) High sound velocities which implies incompressibility at least at the zero stress level.

The original powder was purchased from a vendor and the samples fabricated

Table D-1. Properties of beryllium boride.

\begin{tabular}{cclcc}
\hline Compound & $\begin{array}{c}\text { Theoretical } \\
\rho(\mathrm{g} / \mathrm{cc})\end{array}$ & $\begin{array}{c}\text { Crystal } \\
\text { structure }\end{array}$ & $\begin{array}{c}\text { Melting point } \\
\left({ }^{\circ} \mathrm{C}\right)\end{array}$ & $\begin{array}{c}\text { Hardness } \\
\left(\mathrm{HK}_{100}\right)\end{array}$ \\
\hline $\begin{array}{c}\mathrm{Be}_{4} \mathrm{C} \\
\mathrm{Be}_{2} \mathrm{~B}\end{array}$ & 2.01 & Tetragonal & $\sim 1160$ & $600-900$ \\
$\mathrm{BeB}_{2}$ & 2.89 & Cubic & $\sim 1500$ & $\sim 1300$ \\
$\mathrm{BeB}_{6}$ & 2.35 & Hexagonal & $>1970$ & 3180 \\
$\mathrm{BeB}_{12}$ & 2.42 & Tetragonal & $2020-2120$ & 2580 \\
\hline
\end{tabular}

Table D-2. Elastic properties of beryllium compounds.

\begin{tabular}{cccccccc}
\hline Compound & $\begin{array}{c}\rho^{0} \\
(\mathrm{~g} / \mathrm{cc})\end{array}$ & $\begin{array}{c}\mathrm{C}_{\ell} \\
(\mathrm{cm} / \mu \mathrm{sec})\end{array}$ & $\begin{array}{c}\mathrm{C}_{\mathrm{S}} \\
(\mathrm{cm} / \mu \mathrm{sec})\end{array}$ & $\rho^{0} \mathrm{C}_{\ell}$ & $\begin{array}{c}\mathrm{K} \\
(\mathrm{Mbar})\end{array}$ & $\begin{array}{c}\mu \\
(\mathrm{Mbar})\end{array}$ & $\begin{array}{c}\mathrm{Y}^{0} \\
(\mathrm{Mbar})\end{array}$ \\
\hline $\mathrm{BeO}^{\mathrm{a}}$ & 2.84 & 1.15 & 0.703 & 3.27 & 1.85 & 1.43 & 0.064 \\
$\mathrm{TiBe}_{12}$ & 2.28 & 1.14 & 0.75 & 2.60 & 1.23 & 1.28 & 0.045 \\
$\mathrm{Be}_{2} \mathrm{~B}$ & $2.03^{\mathrm{b}}$ & 1.27 & 0.800 & 2.58 & 1.52 & 1.30 & 0.057 \\
$\mathrm{BeB}_{2}$ & $2.25^{\mathrm{C}}$ & 1.28 & 0.828 & 2.88 & 1.63 & 1.54 & - \\
\hline
\end{tabular}

\footnotetext{
${ }^{a}$ Brush-Thermalox Grade BeO.

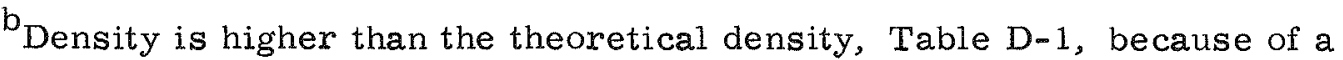
small amount of $\mathrm{BeB}_{2}$.

${ }^{\mathrm{C}}$ Density is lower than the theoretical density, Table D-1, because of a small amount of $\mathrm{Be}_{2} \mathrm{~B}$.
} 
at LRL. The technique used was conventional hot pressing in graphite or graphite lines with $\mathrm{BN}$ dies. The pressing conditions were $1060^{\circ} \mathrm{C}$ for a half-hour at a pressure of $5400 \mathrm{psi}$. The samples were pressed in the form of 3 -in. disks of varying thicknesses. These samples were evaluated for ballistic and equation-ofstate properties. (See Tables 3 and 4.) Typical fractography pictures of pieces received after ballistic tests are shown. in Figs. D-1 and D-2. The salient features are cleavage and twinning. There is as yet no evidence of macroscopic ductility.

The obvious advantage of this material for armor is the low density which permits a greater thickness per equivalent areal density. The ballistic results shown in Table 3 show that this is the highest performing armor material currently available.

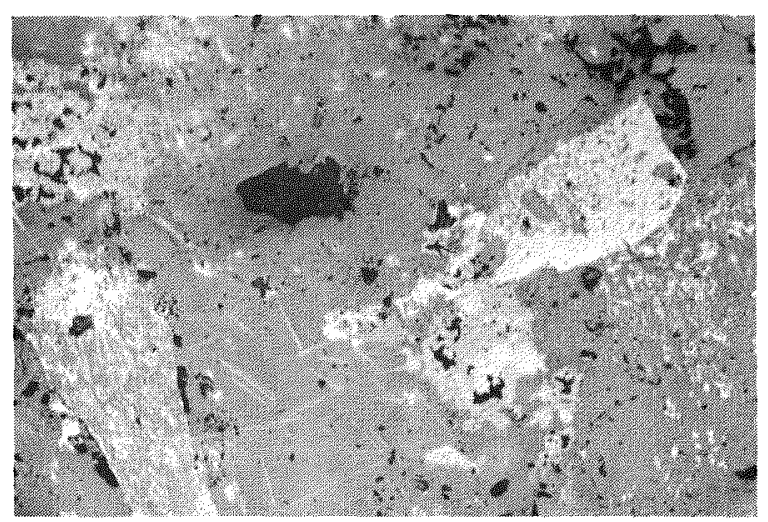

Bright field at $600 \times$

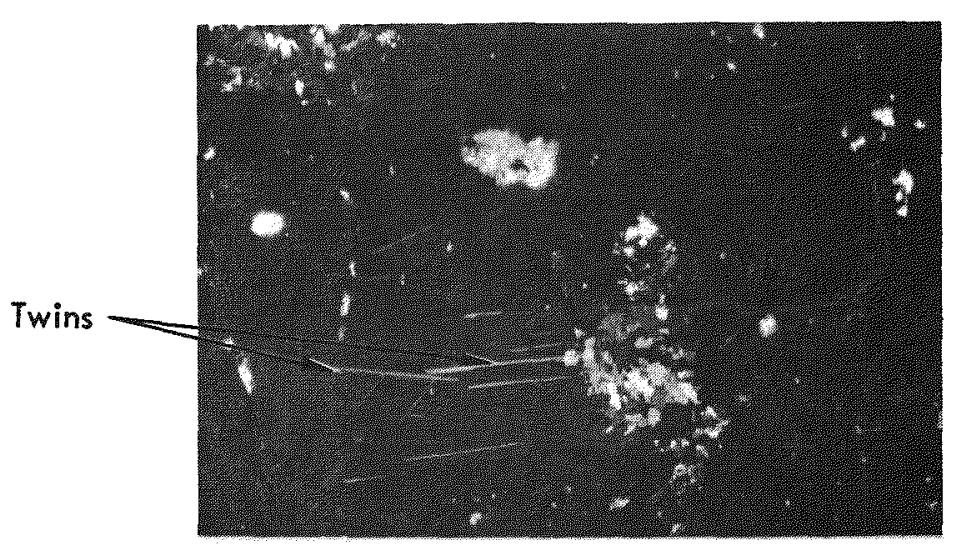

Polarized light at $600 \times$

Fig. D-1. Twinning in ballistically tested $\mathrm{Be}_{2} \mathrm{~B}$. 
Ti AND Zr BERYLLIDES

The only beryllide compositions currently under consideration are the compounds $\mathrm{TiBe}_{12}$ and $\mathrm{ZrBe}_{13}$. Samples of
$\mathrm{TiBe}_{12}$ were purchased from a vendor and ballistically tested. A typical fracture replica is shown in Fig. D-3. The ballistic results are promising in that they are superior to $\mathrm{B}_{4} \mathrm{C}$ (Table 3 ).
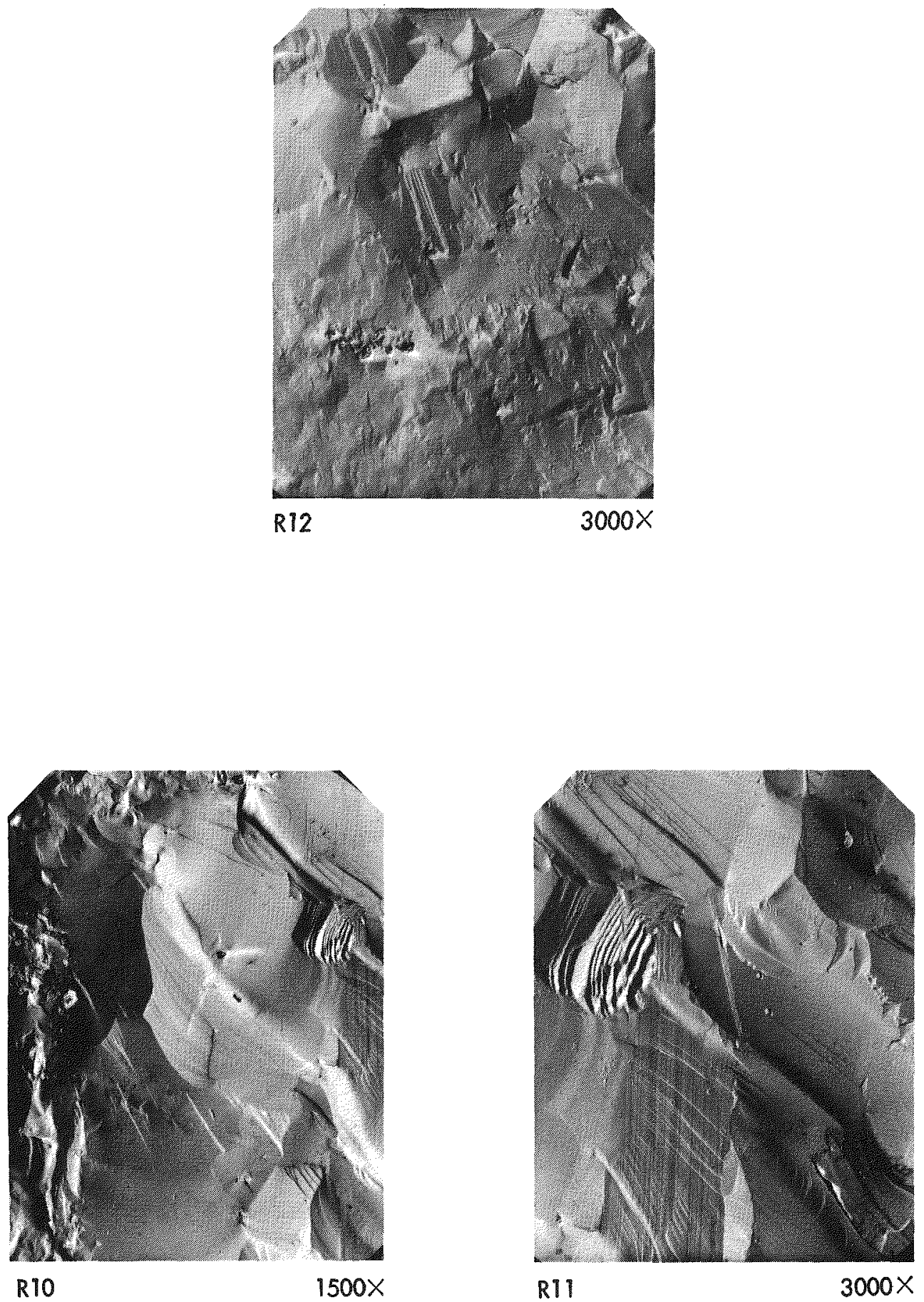

Fig. D-2. Typical fractograph of ballistically tested $\mathrm{Be}_{2} \mathrm{~B}$. 

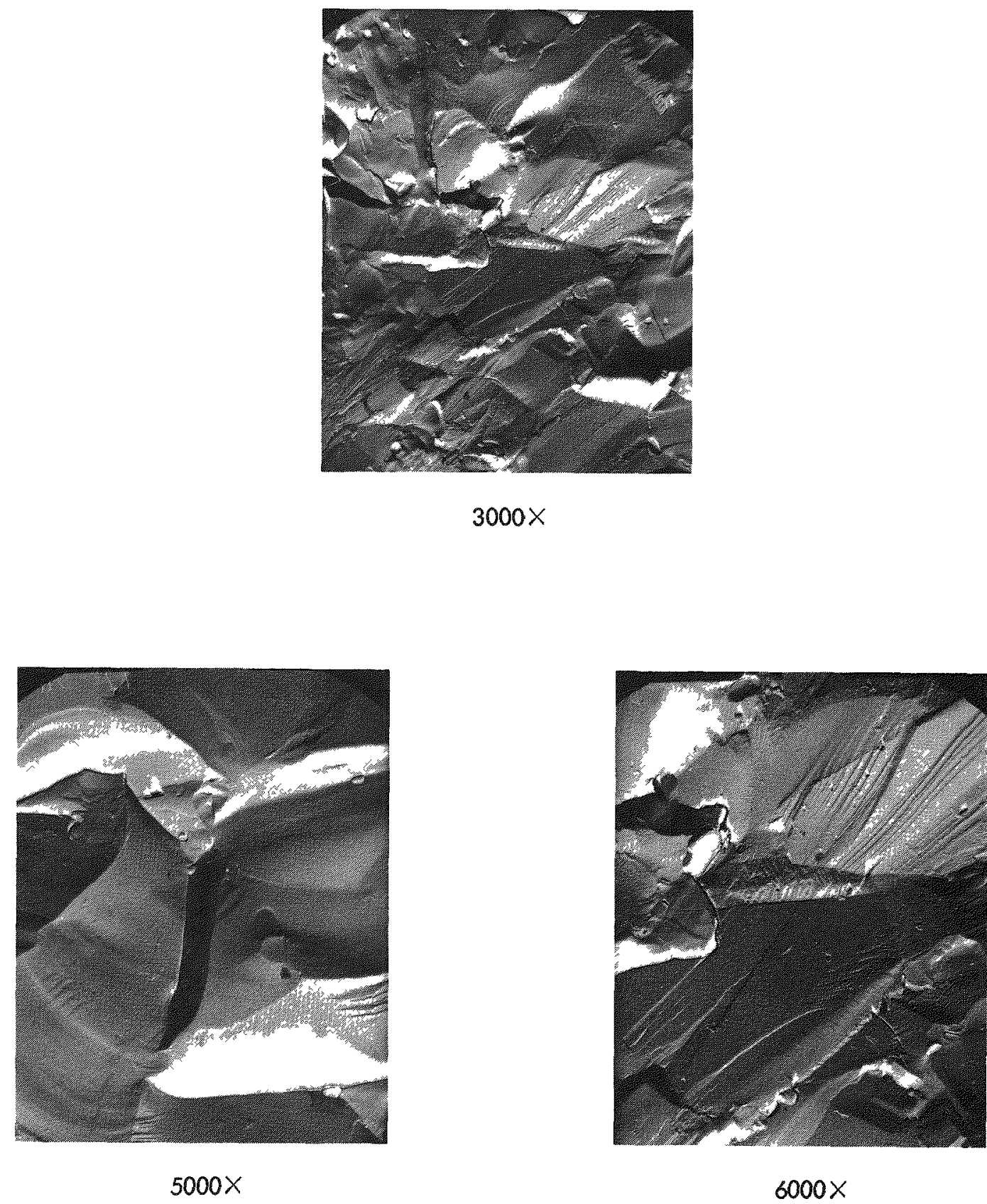

Fig. D-3. TiBe 12 impact fracture. Negative replica Pt-Pd shadow. 


\section{Appendix E \\ Strength of Materials Measurements}

When a projectile of an elastic-plastic material strikes a rigid boundary, the stress at the impact end reaches the elastic limit and plastic flow occurs. A plastic wave front moves back into the projectile and decelerates the undeformed part of the projectile. The magnitude of the decelerating force applied to the still elastic portion of the projectile is related to the yield stress of the material. A strong material would be stopped sooner than a weak material, other factors being equal.
Calculations show that the final length of a blunt cylinder that impacts a rigid boundary is very sensitive to the strength of the cylinder material, $\mathrm{Y}^{0}$. In experiments we used $0.762-\mathrm{cm}$ diameter, $2.347-\mathrm{cm}$ length cylinders of 1090 steel, fired at a rigid boundary provided by a $0.34 \mathrm{in} . \mathrm{Al}_{2} \mathrm{O}_{3}$ ceramic backed by $1-$ in. hardened steel. A streak camera followed the projectile rear surface for some of the experiment.

Figure E-1 shows the results of streak camera records compared with

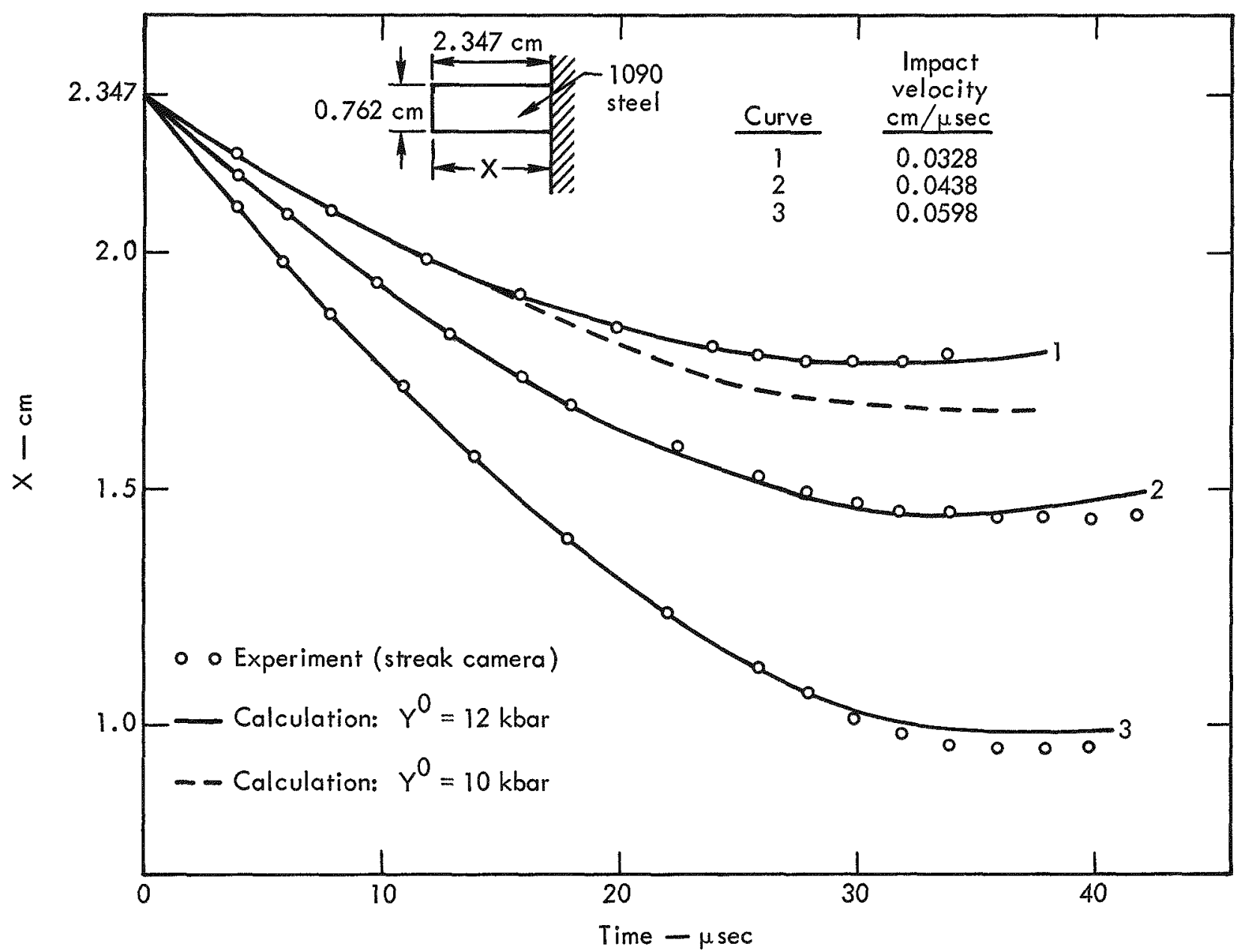

Fig. E-1. Position-time for the rear surface of cylinders that have struck a rigid boundary. 
calculations A yield strength of $Y^{0}=12 \mathrm{kbar}$ was obtained by adjusting the $Y^{0}$ in calculations until the calculated cylinder minimum length agreed with an experiment where the impact velocity was $0.0175 \mathrm{~cm} /$ $\mu \mathrm{sec}$ and the final length $2.138 \mathrm{~cm}$. This value of $Y^{0}$ was then used to calculate the impact shown in Fig. E-1. The sensitivity of the final cylinder length to the yield strength $\mathrm{Y}^{0}$ is seen by comparing the dashed curve with curve 1 . The strength of the material is independent of the impact velocity for the impact velocity range investigated, 0.01 to $0.06 \mathrm{~cm} / \mu \mathrm{sec}$. The target failed for impacts above $0.06 \mathrm{~cm} / \mu \mathrm{sec}$; this accounts for the calculation and experiment difference shown in curve 3.

A second series of experiments used cylinders of 6061-T6 aluminum. The results correlated very well with a yield strength $Y^{0}=4.2 \mathrm{kbar}$ for the impact velocity range 0.005 to $0.05 \mathrm{~cm} / \mu \mathrm{sec}$. For impact velocities greater than $0.05 \mathrm{~cm} / \mu \mathrm{sec}$, the temperature increase due to the impact stress reduces the material strength, and the material starts to behave like a fluid. This technique, then, permits the material strength and the upper bound of the material strength to be determined.

The yield strength of 6061-T6 aluminum obtained from Hugoniot elastic-limit experiments and tension tests is $\mathrm{Y}^{0}=3 \mathrm{kbar}$. The higher value, $Y^{0}=4.2 \mathrm{kbar}$, from these dynamic tests is not considered to be a strain rate effect. Previous calculations using dislocation theory have shown that even if the material had a rate dependent strength property it would not be apparent in this experimental geometry. ${ }^{1}$ The increase in strength is thought to be due entirely to work hardening. This conclusion is substantiated by hardness measurements made after impact that show about a 30 percent increase in hardness in the deformed section of a cylinder. Table E-1 compares the final cylinder lengths, computed with a work hardening model for the aluminum, with the experimental value. (Also see Fig. E-2.) Agreement is very good up to impact velocity of about $0.05 \mathrm{~cm} / \mu \mathrm{sec}$. It is estimated that at this velocity the temperature is about $200^{\circ} \mathrm{C}$. Material strength probably will drop as the impact velocity and temperature increase.

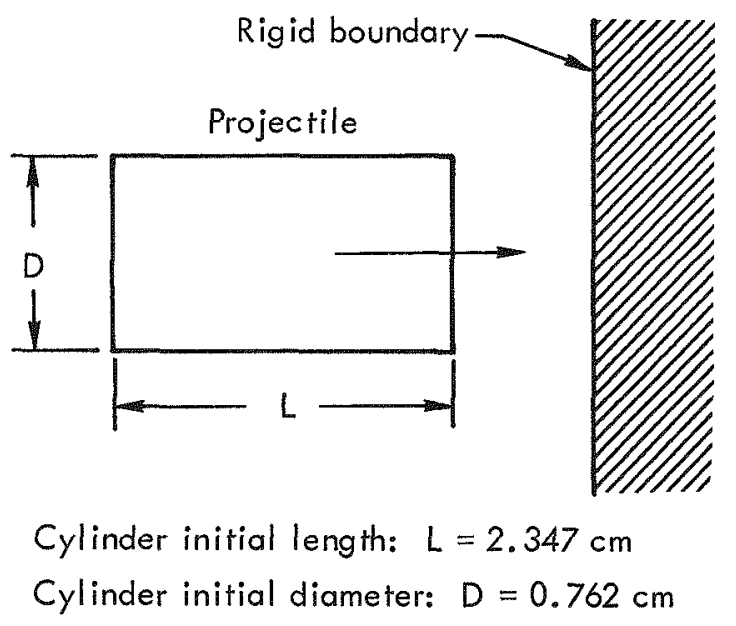

Fig. E-2. Cylinder geometry referred to in Tables E-1 and E-2.

Figure E-3 compares the calculated final cylinder geometry with the recovered experimental cylinder for three impact velocities of Table $\mathrm{E}-1$. The agreement of the cylinder contour was found to be better when work hardening was used in the calculation. These experiments can be used to obtain information on material strength including temperature and workhardening effects.

A third series of experiments was done with pure copper cylinders. Table E-2 gives the results of calculations with a work-hardening model and the experimental 
Table E-1. Impact of 6061-T6 aluminum cylinders on a rigid boundary. (See Fig. E-2 for cylinder geometry.)

\begin{tabular}{cccc}
\hline $\begin{array}{c}\text { Experi- } \\
\text { ment }\end{array}$ & $\begin{array}{c}\text { Impact } \\
\text { velocity } \\
\text { (cm/usec) }\end{array}$ & $\begin{array}{c}\text { Experimental } \\
\text { cylinder final } \\
\text { length } \\
(\mathrm{cm})\end{array}$ & $\begin{array}{c}\text { Calculated } \\
\text { cylinder final } \\
\text { length } \\
\text { (cm) }\end{array}$ \\
\hline 1 & 0.005 & 2.330 & 2.33 \\
2 & 0.0169 & 2.159 & 2.16 \\
3 & 0.0191 & 2.126 & 2.12 \\
4 & 0.0262 & 1.981 & 1.95 \\
5 & 0.0283 & 1.892 & 1.90 \\
7 & 0.0306 & 1.839 & 1.84 \\
8 & 0.0373 & 1.651 & 1.65 \\
9 & 0.0478 & 1.318 & 1.35 \\
10 & 0.0603 & 0.8687 & 0.96 \\
\hline 2 & 0.0757 & 0.457 & 0.59 \\
\hline
\end{tabular}

${ }^{a}$ Calculations use a work hardening model for the yield strength:

$$
Y\left[=0.003+\left(\frac{\gamma}{0.05+\gamma}\right)(0.0015)\right] \text { Mbar }
$$

where

$$
\begin{aligned}
& \gamma=2 / 3 \sqrt{\left(\epsilon_{1}^{\mathrm{p}}-\epsilon_{2}^{\mathrm{p}}\right)^{2}+\left(\epsilon_{2}^{\mathrm{p}}-\epsilon_{3}^{\mathrm{p}}\right)^{2}+\left(\epsilon_{3}^{\mathrm{p}}-\epsilon_{1}^{\mathrm{p}}\right)^{2}} \\
& \epsilon_{1}^{\mathrm{p}}, \epsilon_{2}^{\mathrm{p}}, \epsilon_{3}^{\mathrm{p}}=\begin{array}{l}
\text { principal components of the } \\
\text { plastic strain. }
\end{array}
\end{aligned}
$$

Table E-2. Impact of pure copper cylinder on a rigid boundary. (See Fig. E-2 for cylinder geometry.)

\begin{tabular}{cccc}
\hline $\begin{array}{c}\text { Experi- } \\
\text { ment }\end{array}$ & $\begin{array}{c}\text { Impact } \\
\text { velocity } \\
(\mathrm{cm} / \mu \mathrm{sec})\end{array}$ & $\begin{array}{c}\text { Experimental } \\
\text { cylinder final } \\
\text { length } \\
\text { (cm) }\end{array}$ & $\begin{array}{c}\text { Calculated } \\
\text { cylinder final } \\
\text { length } \\
(\mathrm{cm})\end{array}$ \\
\hline 1 & 0.0089 & 2.10 & 2.10 \\
2 & 0.0123 & 1.96 & 1.96 \\
3 & 0.0153 & 1.83 & 1.80 \\
5 & 0.0183 & 1.68 & 1.69 \\
6 & 0.0204 & 1.57 & 1.60 \\
\hline
\end{tabular}

${ }^{a}$ Calculations use a work hardening model for the yield strength:

$$
Y^{0}=\left[0.0012+\left(\frac{\gamma}{0.2+\gamma}\right) \quad(0.005)\right] \quad \text { Mbar }
$$

$\gamma$ is defined in Table $\mathrm{E}-1$. 

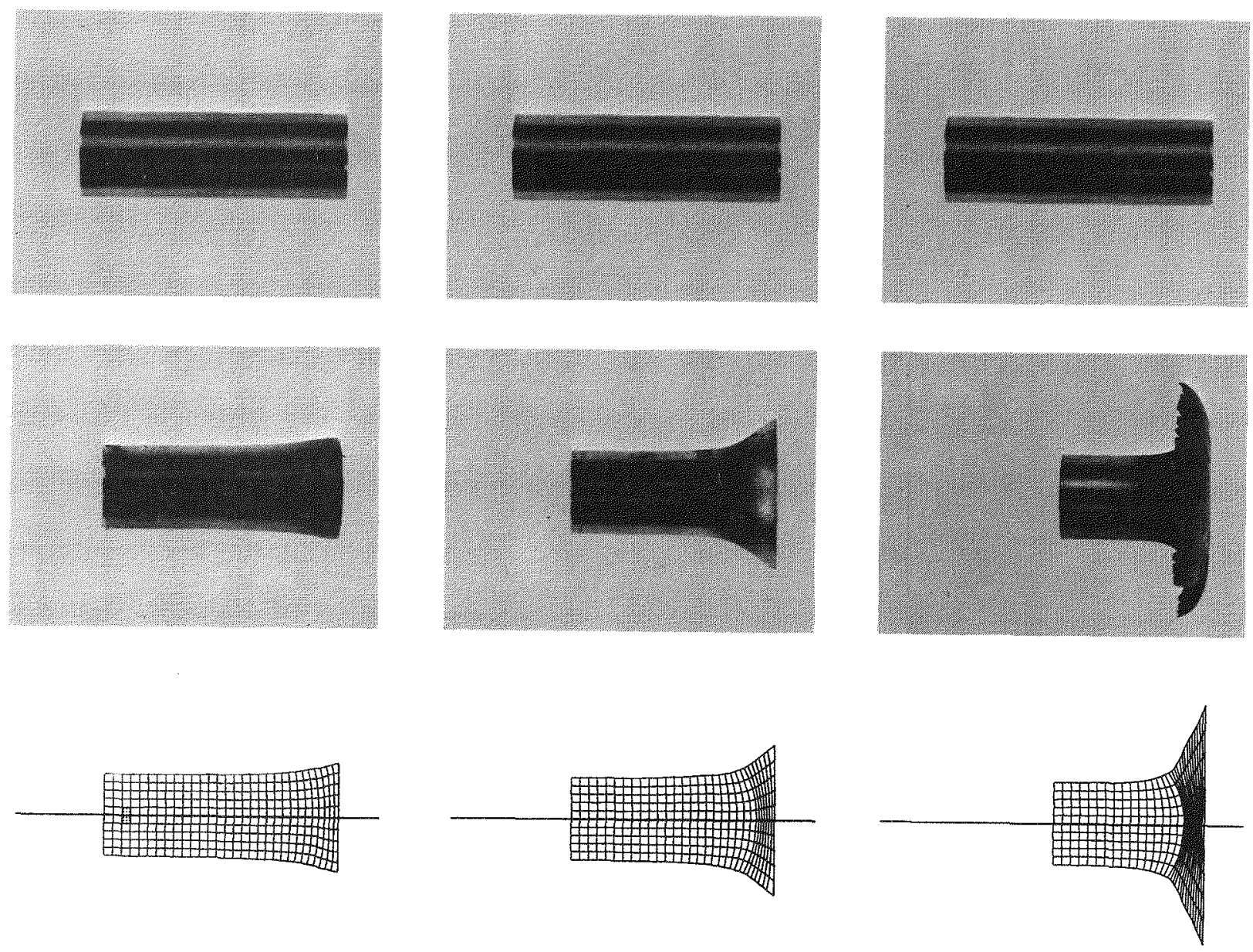
A. Impact velocity $0.0196 \mathrm{~cm} / \mu \mathrm{sec}$
B. Impact velocity $0.0306 \mathrm{~cm} / \mu \mathrm{sec}$

Fig. E-3. Calculated and experimental final shapes of 6061-T6 aluminum cylinders after an impact on a rigid boundary. Top photo: original cylinder; center photo: final shape; bottom photo: calculated shape.

values for the cylinder final lengths. Figure E-4 shows the calculated and experimental geometries.

Microphotographs ${ }^{*}$ of material structure are shown in Figs. E-5 and E-6 for an aluminum cylinder and a copper cylinder.
One impact experiment was done for a pure beryllium cylinder. Figure E-7 shows microphotographs of the recovered cylinder. Note that fracture has occurred in the impact end. More experiments are required to obtain a reliable strength value.

*All specimens were ground from coarse to $3 / 0$ silicon carbide paper and then polished several hours with 1 -micron diamond paste using a Syntron vibratory table covered with a nylon microcloth. The final finish was given with Linde B alumina, also on nylon microcloth using a Syntron vibratory table.

Grain boundaries were delineated on the aluminum specimen by cathodically etching. A dichromate chemical-etching solution consisting of $100 \mathrm{ml} \mathrm{H}_{2} \mathrm{O}, 8 \mathrm{ml} \mathrm{H}_{2} \mathrm{SO}_{4}$, $2 \mathrm{~g} \mathrm{~K}_{2} \mathrm{Cr}_{2} \mathrm{O}_{7}$, and $4 \mathrm{ml} \mathrm{NaCl}$ was used on the copper specimen, while only polarized light was used on the beryllium specimen to reveal the microstructure. 

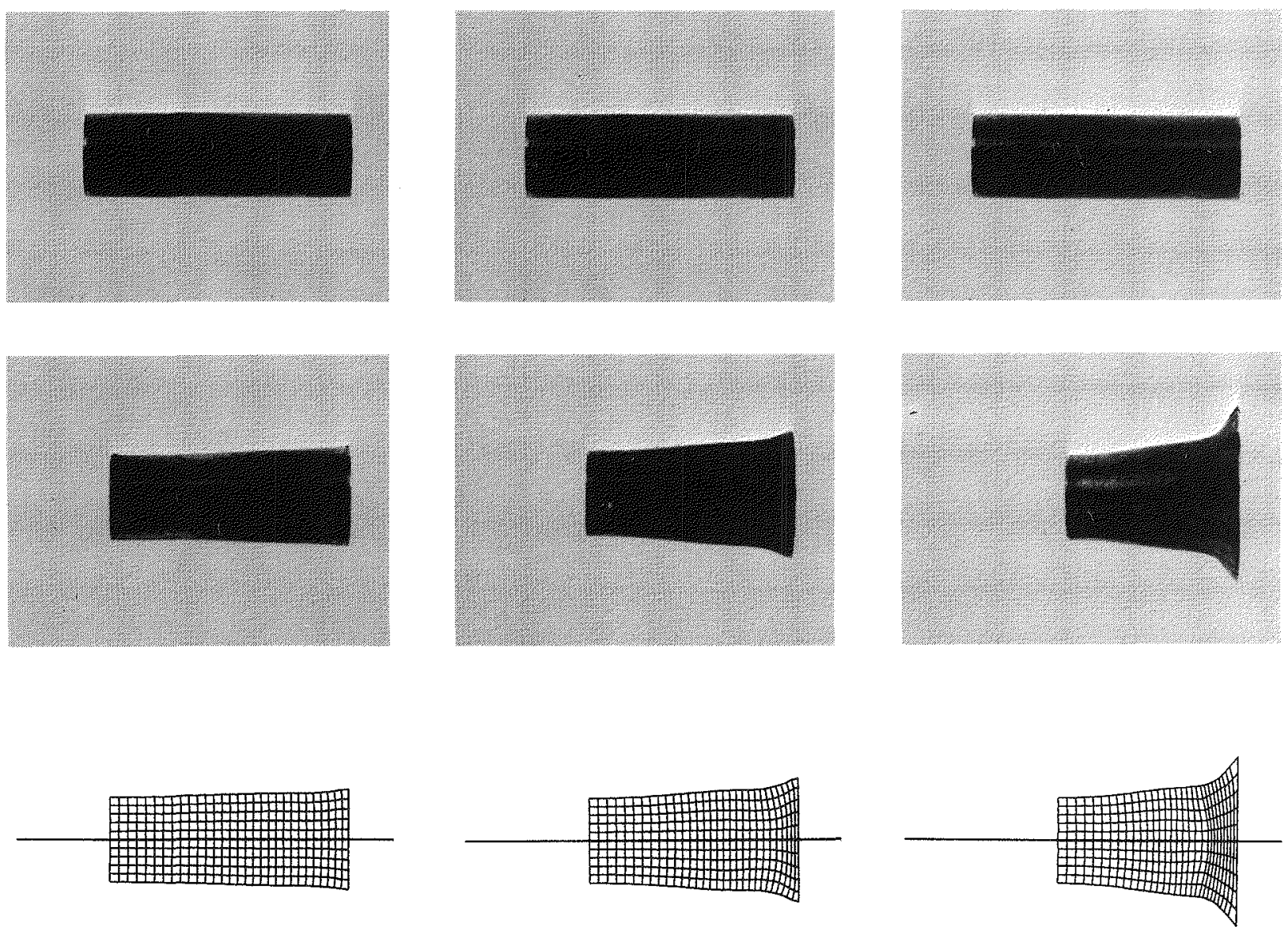
A. Impact velocity $0.0089 \mathrm{~cm} / \mu$ sec
B. Impact velocity $0.0153 \mathrm{~cm} / \mu \mathrm{sec}$
C. Impact velocity $0.0210 \mathrm{~cm} / \mu \mathrm{sec}$

Fig. E-4. Calculated and experimental final shapes of pure copper cylinders after impact on a rigid boundary. Top photo: original cylinder, center photo: final shape; bottom photo: calculated shape. 


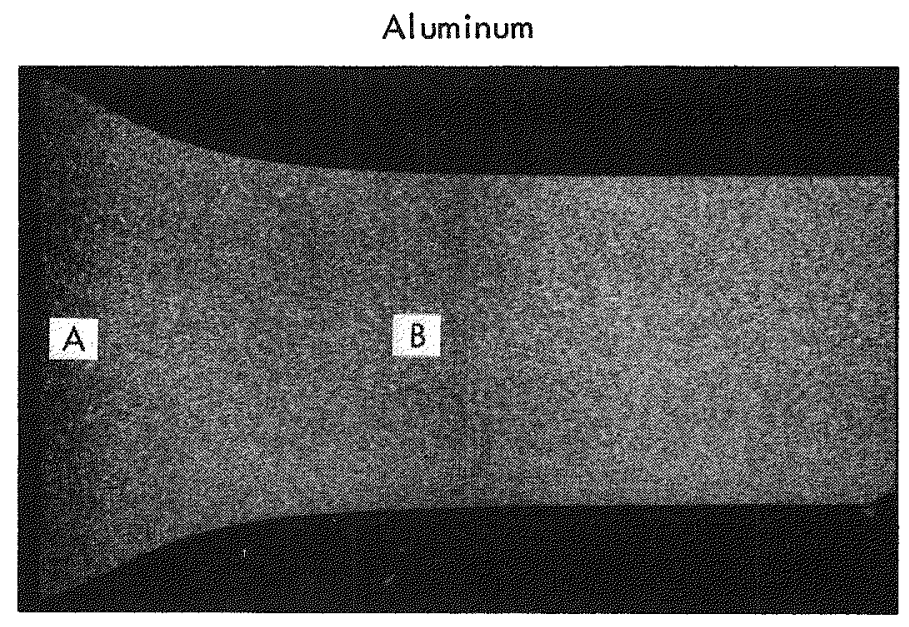

$8 \times$

a. Macrostructure of 6061 - T6 aluminum cylinder. Impact velocity: $0.0262 \mathrm{~cm} / \mu \mathrm{sec}$.

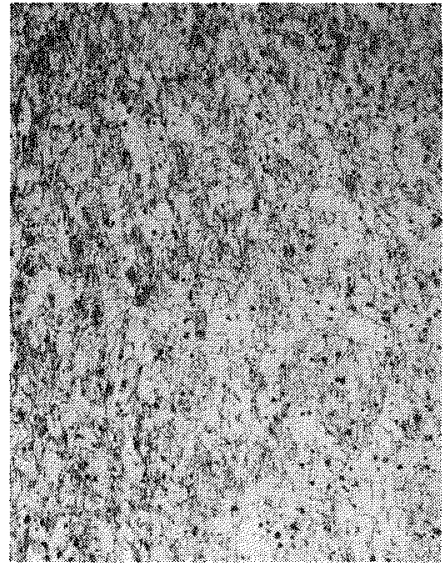

Area $\mathrm{A}$ above

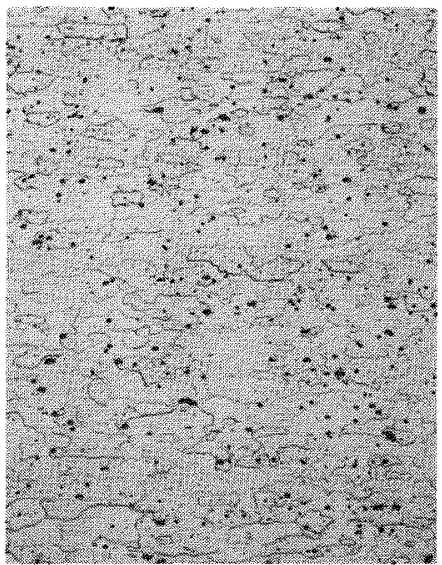

Area $B$ above

(100X cathodically etched)

b. Microstructures of areas $A$ and $B$.

Fig. E-5. Microphotographs of sectioned aluminum cylinder. 


\section{Copper}

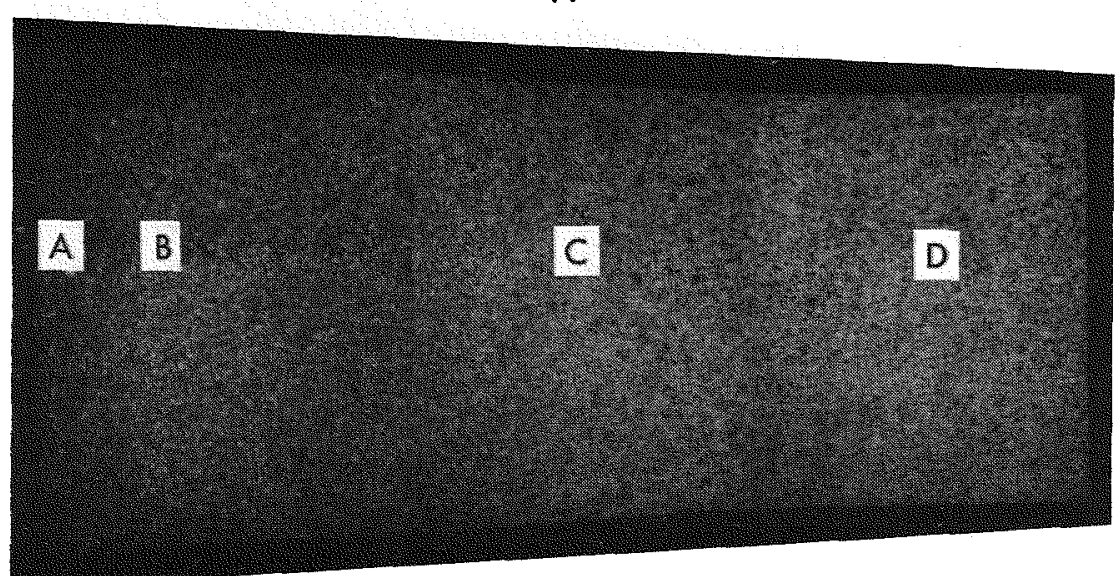

$10 \times$

a. Macrostructure of pure copper cylinder Impact velocity: $0.0123 \mathrm{~cm} /$ usec.

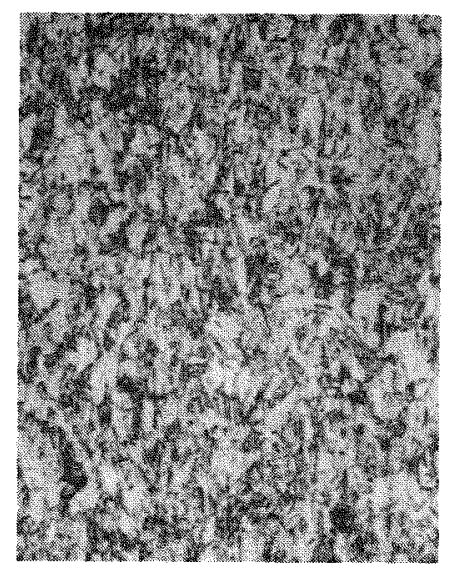

Area A above

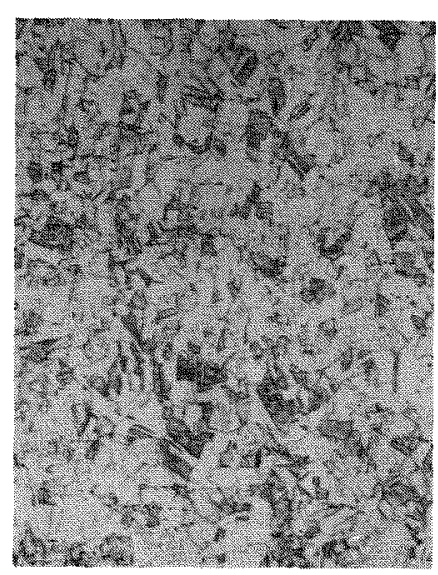

Area B above

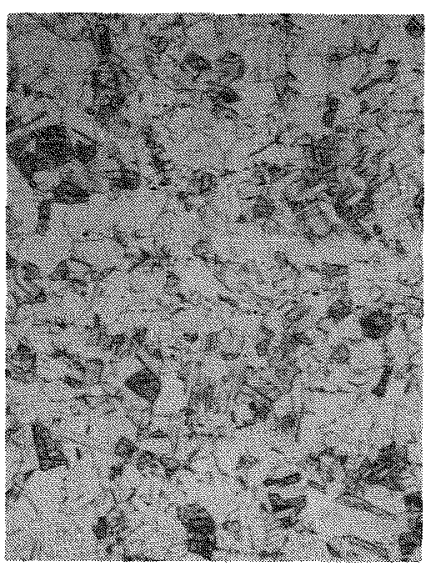

Area Cabove

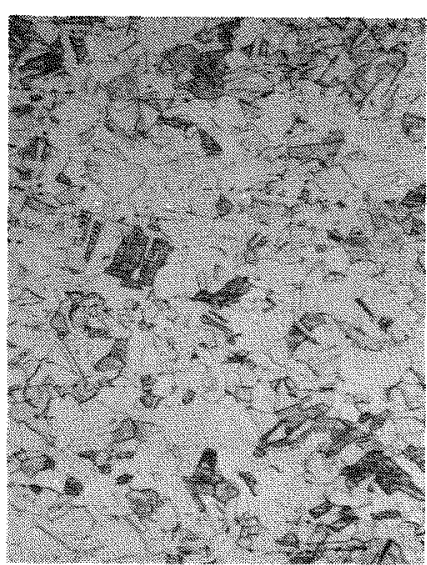

Area D above

$100 X$ - dichromate etchant

b. Microstructures of areas $A, B, C$, and D.

Fig. E-6. Microphotographs of sectioned copper cylinder. 


\section{Beryllium}
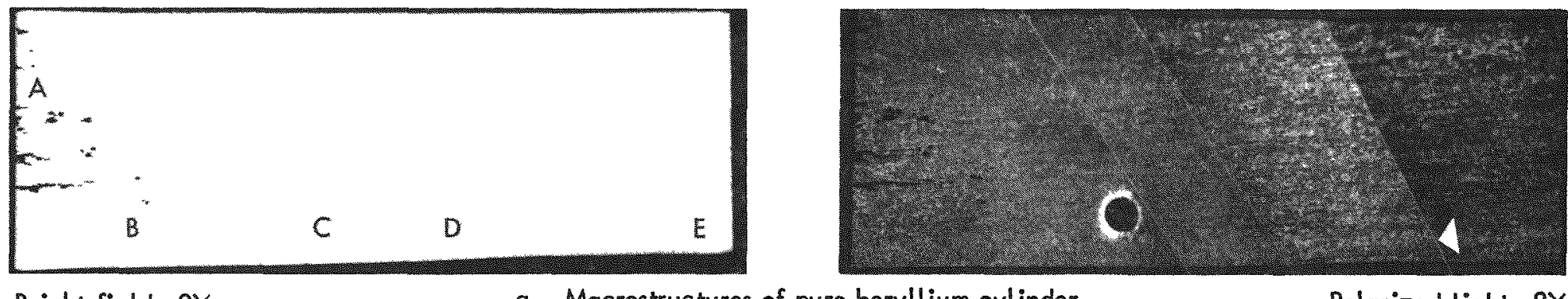

Bright field, $8 x$

a. Macrostructures of pure beryllium cylinder

Polarized light, $8 x$

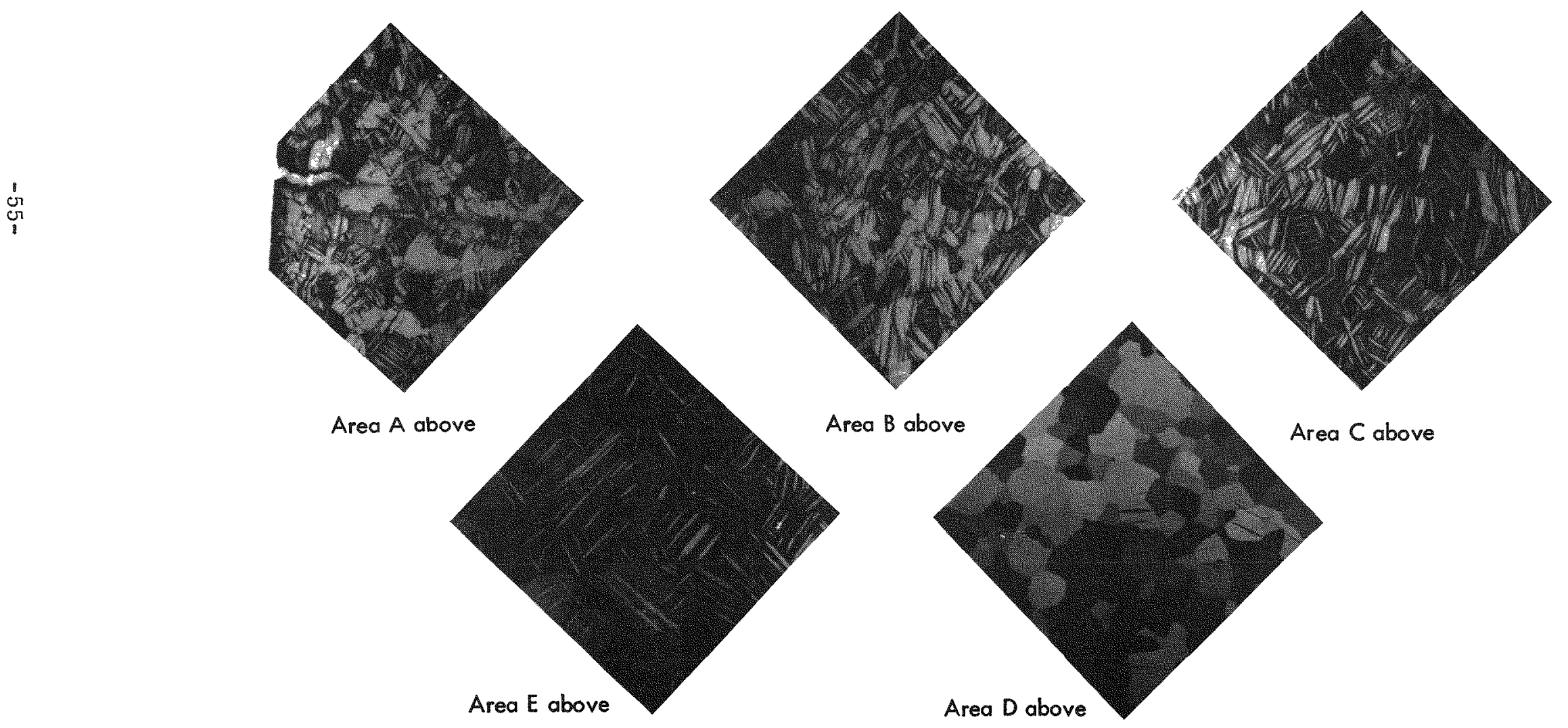

b. Microstructures of areas $A, B, C, D$, and $E$ (polarized light, 100X

Fig. E-7. Microphotographs of sectioned beryllium cylinder. 


\section{References}

1. M. L. Wilkins, C. A. Honodel, and D. R. Sawle, An Approach to the Study of Light Armor, Lawrence Radiation Laboratory, Livermore, Rept. UCRL-50284 (1967).

2. M. L. Wilkins, Second Progress Report on Light Armor, Lawrence Radiation Laboratory, Livermore, Rept. UCRL-50349 (1967) (CRD).

3. M. L. Wilkins, Third Progress Report on Light Armor, Lawrence Radiation Laboratory, Livermore, Rept. UCRL-50460 (1968).

4. J. Taylor, Los Alamos Scientific Laboratory, New Mexico, Rept. LA-4113 MS, 2 (April 1969).

5. M. Humenik, Jr. and T. J. Whalen, Cermets, J. R. Tinklepaugh and W. B. Crandall, Eds. (Reinhold Publishing Corp., New York, 1960), Chapter 2.

6. T. J. Whalen and M. Humenik, Jr., Progress in Powder Metallurgy, 85-98 (1962).

7. T. J. Whalen and M. Humenik, Jr., Trans. of Amer. Inst. of Mining and Metallurgical Engrs. 218, 401 (1960).

8. M. Humenik, Jr. and N. M. J. Parikh, Am. Cex. Soc. 39, 60 (1956).

9. G. V. Samsonov, Boron, Its Compounds and Alloys (Book 2), AEC-tr-5032 (1960). 